\title{
Targeting GPCRs \& their signaling as a therapeutic option in melanoma
}

by

\author{
Jérémy H. RAYMOND ${ }^{1,2}$, Zackie AKTARY ${ }^{1,2}$, Lionel LARUE ${ }^{1,2}$, \\ and Véronique DELMAS ${ }^{1,2}$
}

1 Institut Curie, Université PSL, CNRS UMR3347, Inserm U1021, Normal and Pathological Development of Melanocytes, 91400 Orsay, France

2 Université Paris-Saclay, CNRS UMR3347, Inserm U1021, Signalisation radiobiologie et cancer, 91400 Orsay, France

\section{Keywords}

G protein-coupled receptor, mouse models, skin cancer, UVR, drug, network 


\title{
Summary
}

Sixteen G protein-coupled receptors (GPCRs) have been involved in melanogenesis or melanomagenesis. Here, we review these GPCRs, their associated signaling, and therapies.

\begin{abstract}
G protein-coupled receptors (GPCRs) serve prominent roles in melanocyte lineage physiology, with an impact at all stages of development, as well as on mature melanocyte functions. GPCR ligands are present in the skin and regulate melanocyte homeostasis, including pigmentation. The role of GPCRs in the regulation of pigmentation and, consequently, protection against external aggression, such as ultraviolet radiation, has long been established. However, evidence of new functions of GPCRs directly in melanomagenesis has been highlighted in recent years. GPCRs are coupled, through their intracellular domains, to heterotrimeric $\mathrm{G}$ proteins, which induce cellular signaling through various pathways. Such signaling modulates essential cellular processes of melanomagenesis, such as proliferation and migration. GPCR-associated signaling in melanoma can be activated by the binding of paracrine factors to their receptors or directly by activating mutations. In this review, we present melanomaassociated alterations of GPCRs and their downstream signaling and discuss the various preclinical models used to evaluate new therapeutic approaches against GPCR activity in melanoma. Recent striking advances in our understanding of the structure, function, and regulation of GPCRs will undoubtedly broaden treatment options in melanoma in the future.
\end{abstract}




\section{Introduction}

G protein-coupled receptors (GPCRs) participate in intercellular communication by receiving extracellular stimuli from the microenvironment. They then amplify and transduce the signal, passing it on to the nucleus, where it triggers an appropriate cellular response. GPCRs can bind to a wide variety of ligands (hormones, proteins, peptides, amino acids, lipids, nucleotides, xenobiotics, etc.) and regulate numerous essential physiological processes during development and in adult life. GPCRs are the largest receptor family in the mammalian genome, with over 800 members (Hu zet al., 2017). The GPCR family is composed of receptors that share a common structure consisting of seven transmembrane helices and are associated with a heterotrimeric $G$ protein. These receptors are known to regulate many essential physiological processes and their aberrant expression or activity can contribute to human disease, including cancer. GPCRs are among the most common drug targets because they can be activated or blocked by low molecular weight molecules that have a very strong interaction with their receptors. Their importance in drug discovery is demonstrated by the fact that nearly $60 \%$ of drugs in the developmental stage and $36 \%$ of currently marketed drugs target human GPCRs, representing around 700 molecules [1]. However, only 10 molecules are used in cancer therapy and none have yet been approved for melanoma $[2]$.

Melanoma is a skin cancer that arises from melanocytes, the cells responsible for pigmentation. It affects more than 320,000 people worldwide each year, resulting in the death of nearly 60,000 patients [3]. According to the International Agency for Research on Cancer of the WHO, the incidence is expected to continue to rise in the coming years, reaching half a million patients by 2040 . Mortality estimates are also on the rise, with 97,000 deaths estimated for 2040, despite the appearance of new therapies in the second half of the 2010s [3]. These treatments are based on two approaches: 1) inhibition of the MAPK/ERK pathway in melanoma using a combination of BRAF and MEK activation inhibitors - targeted therapy (TT) - and 2) inhibition of immune cell exhaustion using the checkpoint inhibitors iCTL4 and iPD1 - immunotherapy (IT) - [4]. Although these treatments have significantly increased patient survival, they do not prevent half of patients from relapsing [5]. Furthermore, despite significant recent progress in both targeted therapies and immunotherapies for treating advanced-stage disease, the long-term prognosis for patients with cutaneous melanoma is still poor. An 
effective, reliable cure of melanoma undoubtedly requires further therapeutic innovation. Moreover, 40-60\% patients are not responsive to current treatments.

GPCRs play crucial roles in various physiological processes, including neurotransmission, cardiac and sensory function, immune responses, and regulation of the pigmentary system. Pigmentation phenotypes have been observed with eight GPCRs (Table 1). Aside from its cosmetic role, pigmentation is a natural sunscreen that potently absorbs ultraviolet radiation (UVR) and is among the most important factors that determine UV sensitivity and melanoma risk. The melanin pigment responsible for the color of the skin and hair are synthesized within the melanosomes of melanocytes. In the epidermis, melanosomes synthesized by melanocytes are transferred to keratinocytes to allow homogenous pigmentation and protection of the entire skin against UVR. Melanocytes, keratinocytes, and dermal fibroblasts communicate with each other via secreted factors and cell-to-cell contact. The crosstalk of the various signaling pathways between these cells constitutes a complex network that controls pigmentation and melanocyte homeostasis. Genetics and in vitro studies have identified loci that regulate pigmentation, among them, certain key regulators belonging to the GPCR family. For example, the identification of the mouse extension locus (extension, recessive yellow, or Mc1r) associated with cloning of the melanocortin 1 receptor $(M C 1 R)$ gene in human melanocytes identified this GPCR as the primary regulator of pigment synthesis. Apart from its effects on melanin production and, consequently, UVR protection, the MC1R has functions extending beyond pigmentation that explain how MC1R activity is directly involved in multiple aspects of melanomagenesis.

In contrast to epidermal melanocytes, which have a long-life span and low proliferative capacity during adult life, the precursor cells of melanocytes, called melanoblasts, proliferate and actively migrate during embryonic development to colonize the entire skin. Many signaling molecules/ligands are required during all stages of melanocyte development. These ligands educate neural crest cells (NCCs) to specify the melanocytic fate and instruct melanoblasts to proliferate, migrate, survive, and home (final destination) prior to terminal differentiation into pigmented melanocytes. Approximately 100 genes have been shown to be specifically involved in melanocyte development, among them, two GPCRs that play a key role, the ET3/EDNRB (endothelin 3 ligand and its receptor, endothelin receptor type B) and WNT/FZL/ $\beta$-catenin (Wnt1/3A and frizzled receptors, with one of its mediators, $\beta$-catenin). Of note, the 
molecular and cellular mechanisms involved in the proliferation and migration of melanoblasts during development and those of melanoma cells during tumor progression are often closely related. Therefore, it is not surprising to find that key regulators of melanocyte development are also important players of melanomagenesis. The objective of this review is to provide an update on the GPCRs that have an important, well-identified role in melanomagenesis and to discuss the therapeutic strategies that have been used.

\section{Impact of GPCRs on melanoma initiation and progression}

\section{1.a. Melanomagenesis}

During a multi-step process, known as melanomagenesis, skin melanocytes are transformed into melanoma. Briefly, the first steps consist of the benign proliferation of melanocytes to form a nevus, in which the melanocytes are grouped together and lose their characteristic contacts with keratinocytes. The melanocytes in the nevus eventually stop proliferating and become senescent. As melanomagenesis continues, nevus melanocytes are able to bypass senescence and enter the radial growth phase (RGP), where they typically superficially proliferate toward the basement membrane of the epidermis. These primary steps can be defined as "melanoma initiation". Then, during the vertical growth phase (VGP), melanoma cells continue to actively proliferate and acquire migratory and invasive properties, allowing them to cross the basement membrane and invade the dermis. The cells eventually acquire metastatic characteristics as they enter the bloodstream and/or lymphatic vessels and eventually colonize various tissues and organs. These latter stages can be considered as the "progression" of the disease. Melanomagenesis is associated with changes in many cellular processes, such as proliferation, immortalization, pseudo-epithelialmesenchymal transition, migration, and invasion. Cutaneous melanomas are molecularly classified into four groups based on their mutations: BRAF, RAS, NF1, and the "triple wildtype". All four genomic subtypes of cutaneous melanomas are associated with aberrant activation of the MAPK and/or PI3K/AKT pathway that supports tumor cell growth, proliferation, survival, and anti-apoptotic signals.

The only effective way to demonstrate the causal role of a gene in tumor initiation is to use animal models. Their use allows a better understanding of tumor 
progression in a physiological context. Indeed, it is very difficult, if not impossible, to reproduce the cell-cell organization and microenvironment in vitro. However, simple or complex in vitro models are very useful for deciphering the involvement of key genetic elements in various cellular processes but cannot be used to determine the causal role of a gene in tumorigenesis because (i) established melanoma cell lines are often derived from metastases in which the cells have already undergone a complete transformation process, (ii) the cells are grown on plastic, without their microenvironment, and (iii) colonization of distant organs is very difficult or impossible to assess. Various animal models allow evaluation of the proliferation and bypass of senescence (initiation) and invasion and metastasis (progression). Several animal models have been used to better understand melanomagenesis, including mouse, dog, pig, horse, chicken, and zebrafish. In this review, we focus on the currently best studied mouse models for melanomagenesis.

\section{1.b. GPCRs in melanoma}

GPCRs regulate many key biological functions, such as cell differentiation, proliferation, migration, and metabolic activity. Thus, it is not surprising that they play a role in tumorigenesis, including melanomagenesis [6]. There are four main mechanisms by which GPCRs can drive tumorigenesis: (i) excess ligand availability, (ii) excess GPCR expression, (iii) activating mutations in GPCRs, and (iv) activating mutations in G $\alpha$ proteins.

The role of certain GPCRs during melanomagenesis has been studied using natural (or chemically induced) mouse mutants of genes of interest or novel engineered gainand loss-of-function mutants. A list of mouse mutants with pigmentation phenotypes is available and regularly updated (http://www.ifpcs.org/colorgenes/) [7]. In the case of genetically modified mutants, targeting of the melanocytic lineage is performed using tyrosinase (Tyr), tyrosinase related protein 1 (Tyrp1), dopachrome tautomerase (Dct), or microphthalmia-associated transcription factor (Mitf) promoters/enhancers in the transgenic constructs [8]. Cre recombinase is used to generate conditional mutants, which are required when genes are essential in other lineages and/or during development: Tyr::Cre, Tyr::CreER ${ }^{\mathrm{T} 2-\mathrm{Lar}}$, and Tyr::CreER ${ }^{\mathrm{T} 2-B o s}$ [9-11].

The known GPCRs involved in melanomagenesis are presented in the following section. The role of certain GPCRs in melanocyte transformation is predictable, given 
their key function in melanocyte development and homeostasis (ET/EDNRB, MSH/MC1R, WNT/FZD), whereas the involvement of other GPCRs in melanomagenesis was less expected such as GRM1, GRM3, GRM5, GPER1, PAR1, CXCR4, CCR7 and CCR10 (Table 2).

\section{1.b.1. Endothelin receptor type B (EDNRB)}

The endothelin (ET) system consists of two class A G-protein-coupled receptors, endothelin receptors type A and B (EDNRA and EDNRB, respectively) and their three similar peptide ligands, endothelin-1, -2 , and -3 (ET1, 2, 3). The ENDRB is the predominant receptor expressed by melanocytes/melanomas and binds all ETs with the same affinity. Edn3 and Ednrb were first found to play a major role during the development of melanocytes from NCCs using genetic knockout mouse models and then, by analogy, of the classic mouse mutants, piebald and lethal spotting $[12,13]$. Indeed, Ednrb and Edn3 genetically engineered mice (GEM) are both allelic to the spontaneous mouse mutations that occur at the piebald and lethal spotting loci. Recessive mutants at either of these loci give rise to similar phenotypes consisting of differing degrees of hypopigmentation and aganglionic megacolon due to the absence of enteric ganglia, which have the same neural crest embryonic origin as melanocytes. Reciprocally, increased expression of Edn3 in the epidermis leads to increased numbers of melanocytes and hyperpigmentation [14]. Moreover, neonatal UV-irradiation of these mice overexpressing Edn3 in the epidermis leads to melanoma formation [15]. Germline $E d n r b$ deletion does not lead to tumorigenesis but to the absence of melanocytes, mainly in the dermis. The role of Ednrb in melanomagenesis has been evaluated in the context of oncogenic GNAQQ209L signaling (see next paragraph). The expression of GNAQQ209L (encoding for $\mathrm{G}_{\mathrm{q}}$ ) is not sufficient to replace EDNRB signaling during embryonic development, suggesting that $\mathrm{G} \alpha_{\mathrm{q}}$ may not be the only G-protein activated downstream of EDNRB (or other signaling pathways). Using a conditional knockout approach, GNAQQ209L-induced melanomagenesis is inhibited in the absence of Ednrb, including lung metastases (Mitf-cre/+; Rosa-fs-GNAQQ209L/+; Ednrb ${ }^{\mathrm{F} / \mathrm{F}}$ background) [16]. Intriguingly, germline haploinsufficiency for Ednrb has the opposite effect in the RET mouse melanoma model (Metallothionein-1/RFP-RET; Ednrb (+/-) mice), in which it accelerates tumorigenesis, with an increase in lung metastases [17]. These two mouse models are of interest and clearly show that Ednrb expression affects melanomagenesis 
but have the disadvantage of representing an uncommon oncogenic situation in cutaneous melanoma, consisting of haploinsufficiency or the lack of Ednrb combined with a GNAQQ209L driver mutation or with increased RET signaling, which is not observed in human melanoma, reducing the clinical relevance of this model.

Interest in EDNRB in melanoma stems primarily from early observations in humans showing that EDNBR expression was positively associated with cutaneous melanoma progression; EDNRB mRNA and protein levels were found to increase from common nevi to dysplastic nevi and from primary to metastatic melanoma [18]. Consistent with this observation, in vitro experiments showed that ET promoted melanoma cell proliferation, migration, and invasion and that EDNRB inhibitors reduced melanoma cell growth and survival in culture and xenografts [19-21]. However, overexpression of EdnrB alone or combined with driver mutations was not performed in mice to genetically address its role in tumorigenesis in physiological situation.

Another aspect of ET signaling in melanoma is its activity in DNA repair, which has a role in reducing the genotoxic effect of UVR [22]. Indeed, ET signaling increases intracellular $\mathrm{Ca}^{++}$mobilization, and downstream activation of the stress-induced MAP kinases JNK and p38, which enhances the repair of cyclobutane pyrimidines (CPDs), the major form of DNA photoproducts, in UV-irradiated human melanocytes [23]. Finally, a recent study has suggested that ET signaling has a multifunctional role in melanoma, acting on both tumorigenic and stromal cells, where it mediates immunosuppression by increasing Treg proliferation [24]. Thus, although the role of EDNRB signaling is relatively well understood during melanocyte development, its role in malignant transformation is much less clear, as it acts in multiple signaling pathways and is context dependent. Thus, it is not surprising that therapies that target EDNRB have thus far not been very successful. Small-molecule inhibitors of EDNRB, A-192621 and BQ788, were shown to inhibit the growth and survival of melanoma cells in culture and in xenografts $[20,21,25]$. However, the dual EDNRA/EDNRB antagonist, Bosentan, was tested in phase II clinical trials and failed to produce a robust response in cutaneous melanoma patients in the clinic, either alone or in combination with dacarbazine [26,27]. Similarly, A192621 treatment of mice expressing Ednrb in the context of oncogenic GNAQQ209L showed no effect on tumorigenesis, whereas haploinsufficiency for Ednrb reduced it. Targeting EDNRB with an antibody-drug conjugate (DEDN6526A) is currently being tested in phase I [28]. It would be of great interest to generate a mouse model that 
reflects the human EdnRB situation in cutaneous melanoma: overexpression of EDNRB (human and mouse) in melanocytes/melanoma combined with oncogenic BRAFV600E or NRASQ61K/R, the major driver mutations in human cutaneous melanoma. Such models would allow a better understanding of the effect of Ednrb overexpression on melanomagenesis, the study of its downstream signaling, and the testing inhibitors in a human relevant preclinical mouse model before clinical trials.

\section{1.b.2. The melanocortin receptor (MC1R)}

Melanocytes exhibit a receptor (MC1R) that controls melanogenesis. The MC1R belongs to a small subfamily of GPCRs, classified into five subtypes (MCR1-5) that contribute to important physiological processes. MC1R is the only melanocortin receptor expressed in melanocytes. MC1R is a class A receptor and coupled to $G_{S}$ protein. MC1R binds to the pro-opiomelanocortin-derived peptide $\alpha$-melanocyte-stimulating hormone ( $\alpha$-MSH), resulting in the activation of downstream signaling cascades in a cAMP-PKA-dependent manner [29]. Upon UV exposure, $\alpha-M S H$ is released by keratinocytes, leading to stimulation of the MC1R at the melanocyte membrane, the activation of protein kinase $A$ (PKA), and ultimately, to increased cAMP levels. Other pathways independent of UV exposure can lead to increased of $\alpha-\mathrm{MSH}$ production and hyperpigmentation, as observed in the Dopamine receptor D2 knockout (DRD2tm1Ebo) [30]. An important target of cAMP is the transcription factor CREB (CAMP-responsive element-binding protein), which becomes phosphorylated and then activates the promoter of the MITF, which in turn up-regulates the transcription of the melanogenesis enzyme genes Tyr, Tyrp1, and Dct, as well as those regulating other cellular processes, including proliferation, invasion and metabolism [31,32]. In addition, binding of neurofibromin 1 (NF1) to MC1R regulates intracellular signaling pathways involved in pigmentation [33]. MC1R is the product of the gene located at the extension locus and stimulates the synthesis of the pigment, eumelanin (black, brown). The loss-of-function mutation in this locus, recessive yellow (e/e), results in the production of pheomelanin (yellow, red) instead of eumelanin [34,35]. An MC1R antagonist is the agouti signaling protein (ASP). Mutations in the mouse Agouti gene that cause increased and ectopic expression of ASIP (viable yellow, $A^{v y}$ ) result in yellow coat color, similar to the phenotype of $e / e$ mice, as well as obesity due to ASIP binding to the MC4R. In humans, more than $200 \mathrm{MC} 1 \mathrm{R}$ variants have been identified and high numbers of natural MC1R variants are strongly 
associated with pigmentary phenotypes, providing evidence that the MC1R is the main determinant of human pigmentation and central to eu- and pheo-melanin regulation [29]. Similarly to mice, MC1R variants in humans can result in the reduction of receptor activity and a shift in melanin synthesis from eumelanin to pheomelanin. MC1R is inactivated in people with red hair, due to mutation(s) that make(s) them more susceptible to melanoma than dark-skinned individuals. For example, variants of the gene encoding $M C 1 R$, mainly R151C, R160W, and D294H, have been shown to be associated with light and poorly pigmented skin [36], whereas the WT form is associated with dark, highly pigmented skin [37,38]. These variants decrease the sensitivity of the receptor and binding of the hormone $\alpha-\mathrm{MSH}$, produced by keratinocytes in response to UVR. Epidemiology studies have strongly established that the MC1R functions as a melanoma predisposition gene. However, it is still not clear whether this is due to the lack of eumelanin, with photoprotective and antioxidant activities, or the expression of pheomelanin, which is known to amplify UVA-induced reactive oxygen species (ROS), or other functions not related to pigmentation. Indeed, pheomelanin was shown to promote melanomagenesis via the induction of oxidative DNA damage, without exposure to any carcinogens, such as UVR, in mice harboring the activating Braf $^{\mathrm{V} 600 \mathrm{E}}$ mutation combined with $\mathrm{MC}^{\mathrm{e}} \mathrm{R} / \mathrm{e}$ [39]. Thus, loss of function of MC1R promotes initiation in UV-independent manner, demonstrating its tumor suppressor activity and a key role in the initiation of melanoma. Apart from its central role in pigment switching, it is now recognized that MC1R has non-pigmentary roles in antioxidant defenses and DNA-repair mechanisms [40-42]. The cAMP pathway enhances melanocyte nucleotide excision repair (NER) activity, which operates by a «cut and patch» mechanism, to remove UV lesions. Activation of the MC1R by $\alpha$-MSH binding results in phosphorylation of the DNA damage sensors ataxia telangiectasia mutated (ATM) and Rad3 related (ATR), as well as recruitment of the xeroderma pigmentosum complementing proteins XPC (Group C) and XPA (Group A) [22]. Consistent with MC1R promoting DNA damage repair, impairment of the NER pathway in subjects carrying a $M C 1 R$ loss-of function mutation has been observed. Additional non-pigmentation-related effects of MC1R can be attributed to the activation of MITF expression, which controls genes involved in DNA damage repair, chromosome stability, and centromere integrity [43].

Therapies involving defective MC1R signaling aim to restore its activities. Mouse 
mutants of MC1R have been characterized for years and can be used to evaluate therapies for better protection against UVR. Topical application of the cAMP permeableinducer forskolin onto mice harboring loss-of-function mutations or haploinsufficiency of Mc1re/e stimulated eumelanogenesis and induced UV-resistance [44,45]. These studies confirmed epidemiological studies suggesting that MC1R haploinsufficiency increases mutagenic susceptibility to UVR and melanoma risk. Another therapeutic approach is to use MC1R agonists to increase pigmentation, antioxidant defense, and DNA repair. The best-known analogue is NDP-MSH, which is 100 times more potent than $\alpha$-MSH and is currently used to treat photosensitivity diseases, such as erythropoietic protoporphyria (EPP). A very promising analog is the tripeptide (LK-514), which is $>10^{5}$ times more selective for MC1R than other melanocortin receptors [46]. The challenge of MC1R-based therapies is to use an analog that is highly specific to MC1R to prevent toxic effects due to the activation of other receptors and to avoid targeting expression of MC1R in non-melanocytes.

\section{1.b.3. The Wnt/Frizzled receptor}

The Wnt (fusion of the words wingless and integrated) pathway is one of the most important signaling pathways during embryonic development and adult homeostasis and its deregulation has often been linked to cancer. Wnt proteins activate at least three different intracellular signaling pathways: the Wnt/ $\beta$-catenin (or canonical), Wnt/Ca ${ }^{2+}$, and Wnt/planar polarity pathways. The type of Wnt protein secreted determines which of these three signaling cascades is activated. The Wnt family contains at least 19 secreted cysteine-rich glycoproteins in humans. Wnt proteins bind to target cells via two families of receptors: the seven transmembrane receptors Frizzled (Fzd) and LDLreceptor-related proteins. The Frizzled (FZDs) receptors are comprised of ten members (FZD1-FZD10), most of which are coupled to the $\beta$-catenin (bcat) canonical signaling pathway.

The Wnt/bcat pathway is essential for melanocyte development from NCCs [47]. The ligands Wnt1 and Wnt3a are required for the specification, expansion, and differentiation of melanoblasts from NCCs [48,49]. bcat itself has been directly implicated in melanoblast determination in several models, with varying effects depending on the temporality of its activation [50,51]. In mice, loss of bcat from premigratory NCCs (Wnt1::Cre; Ctnnb1ex2-6F/F) or melanoblasts (Tyr::Cre; Ctnnb1ex2-6F/F) 
induces the disappearance of melanoblasts [51,52]. The expression of a stabilized form of bcat (Tyr::bcat-mut-nls-egfp) leads to mice with a ventral white coat area associated with a defect in melanoblast migration [53]. Various bcat targets have been shown to be involved in cell proliferation and include the ubiquitous genes Myc and CyclinD1 and the melanocyte-specific gene Mitf-M.

Only one member of the Frizzled family, FZD4, was implicated in pigmentation. FZD4 knockout (Fzd4 ${ }^{\text {tm1Nat}}$ ) induced a depigmentation of coat color in addition to multiple defect in nervous system [54]. FZD receptors are frequently overexpressed in tumor tissues relative to normal tissues and are potentially associated with a poor prognosis. No FZD overexpression has been directly linked to melanoma. Nevertheless, FZD7 receptor was found to be upregulated in metastatic-derivative melanoma cell lines compared to the parental A375P. It expression was associated with amoeboid invasion [55] FZD7 knocked-down reduces tumor growth after subcutaneous injection of WM1361 melanoma cell line as well as metastasis formation after tail-vein injection of several melanoma cells in NSG mice [55,56]. OMP-18R5, a monoclonal antibody targeting several FZD including FZD7, is able to block tumor growth in xenograft mouse models for multiple cancers but was not evaluated for melanoma [57].

Although little evidence implicates FZD receptors in melanomagenesis studies of its associated signaling with $\beta$-catenin clearly highlight a central role of this pathway in melanoma. Melanoma was one of the first cancers in which CTNNB1 mutations were identified. In mouse models, the activation of WNT/bcat signaling participates in the initiation of melanomagenesis but is not, alone, sufficient for initiation. Expression of a stabilized mutated bcat in melanocytes associated with a mutated human NRAS oncogene, constitutively activating the MAPK pathway, in a mouse model (Tyr::NRAS ${ }^{\mathrm{Q} 61 \mathrm{~K}} /{ }^{\circ}$; Tyr::bcat-mut $/{ }^{\circ}$ ) led to accelerated onset and increased the number of melanomas [58]. This property has been linked to the increased immortalization of melanocytes in vitro by the repression of p16 expression. In a Braf $600 \mathrm{E}$; Pten $/-;$ bcatnull-KO (Tyr::CreER ${ }^{\mathrm{T} 2-\mathrm{Bos}}$; BrafCA; Pten ${ }^{\mathrm{F} / \mathrm{F}}$; Ctnnb1ex2-6 ${ }^{\mathrm{F} / \mathrm{F}}$ ) mouse model, in which $\beta$ catenin is inactivated, the occurrence of melanoma is strongly delayed relative to that in a Brafv600E; Pten /- model [59]. In a Brafv600E; Pten-/; bcat-STA (Tyr::CreERT2-Bos; BrafCA; Pten $^{\mathrm{F} / \mathrm{F}}$; Ctnnb1ex3 ${ }^{\mathrm{F} / \mathrm{F}}$ ) mouse model, in which bcat is activated, the occurrence of melanoma is accelerated [59]. In mouse models of Braf ${ }^{\mathrm{V} 600 \mathrm{E}}$, Pten $\%$, and NRASQ61R melanoma, bcat activation increases the number of lung metastases, whereas bcat 
inactivation decreases the number of lymph-node and lung metastases [53,59]. In conclusion, the activation of bcat increases both the initiation and progression of melanoma in mouse models. Of note, in humans, several studies have linked the Wnt/bcat pathway to the antitumor immune response in melanoma [60-62].

\section{1.b.4. Glutamate receptors (GRM1, GRM3 and GRM5)}

Glutamate is the most abundant excitatory neurotransmitter in the human central nervous system, where it plays a critical role in intercellular communication. Glutamate receptors are also expressed in tissues outside of the nervous system and are involved in the modulation of various normal and pathological processes. The glutamate receptor family is divided into two major groups: ionotropic glutamate receptors (iGluRs) and metabotropic glutamate receptors (Grms). The Grm1s belong to the class C family of GPCRs, characterized by a large, globular, extracellular ligand-binding domain. The Grm1 family consists of eight members (Grm1-8), which are organized by sequence homology, signaling effectors, and general localization. Group I Grms, consisting of

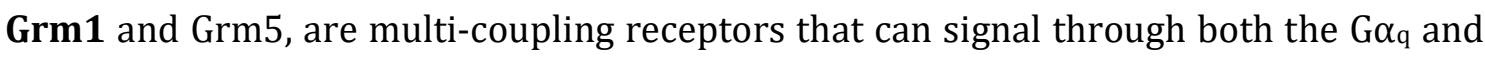

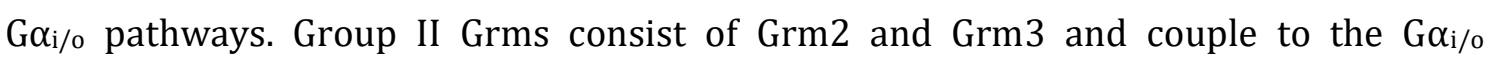
pathway. Group III Grms consist of Grm4, Grm6, Grm7, and Grm8 and couple to Go $\alpha_{i / o}$ signaling pathways. Three members of the metabotropic glutamate receptors (mGluR1, mGluR5, mGluR3) have been clearly identified as regulators of melanomagenesis (see for review [63]).

The involvement of metabotropic glutamate receptors in melanomagenesis was initially revealed by chance in a complex study using insertional mutagenesis, leading to aberrant expression of Grm1. Surprisingly, the mouse developed metastatic melanoma, whereas Grm1 is not detected in normal melanocytes in mice [64]. Confirming this initial observation, transgenic mice containing Grm1 under the control of the Dct promoter (Dct::Grm1) developed melanoma with 100\% penetrance [65]. Initially, no distant organ metastases were observed but disseminated cells were later detected in distant organs, such as the lung and liver [66]. The importance of Grm1 on tumor growth in vivo was supported by the decreased in growth induced by Grm1 knock-down in xenografted cells [67]. A conditional transgenic model using the tetracyclineregulated system to express mGluR1 in adulthood demonstrated that Grm1expression is required not only for the initiation of melanoma initiation but also for its progression in 
vivo [68]. The gene encoding the human receptor (GRM1) is altered in melanoma by point mutations, amplification, and/or deletions. In humans, GRM1 expression is not detected in normal melanocytes but it is expressed in $80 \%$ of metastatic melanoma or cell lines. Works from the laboratory of S. Chen showed that Grm 1 and GRM1 expression results from activation of the MAPK and PI3K/AKT pathways, the main pathways activated in melanoma [69,70,63]. Melanomas expressing GRM1 show elevated levels of glutamate in the tumor microenvironment, contributing to hyperactivation of the receptor and its downstream effectors. The identification of this autocrine loop between GRM1 expression and the secretion of glutamate led to clinical trials to test riluzole, known to reduce glutamate release and thus reduce activation of the receptor. Despite being efficient in mice, no objective responses were observed in humans [71,72]. Recently, the secretion of glutamate by the melanoma cells has been associated with an increased glutaminolysis due to aberrant expression of glutaminase. Co-inhibition of glutaminolysis and GRM1 have been proved to be efficient to decrease melanoma xenograft growth in vivo [73]. This co-treatment remains to be tested in clinics. Furthermore, riluzole monotherapy showed more immune cell infiltrates in stable disease patients than those with progressive disease, suggesting that combining riluzole with immune checkpoint blockade therapy could enhance the efficacy of either agent alone. However, this has not yet been tested.

In contrast to Grm1, Grm5 is normally expressed in both normal melanocytes and melanoma tumors. Transgenic mice overexpressing Grm5 (Tyrp1-Grm5) present with multiple melanoma located on the tail, with 100\% penetrance and metastases, demonstrating that Grm5 drives melanoma initiation and progression [74]. Of note, mice with Grm1or Grm5melanoma both exhibit tumor formation on the hairless skin, including the pinnae and tails, rather than on trunk areas, as observed for BRAFV600E and NRASQ61K induced melanoma, suggesting that the origin of the transformed cell may not be identical (epidermal vs. hair follicle). No information concerning GRM5 in humans is available.

Exon capture sequencing of 734 GPCRs in malignant melanoma showed that a third glutamate receptor, GRM3, is frequently mutated in human melanoma. The identification of the same mutations (G18E/R, M518I) in multiple individuals suggests that these mutations may be "drivers" of the oncogenic process. GRM3 mutant selectively regulates the phosphorylation of MEK, leading to increased anchorage- 
independent growth and migration [75]. Mutated GRM3 cells are more sensitive to MEK inhibitors. To date, no transgenic models with GRM3 mutants to study its effect on cellular transformation and sensitivity to MEK inhibitors have been developed. GRM3 mutants may contribute to melanomagenesis through cross talk between the cAMP and MAPK signaling pathways [76]. The misexpression of two other glutamate receptors, GRM4and GRM8, has been detected in melanoma but their precise role has not yet been clearly demonstrated [63]. Over $60 \%$ of human melanomas express Grm, indicating the importance of glutamatergic signals in this type of tumor. It appears that glutamate receptors are not only involved in neuronal signaling and neuronal disorders but also in the transformation of the originating neural crest-derived cells, melanocytes, into melanoma. Note that other NCC derivatives express GRMs. As an example, GRM1 is expressed in chromaffin cells of the adrenal medulla and GRM5 is expressed in the Meckelian cartilage [77,78]. However, no other NCC derivatives transformed by glutamatergic signaling have been reported so far.

The GPCRs that are cited in the next paragraphs (PAR1, CXCR4, CCR7, CCR10 and GPER1) have been implicated in melanomagenesis. However, their functional role in melanoma initiation and in an immunocompetent environment have not been studied.

\section{1.b.5. PAR1}

The protease-activated receptors (PARs) are a family of GPCRs comprised of four members (PAR1-4) involved in the regulation of various cellular processes, including inflammation and coagulation. Cleavage of PAR1 (also known as the thrombin receptor) by thrombin activates the receptor and downstream signaling through multiple heterotrimeric G-proteins such as $\mathrm{G} \alpha_{\mathrm{q}}, \mathrm{G} \alpha_{\mathrm{i} / 0}$, and $\mathrm{G} \alpha_{12 / 13}$. In turn, MAPK, the phosphatidylinositol 3-kinase (PI3-K) signaling pathways, and phospholipase C- $\beta$ (PLC$\beta)$ are activated. Elevated PAR-1 expression during melanoma progression has been suggested to promote key processes that contribute to melanoma metastasis. Targeting PAR-1 reduced tumor growth and the metastases of melanoma cells in xenograft experiments [79]. Overexpression of PAR-1, as well as the continuous activation of thrombin, promotes the upregulation of genes involved in adhesion, invasion, angiogenesis, and metastasis [80]. As PAR-1 signaling affects both melanoma cells and their microenvironment, it was considered to be an attractive therapeutic target for the 
treatment of melanoma patients. However therapeutic trials were not continued in melanoma due to the activity of PAR1 in coagulation.

\section{1.b.6. Chemokine receptors (CXCR4, CCR7, CCR10)}

Chemokine receptors belong to the GPCR family and are classified into four groups, CXCR, CCR, XCR, and CX3CR. Each receptor can bind to several chemokines. A variety of chemokine receptors are expressed on the surface of both immune and tumor cells. Expression of CXCR4, CCR7 and CCR10 on the surface of melanoma cells is associated with a poor prognosis [81]. Aside from their critical role in the immune response, chemokines and their receptors have been studied for their capacity to guide cancer cells to specific organs. Chemokines have chemotactic properties and can attract melanoma cells expressing their corresponding receptors. High concentrations of CXCL12, the ligand of CXCR4, are produced in the lungs and injected CXCR4-expressing B16 melanoma cells are able to efficiently colonize the lung. Such colonization is reduced in the presence of T22, a specific inhibitor of CXCR4 [82]. In addition, a commercially available dermal filler, hyaluronic acid (HA)-based gel, loaded with CXCL12 was able to recruit and trap CXCR4-expressing B16 melanoma cells injected into mice, consequently leading to a reduction in lung metastases [83]. One hundred and thirty-eight (138) clinical trials with CXCR4 inhibitors are being/have been performed, none of which include(d) melanoma. In mice, the overexpression of CCR7 or CCR10 in B16 melanoma cells was shown to increase regional lymph node metastases, which was blocked by neutralizing its ligand, CCL21, using a specific antibody $[81,84,85]$. However, most of these experiments used mouse B16 melanoma cells, which are not necessarily the best representative of human melanoma. The effect of the various chemokines on the immune response is not discussed here.

\section{1.b.7. G protein-coupled estrogen receptor 1 (GPER1)}

There are three estrogen receptors, two nuclear receptors ER $\alpha$ and ER $\beta$ that act mainly as transcription regulators and the G-protein-coupled estrogen receptor 1 (GPER1 or GPER or GPR30) that can induce rapid, non-genomic estrogen signaling [86]. GPER1 coupled with $G \alpha_{\text {s }}$ protein inducing the cAMP pathways. Using various mouse models, GPER1 has been shown to plays pleiotropic functions in particular in endocrine, immune, cardiovascular and central nervous systems. In these mice, no pigmentary 
phenotype has been observed. The impact of estrogen in melanomagenesis is still controversial since multiple genetic and environmental factors can influence greatly to the development of this cancer and its severity. Nevertheless, Natale at al., propose that repeated pregnancies inhibit the growth of BRAF-driven human melanocytic neoplasia in xenografts and that GPER1 signaling promotes cell differentiation instead of proliferation inhibiting tumor development [87]. Furthermore, in this study GPER1 signaling render melanoma cells more vulnerable to immunotherapy. These results lead to the initiation of a clinical trial targeting GPER1 and anti-PD1 immunotherapies (Phase I/IIA trials: NCT04130516). It should be pointed out that there is an important controversy about the role of GPER1 as the principal mediator of estrogen response in vivo because even though nuclear receptors are less expressed in melanoma than GPER1 (Median level for GPER1=1,86; ER $\alpha=0,61 ; E R \beta=0,31 \mathrm{Tpm}$ according to TCGA data base) they have a higher affinity for $17 \beta$-estradiol (GPER1=3-6nM and ERs=0,1-1nM) [88]. It is clear that the role of GPER1 in melanoma needs further investigation particularly in physiological relevant mouse melanoma models.

Other GPCRs (GPR143, GPR161, SM0) give pigmentation phenotype but were not

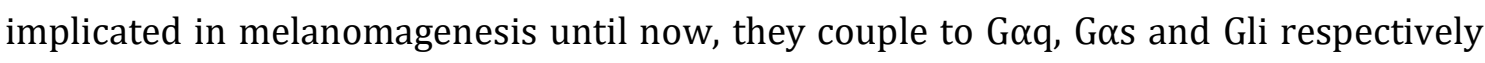
[89-91].

\section{GPCR associated signaling in melanoma}

The activation of GPCRs leads to the modulation of the activity of cellular signaling pathways, marked by the production of second messengers. The first element of such signaling is the heterotrimeric G proteins to which these receptors are coupled through their intracellular domain. These G proteins consist of three subunits, G $\alpha, G \beta$, and $\mathrm{G} \gamma$ [92]. The C-terminal subunit of the GPCR is responsible for the selectivity of receptor/G protein binding [92,93]. The G subunit is also responsible for the selectivity of downstream signaling pathways [94]. There are a total of $21 \mathrm{G}$ subunits grouped into

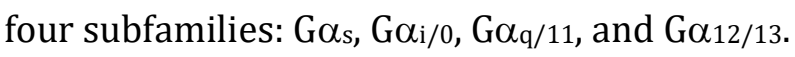

GPCRs generally couple to a specific G protein but may interact with several different G proteins $[37,95]$. Coupling appears to be cell-dependent. Thus, a careful analysis of the downstream signaling is required for each cell type. Binding of a ligand to its GPCR causes a conformational change in the GPCR that is transmitted to the Ga subunit, which exchanges the GDP to a GTP molecule. The binding of GTP induces the 
dissociation of $\mathrm{G} \alpha$ from the $\mathrm{G} \beta-\mathrm{G} \gamma$ subunits of the receptor. This dimer then modulates

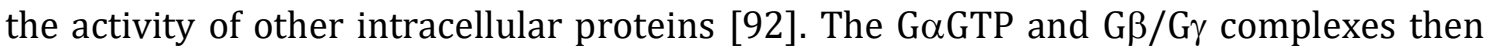
generate different intracellular signals that included cAMP, inositol tri-phosphate, diacyl-glycerol, and Rho proteins (Figure 1).

\section{2.a. Signaling via cAMP}

The induction of MC1R by its ligand activates the CAMP pathway whereas the induction of GRM1, GRM3 and GRM5, CXCR4, CCR4, CCR7, and CCR10 represses this pathway. cAMP was the first second messenger to be discovered and regulates many downstream cellular processes $[96,97]$. Two classes of G subunit modulate intracellular cAMP levels, $\mathrm{G \alpha}_{\mathrm{s}}$ and $\mathrm{G} \alpha_{\mathrm{i} / 0}$, with diametrically opposed effects [94,98]. The enzyme responsible for cAMP production, adenylate cyclase (ADCY), is a membrane-associated enzyme that converts ATP to cAMP $[98,99]$. The difference between $G \alpha_{s}$ and $\mathrm{G \alpha}_{\mathrm{i} / 0}$ is due to the difference in the binding domain on the adenylyl cyclase: members of the Gas family bind to the $\mathrm{C} 2$ intracellular domain of the adenylyl cyclase, which then activate its enzymatic activity, ultimately leading to an increase in intracellular cAMP levels [100]. Conversely, members of the $\mathrm{G}_{\mathrm{i} / 0}$ family bind to the $\mathrm{C} 1$ intracellular domain of the adenylyl cyclase, thereby inhibiting its activity.

The heterotrimeric G protein subfamily $G \alpha_{s}$ is composed of three members: $G \alpha_{s}$ and $\mathrm{G} \alpha_{\text {sxl }}$, two splice variants of the GNAS gene, and Goolf, encoded by the GNAL gene [94]. Only $\mathbf{G} \alpha_{\text {s }}$ is expressed in melanocytes and melanoma [101] and is activated by an associated receptor, such as the MC1R [102]. Gain-of-function mutations of GNAS are clustered at amino-acids R201 and Q227, located in the pocket where GTPase activity is located, and induce the loss of intrinsic GTPase activity and maintain the Gos protein in an activated state. Mutations of GNAS are frequently found in various tumors of the pancreas, kidney, and stomach but are more anecdotal in melanoma, affecting less than $1 \%$ of cases [103,104]. More strikingly, the GNAS T393C SNP polymorphism is associated with tumor progression in metastatic melanoma [105], as well as in other cancers, such as colorectal cancer or bladder cancer [106,107]. The effect of this polymorphism on the activity of $\mathrm{G} \alpha_{\mathrm{s}}$ has not been evaluated nor on the oncogenic process. However, this observation suggests that $\mathrm{G} \alpha_{\text {s }}$ inactivation favors melanoma progression. 
The $\mathrm{G}_{\mathrm{i} / 0}$ heterotrimeric $\mathrm{G}$ protein subfamily is composed of eight members: $\mathrm{G}_{\mathrm{i} 1}$, $\mathrm{G} \alpha_{\mathrm{i} 2}, \mathrm{G} \alpha_{\mathrm{i} 3}, \mathrm{G} \alpha_{0}, \mathrm{G} \alpha_{\mathrm{z}}, \mathrm{G} \alpha_{\mathrm{t}-\mathrm{r}}, \mathrm{G} \alpha_{\mathrm{t}-\mathrm{c} \text {, }}$ and $\mathrm{G} \alpha_{\text {gust. }}$. However, only $\mathbf{G} \alpha_{\mathrm{i} 1}, \mathbf{G} \alpha_{\mathrm{i} 2}$, and $\mathbf{G} \boldsymbol{\alpha}_{\mathrm{i} 3}$ are expressed in melanocytes and melanoma, and encoded respectively by GNAI1-3 [94,104,108,109]. Gain-of-function mutations of GNAI2 are clustered at amino-acids R179 and T182 and lead to constitutive activation of the Ga $\alpha_{2}$ subunit by increasing the GTP binding capacity [110,111]. GNAI2 is mostly involved in cell injury and inflammatory responses but these activating mutations can lead to tumors, depending on the cellular context, due to increased MAPK activity. G $\alpha_{\mathrm{i} 2}$ R179 and T182 mutations are found in $1.4 \%$ of melanoma patients [104] but their impact has not yet been evaluated.

$\mathrm{G} \alpha_{s}$ and $\mathrm{G} \alpha_{\mathrm{i} / 0}$ directly regulate adenylate cyclase. There are ten (10) enzymes encoded by ten (10) different $A D C Y 1-10$ genes [112,113]. All are membrane bound via their two series of six transmembrane helices (TM1 and TM2), followed by a cytoplasmic domain (C1 and C2, respectively). Only ADCY10, which is soluble, differs from the others, as its activation is GPCR independent, being activated by bicarbonate and calcium [114]. Most adenylate cyclases are expressed in melanoma, with the exception of ADCY5 and ADCY8 [104,109]. The expression of ADCY10 is unclear because, although teams have found the protein by IHC, databases suggest that the mRNA is absent $[104,115]$. It has been shown that metastatic melanomas express more ADCY1 mRNA than primary melanomas and that a high level of ADCY1 expression correlates with a poorer prognosis [116]. Consistent with this observation, the silencing of ADCY1 in vitro in mucosal melanoma cell lines decreases the ability of cells to form clones in a colony-formation assay, as well as their migratory and invasive capacity [117]. In xenograft experiments, decreased ADCY1 expression decreased subcutaneous cell growth, as well as colonization of the lung after the injection of melanoma cells into the tail vein of NOD/SCID [117]. More generally, stimulation of adenylate cyclase activity by forskolin promotes tumor growth in the BrafCA/Pten $\%$ melanoma mouse model, whereas its pharmacological inhibition by SQ22536 leads to a decrease in tumor growth in a MAPK pathway-independent manner [118,119]. However, treatment of human primary and metastatic melanoma cell lines with SQ22536, even at high concentrations, does not alter cell survival. This implies that the targeting of transmembrane adenylate cyclase is not a feasible therapeutic strategy on its own. Adenylate cyclase activity is also involved in resistance to MAPK inhibitors. Indeed, treating BRAFV600E melanoma cells 
with forskolin increases ADCY9 expression and cAMP synthesis, leading to greater resistance to MAPK inhibition [120].

The intracellular concentration of cAMP is negatively regulated by phosphodiesterases (PDEs), which hydrolyze cAMP to AMP, thus controlling the amplitude and duration of the signal. There are 11 families of PDEs (PDE1-11) encoded by a total of 21 different genes [121]. Specific PDE isoforms are located in different subcellular compartments, where they regulate cAMP levels. Indeed, cAMP does not freely diffuse across the cell but is rather produced in subcellular compartments. This feature has important consequences, allowing only appropriate targets to be activated in microdomains [122].

In melanocytes, phosphodiesterase 4 (PD4E), more specifically its variant PD4ED3, is a direct target of MC1R-cAMP signaling, constituting a negative feedback mechanism [123]. Blocking PDE4D3 activity in conjunction with forskolin treatment can efficiently restore cAMP levels and pigmentation in $\mathrm{MC}^{\mathrm{R}} \mathrm{R} / \mathrm{e}$ mice. In melanoma, the expression of numerous PDEs has been reported and their effect was initially shown on cell proliferation [124,125]. Their specific functions in BRAF or NRAS-mutated melanoma highlight the connection between the cAMP and MAPK pathways (see below). The overexpression of PDE4 and, therefore, the inhibition of cAMP signaling is critical for MAPK activation by oncogenic RAS in melanoma $[125,126]$. In BRAF-mutated melanoma, the inhibition of PDE4 activity by pharmacological inhibitors or RNA interference decreases melanoma cell invasion by interacting with the focal adhesion kinase FAK [127]. Overall, 3.5\% of solid tumors (including melanoma) have homozygous microdeletions of PDE4D associated with increased expression and a tumor-promoting effect [124]. PDE4D expression is elevated in advanced melanoma and negatively associated with survival. More generally, inhibiting cAMP signaling through the expression of phosphodiesterases (PDE1, PDE2, PDE4, and PDE8) is associated with the oncogenic progression in melanoma [122]. Whether phosphodiesterase inhibitors can prevent proliferation, invasion, or migration in melanoma needs to be evaluated in the future.

The first and main target of cAMP is protein kinase A (PKA) [94,128]. PKA is a serine/threonine kinase composed of four subunits: two regulatory and two catalytic. There are four isoforms for both the regulatory $(\mathbf{R I} \alpha, \mathbf{R I} \beta, \mathbf{R I I} \alpha$, and $\mathbf{R I I} \beta)$ and catalytic subunits $(\mathbf{C} \alpha, \mathbf{C} \beta, \mathbf{C} \gamma$, and PRKX), each isoform showing individual localization and 
specificity. In humans, all are expressed, but $\mathrm{C} \gamma$ in melanocytes and melanomas [129]. Theoretically, since RIs cannot interact with RIIs, a maximum of 36 combinations can be generated between regulatory and catalytic subunits. At this point, specific combinations were not characterized in melanocytes nor melanomas.

Binding of cAMP to the regulatory subunits induces their dissociation from the catalytic units, which become active and phosphorylate downstream targets [130]. More than $70 \%$ of patients with familial Carney complex carry three mutations associated with pathogenic features (82C->T, 491_492 delTG, c.709-2_709-7 delATTTTT) in the PRKAR1A gene, which encodes the RIa subunit [131]. This mutation induces a dominant-negative action of the regulatory subunit and in consequence a constitutive activation of the catalytic subunit of PKA. This autosomal dominant multiple neoplastic syndrome is marked by mottled pigmentation of the skin [132]. Inactivating mutations of PRKAR1A lead to constitutive activation of the cAMP-PKA pathway through the loss of regulation of the catalytic subunits of PKA. In melanoma, mutations are found in $1.4 \%$ of cases, as well as loss of heterozygosity in $11.8 \%$ of patients [104]. Furthermore, loss of function of PRKAR1A is found in epithelioid pigmented melanocytomas, a rare intermediate/borderline form of melanoma [133]. By comparing PKA activity in primary and metastatic melanoma cells, Beebe and colleagues suggested that PKA activity is higher in melanoma metastases [134]. The pharmacological inhibition of PKA induces the growth and invasion of melanoma cells [135].

A large number of cytosolic and nuclear proteins have been identified as substrates for PKA [96]. Importantly, PKA is located at the crossroads between cAMP and MAPK/ERK. Constitutive activation of cAMP leads to the phosphorylation and inactivation of CRAF by PKA in melanoma [125]. CRAF is important in maintaining activation of the MAPK pathway in RAS-mutated cancers because ERK1/2 has a negative feedback action through the phosphorylation of BRAF, which causes its inhibition $[125,126,136]$. As a consequence, activation of MAPK pathways through CRAF requires that the cAMP pathway in melanoma cells be inactivated to release cAMP-mediated inhibition of CRAF. PKA can also directly phosphorylate BRAF on serine 365 , dislocating the RAS/BRAF/KSR complex and thus activating BRAF [137]. The catalytic C $\alpha$ subunit renders BRAFV600E melanoma cells resistant to MAPK inhibitors [120]. The CRTC3 protein, a co-activator of CREB that is phosphorylated and activated by PKA and ERK [138], lies at the interface between signaling through the cAMP and MAPK pathways. A 
knockout mouse model for Crct3 showed graying of the coat due to defects in melanocyte maturation [138]. Mutations in CRCT3 have been identified in 23\% of human melanomas, most leading to an increase in its expression and activity and reduced patient survival [138]. Thus, CRT3 inhibition could be beneficial for such patients.

The regulation of transcription by PKA is mainly achieved by the phosphorylation of CREB. CREB phosphorylation leads to dimerization of this transcription factor and its subsequent binding to cAMP response elements (CRE) in target genes and its interaction with transcription co-activators, such as CREB-binding protein (CBP) and p300. CRE binding sites are located in the promoter regions of many genes, including the master melanocyte regulator MITF [31,139]. MITF regulates numerous major cellular processes, including pigmentation, growth, survival, migration, and invasion essential for melanogenesis and melanomagenesis [32]. In melanoma, CREB overexpression is associated with transition from the radial to vertical growth phase [140].

The inhibition of CREB in melanoma cell lines was shown to decrease metastasis formation after injection into the tail veins of mice [141,142]. This loss of metastatic potential can be explained, in particular, by the loss of the expression of the metalloproteinase MMP2 and the adhesion molecule MCAM/MUC18. Surprisingly, CREB, which generally acts as a transactivator, negatively regulates the transcription factor AP2 $\alpha$ and the gene encoding cellular communication network factor 1 (CCN1/CYR61). In early publications, these two genes were considered to be tumor suppressor genes in melanoma but more recent studies have proposed that AP2 $\alpha$ and CCN1 facilitate melanoma progression [143-145]. The RNA-editing enzyme adenosine deaminase acting on RNA1 (ADAR1) has been recently identified as a new target of CREB. Silencing ADAR1 enhances the invasiveness of melanoma cells [146]. CREB has been associated with resistance to MAPK inhibitors. Phospho-CREB is restored in relapsing melanomas previously treated by MAPK inhibitors, possibly by the up-regulation of adipocyte enhancer-binding protein 1, AEBP1 [120,147].

The second major target of cAMP is the cAMP-activated exchange protein (EPAC) [148]. EPAC is a guanine nucleotide exchange factor (GEF) for small GTPAses, e.g. RAP1 (Ras-related protein 1). Activation of RAP1 occurs through the exchange of GDP for GTP $[96,148]$. The consequences of EPAC activation on the growth of melanoma are still unclear and reports are conflicting. Indeed, pharmacological activation of EPAC using an 
EPAC-specific cAMP analog increases the growth of HMG cells [149] but has no effect on PMP melanoma [135]. The use of shRNA targeting Rap1 increases the growth and survival of cells derived from primary but not metastatic melanomas [118]. The current hypothesis is that the EPAC-Rap1 pathway is anti-proliferative in metastatic melanoma and pro-proliferative in primary melanoma [150].

The third and last major effectors of cAMP are the cAMP-dependent ion channels: the cyclic nucleotide-gated ion channel (CNG) and the hyperpolarization-activated cyclic nucleotide-gated channel (HCN) [148,151]. These channels are relatively nonselective cation channels and have not yet been studied in melanoma.

\section{2.b. Signaling via inositol tri-phosphate and diacyl-glycerol}

The induction of EDNRB and PAR1 by its ligand activates the IP3/DAG pathway. It has to be noted that GRM1 and GRM5 are inducing the IP3/DAG pathway, but repress the cAMP pathway. Cellular levels of inositol tri-phosphate (IP3) and diacyl-glycerol are highly regulated by the stimulation of GPCRs of the $\mathbf{G} \mathbf{\alpha}_{\mathbf{q} / \mathbf{1 1}}$ class. This class contains four

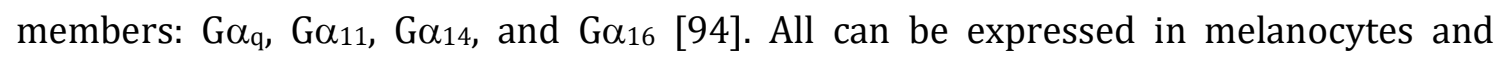
melanoma but only $G \alpha_{q}$ and Go11 are highly expressed in these cells [104,109]. Activation of the receptor induces the exchange of GDP bound to the alpha subunit for GTP, resulting in activation of this subunit. Mutations affecting $G$ proteins of the $\mathrm{G} \alpha_{\mathrm{q} / 11}$ class are almost systematically found in uveal melanoma, of which approximately $90 \%$ of metastatic uveal melanomas are mutated for $\mathrm{G} \alpha_{q}$ or $\mathrm{G} \alpha_{11}$ affecting mainly glutamine 209 in both proteins, but also, to a lesser extent, arginine 183 [152,153]. GNAQ, which is encoding $\mathrm{G}_{\mathrm{q}}$, is mutated in 50 to $85 \%$ of non-epithelial melanocytic lesions, including blue nevi and leptomeningeal melanocytic neoplasms, and GNA11, which is encoding Go $\alpha_{11}$, mutations are more frequent in uveal melanomas [154]. These mutations are found at lower frequencies ( 1-6\%) In other types of cutaneous melanoma [104,155]. Q209L/P and R183C/Q mutations in GNAQ or GNA11 affect the GTPase domain [156] but only Q209L/P mutations have actually been characterized. These mutations reduce the GTPase activity of the G $\alpha_{q}$ subunit and cause hyperactive signaling [156]. Regardless of the tumor context, the mutations are mutually exclusive [152] and are also mutually exclusive with BRAF and NRAS mutations. Of note, in uveal melanoma, mutations of CYSLTR2 (L129G), encoding a Gaq/11-coupled GPCR, are found in a mutually exclusive manner with $\mathrm{G}_{\mathrm{q}}$ and Go11 mutations in approximately 3\% of patients. This mutation is 
also present in blue nevi $[152,157]$. This CYSLTR2L129G mutation constitutively activates the receptor and thus downstream signaling. Depending on the murine models used and the cells targeted (neural crest cells or melanoblasts), embryonic $\mathrm{G}_{\mathrm{q}}{ }^{\mathrm{Q} 209 \mathrm{~L}}$ expression is able to induce a range of lesions from dermal hyperpigmentation to leptomeningeal melanocytoma, nevi, and dermal melanoma to malignant uveal melanomas with lung invasion $[158,159]$. Similarly, postnatal expression of $\mathrm{G \alpha}_{11}{ }^{\mathrm{Q} 209 \mathrm{~L}}$ in melanocytes induces hyperpigmented melanocytic lesions in the uveal tract, skin, and leptomeninges that progress to melanoma with lung invasion [160]. Mice transplanted under the skin with Gaq mutated melanoma cells show inhibition of MAPK signaling and tumor growth following treatment with FR900359 [161]. To date, the inhibition of uveal melanoma with FR900359 appears to be more potent than inhibition with YM254890 [162]. The activation of $\mathrm{G}_{\mathrm{q} / 11}$ is a mechanism of resistance to MAPK pathway inhibition through the overexpression of c-Jun [163]. These data are consistent with the gain in resistance

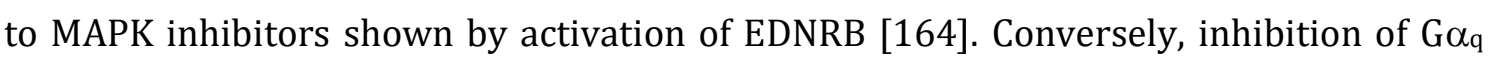
by YM-254890 resulted in inhibition of MAPK signaling, with evidence of a rebound after 24 hours in xenograft experiments of uveal melanoma. Combined treatment with YM-254890 and a MEK inhibitor led to sustained MAPK inhibition and tumor shrinkage [165]. A combination of PKC and MEK1 inhibitors is currently under clinical evaluation for solid tumors harboring GNAQ/11 mutations or PRKS fusions. (Phase I/II trials: NCT03947385).

The primary target of $\mathrm{G} \alpha_{\mathrm{q} / 11}$ subunits is phospholipase C beta (PLC $\beta$ ) [166-168]. This subfamily is encoded by four genes (PLCB1-4) encoding seven proteins, all of which have two isoforms, except PLC $\beta 3$ [169]. All PLC $\beta$ s are likely expressed in cutaneous melanoma [104], whereas, only the PLCB2-4 genes are expressed in uveal melanoma [152]. PLC $\beta$ s function by hydrolyzing membrane phosphatidylinositol-4,5-biphosphates (PIP2) into inositol-1,4,5 trisphosphate (IP3) and diacyl glycerol (DAG) [170]. PLCB4 mutations occur in approximately $5 \%$ of uveal melanoma and are mutually exclusive with GNAQ, GNA11, and CYSLTR2 mutations [171]. PLC $\beta 4$ D630Y mutations affect the Y domain of the catalytic core of PLC4 [171]. Their effect has not been precisely studied, but their exclusivity with the GNAQ, GNA11, and CYSLTR2 mutations and its being downstream of these proteins suggest that PLC $\beta 4$ mutations have a similar effect on the oncogenicity of uveal melanomas [171]. Outside of the context of melanoma, the other 
PLCs have often been shown to induce migration or/and reduce the immune response $[172,173]$.

One of the two secondary messengers produced by PLCs is DAG, which remains anchored in the membrane. Phorbol esters, such as 12-0-tetradeconoyl phorbol-13acetate (TPA) and phorbol 12-myristate 13-acetate (PMA), are synthetic analogues of DAG. TPA is essential for melanocyte growth in vitro [174-176]. Interestingly, the effect of TPA on the proliferation of melanoma cell lines appears to be cell dependent [112,175,177-179]. PMA increases cell survival and invasion and resistance to anoikis $[178,180,181]$. TPA and PMA activate the PKC and MAPK pathways [178]. The other secondary messenger produced by PLCs is IP3. The binding of IP3 to the IP3 receptor (IP3R) increases intracellular $\mathrm{Ca}^{2+}$ levels [182]. Calcium release induced by IP3 supports melanoma cell migration and invasion [183-185].

DAG and calcium activate protein kinase $\mathrm{C}$ by binding to the $\mathrm{C} 1$ and $\mathrm{C} 2$ domains of PKC, respectively [186]. There are nine genes that encode PKC: PKC $\alpha$, PKC $\beta, P K C \gamma$,

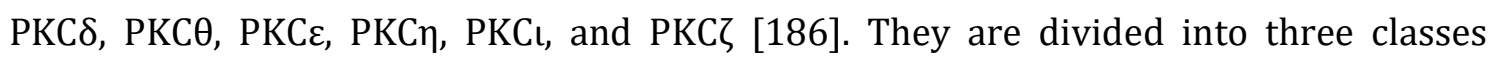
according to their activation mechanism. The classical PKCs (cPKCs) consist of PKC $\alpha$, PKC $\beta$, and PKC $\gamma$ and are activated by calcium and DAGs. The novel PKCs (nPKCs) (PKC $\delta$, $\mathrm{PKC} \theta, \mathrm{PKC} \varepsilon, \mathrm{PKC} \eta$ ) are activated by DAGs alone. Atypical PKCs (aPKCs) (PKCı and PKC $)$ are not activated by calcium or DAGs [186]. At least one PKC from each class is expressed in melanoma cells, except PKC $\gamma[104,186]$. PKC activity is regulated by the presence of their substrates and cofactors and their recruitment by scaffolding proteins, such as receptor for activated kinases $\mathrm{C}$ (RACK) or protein kinase A scaffolding protein 5 (AKAP5) [187-190]. PKC regulates invasion of melanoma cells but the various members have different effects: PKC $\alpha$ and PKC $\delta$ induce melanoma migration, invasion, and lung colonization [191]. Conversely, PKC $\beta$ decreases invasion and promotes cell differentiation and pigmentation $[192,193]$. There are frequent mutations in PRKCB and loss of expression in melanoma but their impact on PKC $\beta$ activity has not been evaluated $[104,190]$. Similarly, the effect of PKC on cell growth is dependent of the isotype [194196].

Among the targets of PKC is Ras guanine-releasing protein 3 (RASGRP3), a guanine nucleotide exchange factor for RAS family proteins [160,194]. PKC phosphorylates RASGRP3 on Thr 133, which contributes to its activation in conjunction with DAG binding [197-199]. The inhibition of RASGRP3 induces the loss of GTP binding 
to RAS and thus its activity [160,194]. This decrease in activity is accompanied by a decrease in MAPK pathway activity associated with a decrease in cell proliferation [160]. This molecular mechanism may explain the activation of the MAPK pathway seen after PKC activation [69,200-202]. PKC $\varepsilon$ and PKC $\eta$ are able to shunt the pharmacological inhibition of BRAFV600E, rendering melanoma cells resistant to these drugs [203]. Consistent with this finding, the use of PKC inhibitors inhibits the survival and migration of melanoma cells resistant to vemurafenib [204].

The activity of Yes-associated protein 1 (YAP1) is positively regulated by many GPCRs but negatively regulated by the Hippo pathway [205,206]. In uveal melanoma, YAP1 is activated by $\mathrm{G} \alpha_{\mathrm{q}}$, inducing cell growth and survival $[158,207,208]$. Inhibition of

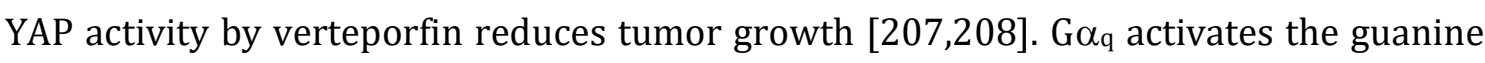
nucleotide exchange factor TRIO, which in turn activates the small GTPases RhoA and Rac1 [207,209]. This likely has a dual action: (i) the activation of FAK, which in turn inhibits the LATS1/2 kinase of the Hippo pathway, inactivating the action of YAP1, and (ii) the direct activation of YAP1 by releasing this angiomotin transcription factor (AMOT) [207,210]. In uveal melanoma, the activation of Rho and Rac is linked to the activation of the MAP kinases JNK \& p38 [209]. JNK and p38 phosphorylate c-Jun and induce the expression of AP-1 targets [211]. Phosphorylation of c-Jun induces cell proliferation via AP1 targets that regulate the cell cycle, such as cyclin D1, p53, p21cip1/Waf1, p19ARF, and p16 [211-214]. Activation of p38 and JNK are likely to be involved in mechanisms of resistance to MAPK inhibitors [212,213]. In cutaneous melanoma, the activation of YAP1 is required for cell invasion [215-218], as well as viability and resistance to anoikis [215,216,218]. Although the effect of YAP1 on invasion is clearly documented, its effect on melanoma growth is still debated [215,217]. YAP1 activity has also been shown to be associated with cell migration via regulation of the arp2/3 complex 3 [215,219]. The invasive phenotype of melanoma cells has been correlated with the activation signature of YAP [217]. In vivo, YAP1 activation induces the formation of very large numbers of metastases in the lungs after the injection of cells carrying the activating mutation of YAP1-5SA under the skin of mice [217]. Lung colonization after the injection of cells into the tails of mice also decreases when YAP1 levels are genetically decreased [216,218]. Most interestingly, inhibition of the Hippo pathway replicates this effect, favoring lung colonization [220]. The pro-invasive action of YAP1 is mediated through the transcription of a number of its targets, such as CCN1, 
AXL, and THBS1 [217]. These targets are well known in melanoma. AXL expression is associated with tumor growth and cell invasion and migration and has also been shown to be associated with resistance to MAPK inhibitors [221-223]. CCN1 has been shown to be associated with increased metastatic potential and angiogenesis [144,224]. Genetic inhibition of THBS1 is associated with decreased cell invasion [225,226]. YAP1 requires the transcriptional cofactors TEAD1-4 to bind to its targets. Genetic inhibition of TEAD14 recapitulates the in vitro effects of YAP1 on invasion, with a clear decrease in the invasive capacity of melanoma cells [227]. TEAD1-4 are also involved in resistance to MAPK inhibitors and inhibition of all four TEADs sensitizes cells to these inhibitors [227].

\section{2.c. Signaling via Go12/13}

The induction of PAR1 by its ligand activates Ga12/13. It has to be noted that PAR1 induces both the IP3/DAG and Ga12/13 pathways. The third major pathway of GPCR signaling involved in melanoma is the pathway involving $\mathrm{G}_{12 / 13}$ [94]. This class of $\mathrm{G}$

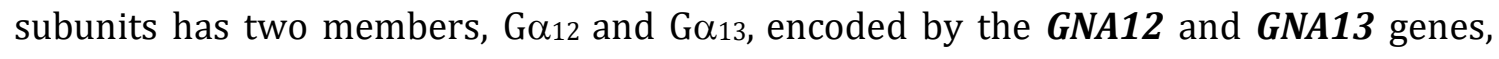
respectively. The expression of these genes is ubiquitous [94,104,109]. Activation of these subunits activates Rho-GEFs, such as leukemia-associated Rho-GEF (LARG) or p115 Rho-GEF [228,229]. Activation is achieved by the attachment of the G12/13 subunit to the RH domain of Rho-GEFs [230]. Once activated, Rho-GEFs induce RhoA activation [231-234]. Rho is a converging point for $\mathrm{G} \alpha_{12 / 13}$ and $\mathrm{G} \alpha_{\mathrm{q} / 11}$ signaling [233]. Signaling induced downstream occurs through the activation of YAP1, as described above [206]. Ga12/13 signaling has been poorly analyzed in the context of melanoma. PAR1 and 2 receptors, coupled to Go12/13 proteins, are expressed in melanoma [235]. Activation of PAR1 receptors by its ligand TRAP6 induces the activation of YAP1 in a HEK293A cell model (Mo et al., 2012). YAP1 activation subsequently leads to activation

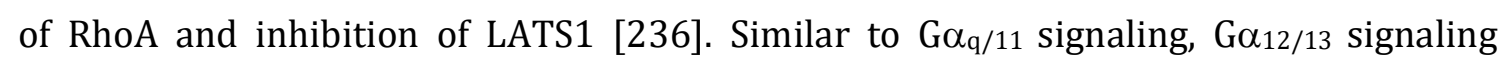
appears to increase invasion and migration while not altering cell growth [237,238]. However, these results were obtained in breast and prostate cancer and need to be confirmed in melanoma. Of note, activation of LPA receptors (LPA1-LPA6), coupled to $\mathrm{G}_{12 / 13}$ receptors, is still poorly documented in melanoma, although it has been reported to enhance chemoresistance to drugs and increase the survival of melanoma cells in vitro [239]. 


\section{2.d. Signaling via $W N T / \beta$-catenin}

The induction of FZD7 by its ligand activates the WNT/ $\beta$-catenin signaling pathway. WNT ligands activate three intracellular pathways: the canonical WNT/ $\beta$-catenin, WNT/Ca ${ }^{++}$and WNT/PCP. Only the canonical WNT/ $\beta$-catenin will be described in this chapter, the WNT $/ \mathrm{Ca}^{++}$corresponds to the $\mathrm{G} \alpha_{\mathrm{q} / 11}$ pathway already described in $2 . \mathrm{b}$ and the WNT/PCP pathways has not been studied in the melanoma context.

The Wnt pathway has been widely studied and reviewed. Here we provide the current knowledge of Wnt/bcat in melanoma, especially through the activity of bcat, which is encoded by Ctnnb1 [240,241].

The canonical WNT pathway is activated only in response to the formation of a complex containing WNT, FZD, and LRP. WNT proteins are difficult to purify in an active form and only a few antibodies are available for their detection. The WNT proteins most studied in the context of $\beta$-catenin activation in melanocyte/melanoma are WNT1 and WNT3a. WNT5a has different roles and acts as an antagonist or agonist of the canonical WNT/ $\beta$-catenin pathway, depending on the cellular context. WNT proteins are subject to post-translational modifications, including glycosylation and lipid modifications. Acylation on conserved serine and cysteine residues is required for WNT secretion and efficient binding to the Frizzled receptor [242,243]. In the basal state, axin protein interacts through distinct domains with GSK-3, CK1 $\alpha, \mathrm{APC}$, and $\beta$-catenin. Axin is considered to be the limiting component of the $\beta$-catenin destruction complex $[244,245]$. Modulation of its levels would therefore be an effective way to regulate $\beta$ catenin destruction. APC is a large protein that interacts with both $\beta$-catenin and axin. It contains three axin-binding domains, interposed between armadillo repeat domains (ARMs), which bind to $\beta$-catenin. $\beta$-catenin is sequentially phosphorylated by CK1 $\alpha$ and GSK-3 on serines (S) and threonines (T) (S45, T41, S37, and S33) in the N-terminal region of the protein. $\beta$-catenin binds to and is ubiquitinated by $\beta$-TRCP1 before being degraded by the proteasome.

Binding of the WNT ligand leads to the dimerization of Frizzled with the coreceptor LRP5/6. This dimerization results in a conformational change of the receptors, leading to relocalization of the degradation complex to the cell membrane under the double interaction of axin with DVL (itself associated with Frizzled) and with the cytoplasmic end of LRP. Such membrane relocalization decreases the activity of the 
degradation complex, such that the amount of unphosphorylated cytoplasmic $\beta$-catenin rapidly increases. The stabilization of cytoplasmic $\beta$-catenin results in an increase in nuclear $\beta$-catenin. The balance between the amount of cytoplasmic and nuclear $\beta$ catenin is dynamic, resulting from multiple mechanisms of transport and retention between the two compartments. In the nucleus, $\beta$-catenin binds to the T-cell factor (TCF)/lymphoid enhancer-binding factor (LEF) family of transcription factors, which themselves are already associated with DNA. In the absence of $\beta$-catenin, TCF factors interact with transcriptional co-repressors of the Groucho/transducin-like enhancer of split (TLE) family and repress the expression of their target genes. Nuclear accumulation of $\beta$-catenin leads to the association of TCF with $\beta$-catenin, resulting in dissociation from Groucho/TLE1 and allowing the recruitment of other coactivators for transcriptional activation through its C-terminal transcriptional activation domain. Many transcription factors outside the TCF/LEF family of transcription factors have been reported to be capable of associating with $\beta$-catenin to activate or repress transcription [246]. In addition, it has to be noted that alternative pathways activate $\beta$-catenin independently of WNTs [247].

In melanocytes/melanoma, MITF interacts with $\beta$-catenin and redirects $\beta$-cateninmediated transcriptional activity from canonical Wnt/ $\beta$-target genes to specific MITF target genes to activate their transcription [248]. For instance, in bcat-sta melanoblasts, stabilised bcat increases MITF-M levels, which may interfere with bcat transactivation, inhibiting the activation of CMYC and CyclinD1 and therefore reducing proliferation [52]. During melanocyte establishment, bcat and MITF-M levels are likely maintained within a very narrow range, with any reduction or increase, such as those observed in the bcat mutants, altering melanoblast proliferation. Other levels of cross-signaling between the WNT/ $\beta$-catenin pathway and MITF have been described. For example, it has been shown that $\beta$-catenin/TCF transcriptionally upregulates MITF-M expression [50]. It has also been shown that MITF-M binds to and upregulates its own promoter through a direct interaction with LEF1 [249]. It would appear to be difficult to target $\beta$ catenin in melanoma without affecting MITF expression and/or activity. MITF could potentially be an attractive target for melanoma therapy but the drug-targeting of MITF is highly challenging. As mentioned already, MITF is considered to be the "master gene" of melanocyte differentiation and has an essential role in the proliferation, survival, senescence, migration, invasion, DNA repair, and metabolism of melanoma cells 
$[32,250]$. Mitf expression is regulated by multiple signaling pathways outside of the canonical Wnt/ $\beta$-catenin pathway, such as the cAMP/CREB, YAP1/PAX3, TGF $\beta / G L I 2$, and TNF/NFKB pathways, and transcription factors, such as SOX10 and BRN2, themselves regulated by multiple pathways in melanoma. The basic concept in melanoma is that the proliferative and invasive states are defined, in part, by the high level/activity of MITF and low level/activity MITF, respectively. High and low MITF level/activity co-exist in melanoma tumors and the switch in MITF expression (high and low) is reversible and responsible for melanoma heterogeneity and plasticity. MITF is also involved in the resistance to BRAF inhibitors. One current view for the therapeutic strategy is to increase MITF levels and therefore those of melanoma antigens, such as MART-1 and GP-100, to increase the recognition of melanoma cells by $\mathrm{T}$ cells and improve the immune response [251]. In any case, therapeutic strategies have to address the versatility and heterogeneity of melanoma cells.

\section{2.e. Signaling via $G \beta / G \gamma$ subunits}

All GPCRs activate the $\mathbf{G} \beta / \mathbf{G} \gamma$ signaling pathways, but remains poorly studied. The activation of GPCRs mainly induces the activation of $\mathrm{G} \alpha$ subunits, but also that of the $\mathrm{G} \beta / \mathrm{G} \gamma$ complex. There are five $\mathrm{G} \beta$ subunits $\left(\mathrm{G} \beta_{1-5}\right)$ in humans encoded by the GNB1-5 genes. All except GNB5 are expressed in melanoma [94]. There are 16 G $\gamma$ subunits encoded by the GNG1-16 genes, of which only $\mathrm{G} \gamma_{2}, \mathrm{G} \gamma_{4}, \mathrm{G} \gamma_{5}, \mathrm{G} \gamma_{6}, \mathrm{G} \gamma_{7}, \mathrm{G} \gamma_{10}, \mathrm{G} \gamma_{11}$, and $\mathrm{G} \gamma_{12}$ are expressed in melanoma [94,104,109]. The significance of $G \beta / G \gamma$ signaling in melanoma has not yet been fully assessed. $G \beta / G \gamma$ subunits activates the PI3K signaling pathway. This activation is either direct or indirect via the calcium release [252-255]. Classically, PI3K activation induces AKT activation and increases cell survival [256]. Also, $G \beta / G \gamma$ were shown to inhibit melanoma migration in vitro through EPAC inhibition [252]. Given the known importance of the PI3K/AKT pathways as well as the role of migration in melanoma, its regulation by $\mathrm{G} \beta / \mathrm{G} \gamma$ subunits needs to be further analyzed.

\section{2.f. $\beta$-arrestin signaling}

All GPCRs activate $\beta$-arrestin biased signaling, but remains poorly studied in melanoma. At the end of the 1990s, it was observed that Src family tyrosine kinases are recruited by $\beta$-arrestins (encoded by ARRB1-2 genes) to the adrenergic receptor $2 \mathrm{a}$ member of the 
GPCR family [257]. Surprisingly, the binding of protein kinases induced activation of the MAPK/ERK pathway only if the receptor was internalized $[257,258]$. Other observations in the mid-2000s showed that such signaling was non-canonical and independent of $G$ proteins. Indeed, the activation of GPCRs activates three types of proteins: G proteins, GPCR protein kinases (GRKs), and arrestins. GRKs and arrestins are the most important elements involved in the termination of GPCR activation. GRKs phosphorylate the receptor on its C-terminal residues, which prevents the activation of G proteins [259]. Such phosphorylation recruits the non-visual arrestins, $\beta$-arrestin $1 \& 2$, which in turn recruit clathrin, resulting in receptor internalization by clathrin coated-pits [259-261]. Depending on the affinity of the GPCR/ $\beta$-arrestin complex, receptors can be recycled or degraded in the proteasome [262]. In early endosomes, the GPCR/ $\beta$-arrestin complex is able to form a signalosome by recruiting signaling proteins, such as members of the MAPK pathway [261,263,264]. Several pathways can be activated, such as the MAPK/ERK and Src pathways [257,265], AKT [266], MAPK/JNK [267], MAPK/p38 [268], or PDEs [269].

GRK-arrestin signaling has been poorly studied in melanoma. $\beta$-arrestin2 is able to bias MC1R signaling by promoting activation of the MAPK pathway towards that of cAMP-dependent signaling [270]. A transcript of the MC1R (MC1R-203) naturally promotes such biased signaling toward the MAPK pathway [271]. Mutants of metabolic glutamate receptors (mGluR3 ${ }^{\mathrm{G} 848 \mathrm{E}}$ ) can promote such biased signaling, characterized by prolonged internalization of the receptor [272]. This mutation is found in rare cases of cutaneous melanoma $(<1 \%$ ) [104]. Conversely, in uveal melanoma, the CYSLTR2L129Q mutation forces signaling via $\mathrm{G} \alpha_{\mathrm{q} / 11}$ and disfavors $\beta$-arrestin-biased signaling. [273] GPCR signaling is certainly much more complex than that presented here. Their interactions with GRKs and arrestins and the dynamics of their desensitization add another level of complexity that needs to be investigated in the future.

\section{Perspectives of targeting GPCRs in melanoma}

The molecular and cellular consequences of the activation of GPCRs in melanoma clearly indicate that they could be interesting targets for therapy. Targeting GPCRs has the advantage of seeking readily available membrane molecules instead of signaling proteins with molecules that need to cross the plasma membrane without deteriorating the intracellular environment and/or endocytotic vesicles and lysosomes [274-276]. 


\section{3.a. Limitation of available tools}

Large-scale sequencing conducted by the cancer genome atlas consortium (TCGA) has shown that approximately $92 \%$ of the melanoma patients tested had at least one nonsense or missense mutation of at least one non-olfactory GPCR [104,277]. Each melanoma patient has an average of 10 mutated GPCRs [104,277]. The functions of the vast majority of the receptors and associated mutations remain uncharacterized. The most frequent GPCR recurrent mutation in melanoma is GPR139R217C but does not exceed $1 \%$ of the patients and may have a driver function. A large number of mutations have been found in various GPCR, but can be considered as passenger since none of these mutations are recurrent in melanoma. Indeed, the Adhesion G Protein-Coupled Receptor V1 (ADGRV1), which is mutated in approximately 30\% of patients but for which only a few recurrent mutations are found. The high number of mutations in ADGRV1 is most likely associated with the size of its cDNA with 19,557 nucleotides $[104,277]$. These data suggest that if we cannot offer patients a personalized and targeted therapy (one patient = one mutation = one drug), patients could be grouped by activated signaling for therapy that is still targeted but less personalized. This less direct choice of therapy would consider the positioning of the GPCR within the signaling pathways and targeting of the downstream node(s) [278]. Such a therapeutic option would also be attractive in the setting of patients who do not have mutated GPCRs but rather mutations in downstream signaling elements.

Receptor activation may result by a mechanism independent of the presence of a mutation in the gene. This could be related to overexpression or de novo expression of a receptor, which would induce a higher basal level of receptor activity, or activation of the receptor by the production of its ligand in the environment [279-281]. Binding of the ligand to the receptor may occur in the primary melanoma in an autocrine/paracrine mode, with ligand production by the melanoma cell or by cells in the microenvironment [282]. For example, activation of EDNRB by ET-1 secreted by surrounding melanoma cells induces reactivation of the MAPK pathway after BRAFi treatment [283]. In this model, ET is secreted by melanoma cells and activates EDNRB in an autocrine and/or paracrine manner [283]. Alternatively, ligand production may only occur at the metastatic site and thus only affect metastasis formation and not melanoma initiation [284,285]. Ligand production may attract tumor cells into the target tissue by 
chemoattraction, promote cell survival and/or proliferation, or induce resistance to drugs. In this perspective, ET-1 is highly expressed in the lungs and can promote the colonization of melanoma cells that express ENDRB in this organ. The reactivation of MAPK pathways by expression of EDNRB may occur at primary sites, as well as in distant organs. Ligand-dependent tissue expression can be observed, in particular, in the lungs, where only 50 highly expressed ligands are found [108,286-289]. An important limitation is our lack of knowledge about the level of gene expression in melanoma cells that colonize distant organs. Transcriptomic analyses would be extremely useful in determining which GPCRs are expressed in melanoma in distant metastases. The correlation of GPCR expression data in melanoma at sites of metastasis with expression in the target tissue of ligands for these GPCRs would allow the selection of potential receptors of interest.

An alternative to transcriptional analysis is likely being the identification of GPCRs at metastatic sites on the basis of protein expression. However, the identification of GPCRs by immunolabeling is difficult, due to the small exposed area of extracellular epitopes and very high conformational variability, or by conventional mass spectrometry, as receptors are not readily isolatable from membranes [290-292].

The improvement of antibody-isolation technologies associated with our knowledge of GPCRs will lead to the generation of new, more selective antibodies. The development of nanobodies appears to be promising for the detection and targeting of GPCRs [293]. The major limitation in the high-throughput identification of GPCRs via mass spectrometry is the depletion of GPCRs from mass spectrometry samples. This bias can be avoided by performing surfaceomes, which will significantly enrich samples for membrane glycoproteins and thus potentially reveal the expression of GPCRs [292,294,295]. Finally, GPCRs can also be indirectly identified by analyzing cell-binding ligands rather than the receptors directly [296].

Data mining of the literature generates databases, such as TCGA. To date, current databases have been extremely useful for the identification of driver mutations in melanoma and prognostic biomarkers. However, they are composed of $80 \%$ primary tumors or skin or lymphatic metastases [104,277] and visceral, bone, and nervous system melanoma metastases are poorly represented. The presence of characteristic and highly aggressive mutations in distant metastasis may be hidden by the small sample size. Furthermore, current databases were generated before the generalization 
of current treatments and the samples constituting the large databases came from patients who were naive to any treatment with MAPK or checkpoint inhibitors. The changes in genetic/epigenetic expression due to such treatments could involve the activation of GPCR expression or the selection of subclones in which GPCR signaling is activated. The generation of databases enriched with samples from distant metastases and patients treated with MAPK and immune checkpoint, inhibitors would be of great interest to the scientific community.

Large-scale high-throughput screening using RNA interference or CRISPR-Cas9 could be performed to identify the dependence of melanoma cells on GPCRs for growth or invasion. Such screens can also be performed in vivo. To evaluate the role of specific GPCR, transplantation of genetically modified cells into animals would reveal the role of this GPCR in internal organs colonization and its role in melanoma progression [297]. Such screening could also be performed by generating transgenic animal models, but the experiments would become extremely complex, time consuming and expensive. Zebrafish may be a suitable model for these types of studies. Indeed, it is relatively easy to generate and maintain large groups of transgenic animals [298-301]. Furthermore, zebrafish express many of the GPCRs expressed in humans, as well as their signaling machinery [302,303]. In addition, there are already many melanoma models that could be used to test genetic modifications in melanoma-producing animals, for example, to assess the pro-metastatic effect [304,305]. Particular attention should be paid to studies based on in vivo cell-injections. Indeed, the type of injection will determine the preferential location of metastasis formation. For example, in mice, tail-vein injections are more likely to result in lung metastasis formation, whereas intrasplenic injections are more likely to result in liver metastases [306]. Thus, the use of a particular type of injection may mask the action of a GPCR on metastasis formation in a tissue not targeted by the injection method. The study of the tissue expression profile of the ligands and the use of an appropriate method can address this concern.

\section{3.b. Novel Structures and drug design approaches}

To target efficiently GPCR, two parallel and complementary approaches are used: binding on GPCR of compounds that includes small molecules, antibodies and radiotherapies, and structure determination of the proteins. The structure of GPCR can be elucidated using X-ray crystallography, Cryo-EM, NMR and artificial intelligence. 
A better knowledge of GPCR structure and molecular ligand-receptor interactions is critical for structure-based molecule design and the design of new receptor-activating agonist or antagonist molecules [307]. Such structural knowledge needs to be as accurate as possible and is currently acquired by two main experimental methods and one predictive method [307,308].

The first three-dimensional structure of a GPCR, rhodopsin, was solved by X-ray crystallization in 2000 [309]. This method requires obtaining stable crystals of the receptor extracted from its membrane in solution, which has been a major obstacle to structure determination [310]. This problem has been solved by modifying GPCRs to make them more stable while retaining their activity [310-313]. This can be achieved, for example, by fusing the T4 lysozyme protein as a replacement for intracellular loop 3 [312] or by mutating the receptor to thermostabilize it [311]. A new technique for crystal structure resolution has recently been developed, X-ray-free electron laser (XFEL) crystallography. The use of lasers reduces the size of the crystals required and, therefore, increases their stability [314,315].

Crystallization has been completed by cryo-electromicroscopy (Cryo-EM). Significant improvements in detectors and structure determination algorithms have enabled the resolution of structures at the particle scale [316-318]. Cryo-EM does not require the formation of crystals, as the receptors are directly vitrified after purification, but requires more computational time to solve the structure, resulting in lower resolution [308,319-321]. These various constraints and the relative novelty of these techniques mean that, currently, the structure of only $20 \%$ of non-olfactory GPCRs has been solved [319]. Nuclear magnetic resonance (NMR) allows the acquisition of dynamic data and thus complements the data from the fixed structures of crystallography and Cryo-EM [322].

More recently, advances in artificial intelligence have made it possible to approach structures using machine learning. Protein structure prediction was revolutionized in 2021 by the publication of the algorithms, not specific to GPCRs, AlphaFold2 and RoseTTAfold, which generated highly accurate three-dimensional structures of proteins [323-325]. These algorithms are completed by GPCR-specific algorithms, such as the already developed arsenal, which is specific to the GPCR field [326-329]. Nonetheless, although these algorithms all regularly perform well, they can still be improved. GPCRs differ, particularly in their loops, which results in a deficit for 
machine-learning algorithms and thus low confidence in the models and often false predictions [326,330]. Generating and publishing more receptor structures will increase both direct knowledge about receptors and knowledge about other receptors via increased substrates for algorithms and in-silico prediction. Predictions of molecular anchors in receptors can also be made by site-directed mutagenesis (SDM) studies to find amino acids that interact with known ligands of the receptor [331,332]. Crystallization and SDM techniques can be used synergistically to better understand the binding of the molecule to the receptor and produce much more refined and/or efficient molecules [331-333].

For the development of an effective therapy, stable, receptor-specific agonists or antagonists must be found. The screening of drug libraries is performed to find molecular scaffolds capable of binding to receptors and modulating their activity [334]. Screening can be performed using affinity assays by assessing the ability of molecules to bind to the target as purified proteins, on whole cells expressing the target, or on isolated membranes [335-337]. Purified proteins are free of binding to secondary targets, but the ability of the molecules to cross a membrane is not analyzed. Moreover, the presence of the membrane is often necessary for receptor stability [336].

Affinity tests are based on the ability of molecules to displace - and replace on the receptor - a reference ligand known to bind the receptor. Detection is either by radiolabeling of the reference ligand, regularly labeled with iodine-125 or tritium [338-340] or by fluorescence resonance energy transfer (FRET), in which both the reference ligand and the receptor are bound to a fluorophore that allows resonance from one molecule to the other [341,342]. Such screening is only able to identify ligands that bind to the same site as the competitor. To overcome this bias, the analysis of the activity of various elements of GPCR signaling, such as IP1 concentration for the G $\alpha_{q}$ pathway or cAMP for the $G \alpha_{s}$ pathway, can be jointly performed on a large scale $[343,344]$. The activity of molecules on downstream G-protein signaling pathways can also be assessed using kinase assays from protein extracts or purified protein or by FRET [345-347]. These screens can be virtually performed with high efficiency if the receptor structure is known [348-350]. The hits that are found are generally of low affinity for their targets and require optimization to be usable [334]. They will then need to undergo pharmacomodulation that will be directed through structural data and docking algorithms to result in lead generation [351-353]. These leads will have to be tested in vivo to verify 
their pharmacokinetic parameters (absorption, distribution, metabolism, elimination) at the risk of obtaining only molecules incapable of producing an effect in vivo and condemned to be used only as an in vitro tool [354,355]. Molecules identified as leads can be used to verify the efficacy of these molecules on the cellular and molecular processes of melanoma progression, as well as on the formation of metastasis and resistance to treatment.

In addition to small chemical molecules, GPCRs can be targeted by monoclonal antibodies. Several have been generated and approved as therapeutic targets, such as mogamulizumab, a humanized antibody against chemokine receptor type 4 . The advantage of using monoclonal antibodies in treating diseases is notable because they have a long half-life.

Finally, targeted radiotherapy is currently being developed and constitutes a promising strategy to target GPCRs in cancer. The radioactivity is delivered to a specific tumor by means of a systemic injection. For melanoma treatment, targeted treatment can be achieved by labeling small molecules, such as melanin ligands, peptides that recognize a specific receptor (MC1R), or antibodies (anti-melanin, anti-GD3) [356,357] The efficacy of targeted radiotherapy depends on the dose delivered, which in turn depends on the radionuclide used and the time that the labeled compound remains associated with the target. Targeted radiotherapy is highly relevant for the treatment of disseminated lesions and overcoming tumor heterogeneity through cross-fire irradiation with $\beta$-radionuclides characterized by a decay spectrum of between a few nanometers and $2 \mathrm{~mm}$. The reception of adequate doses of radiation from neighboring receptor-expressing cells can kill tumor cells lacking the targeted receptor in the tumor. This property is particularly important for melanoma, in which gene expression is often heterogeneous. Targeted radiotherapy of the somatostatin receptor is used for the clinical treatment of neuroendocrine tumors. The same strategy could be adapted for targeting GPCRs in melanoma.

\section{Conclusion}

Of the eight GPCRs shown to be involved in pigmentation, only three have been studied in the context of melanoma (EDNRB, MC1R, and GRM1). The remaining five receptors (DRD2, FZD4, GPR143, GPR161, and SMO) may be of interest in the context of melanoma, but it has not been studied yet. Conversely, it would be relevant to evaluate 
the importance of the eight receptors described only in a melanoma context (FZD7, GPER1, GRM3, GRM5, PAR1/F2R, CXCR4, CCR7, and CCR10) for their implication in the melanocyte lineage as a whole, whether during embryonic development, melanocyte homeostasis/renewal and/or melanogenesis. The identification of completely novel GPCRs, important in melanomagenesis, will require detailed studies of primary and/or metastatic tumors through the development of new and more powerful analysis tools as their detection may escape the current RNAseq and proteomic techniques.

The low number of mutations and their modification of expression/activaty often dependent on temporal, tissue and molecular context render their studies in vivo essential to define precisely their role. It appears clear that the creation of novel Omics databases generated from distant melanoma metastases treated with immune checkpoint or/and MAPK inhibitors would reveal novel GPCR players involved in resistance and metastasis. Once such GPCR target(s) would be identified and characterized, small molecules will have to be developed to directly target it/them GPCRs. These molecules can be screened from chemical libraries or designed according to their structure based on their crystal or artificial intelligence using Alphafold for instance.

\section{Funding}

JHR had a fellowship from PSL and Ligue nationale contre le cancer. This work was supported by FRM, Institut Carnot, Cancer, CNRS, INSERM, Gefluc and is under the program «Investissements d'Avenir» launched by the French Government and implemented by ANR Labex CelTisPhyBio (ANR-11-LABX-0038 and ANR-10-IDEX-000102 PSL).

\section{References}

1. Hauser, A.S.; Attwood, M.M.; Rask-Andersen, M.; Schiöth, H.B.; Gloriam, D.E. Trends in GPCR Drug Discovery: New Agents, Targets and Indications. Nat Rev Drug Discov 2017, 16, 829-842, doi:10.1038/nrd.2017.178.

2. Usman, S.; Khawer, M.; Rafique, S.; Naz, Z.; Saleem, K. The Current Status of AntiGPCR Drugs against Different Cancers. Journal of Pharmaceutical Analysis 2020, 10, $517-$ 521, doi:10.1016/j.jpha.2020.01.001.

3. Sung, H.; Ferlay, J.; Siegel, R.L.; Laversanne, M.; Soerjomataram, I.; Jemal, A.; Bray, F. Global Cancer Statistics 2020: GLOBOCAN Estimates of Incidence and Mortality Worldwide for 36 Cancers in 185 Countries. CA: A Cancer Journal for Clinicians 2021, 71, 
209-249, doi:10.3322/caac.21660.

4. Luke, J.J.; Flaherty, K.T.; Ribas, A.; Long, G.V. Targeted Agents and Immunotherapies: Optimizing Outcomes in Melanoma. Nature Reviews Clinical Oncology 2017, 14, 463-482, doi:10.1038/nrclinonc.2017.43.

5. Carlino, M.S.; Larkin, J.; Long, G.V. Immune Checkpoint Inhibitors in Melanoma. The Lancet 2021, 398, 1002-1014, doi:10.1016/S0140-6736(21)01206-X.

6. Lee, H.J.; Wall, B.; Chen, S. G-Protein-Coupled Receptors and Melanoma. Pigment Cell Melanoma Res 2008, 21, 415-428, doi:10.1111/j.1755-148X.2008.00478.x.

7. Baxter, L.L.; Watkins-Chow, D.E.; Pavan, W.J.; Loftus, S.K. A Curated Gene List for Expanding the Horizons of Pigmentation Biology. Pigment Cell Melanoma Res 2019, 32, 348-358, doi:10.1111/pcmr.12743.

8. Aktary, Z.; McMahon, M.; Larue, L. Animal Models of Melanoma. In Melanoma; Fisher, D.E., Bastian, B.C., Eds.; Springer: New York, NY, 2017; pp. 1-31 ISBN 978-14614-7322-0.

9. Delmas, V.; Martinozzi, S.; Bourgeois, Y.; Holzenberger, M.; Larue, L. Cre-Mediated Recombination in the Skin Melanocyte Lineage. genesis 2003, 36, 73-80, doi:10.1002/gene.10197.

10. Yajima, I.; Belloir, E.; Bourgeois, Y.; Kumasaka, M.; Delmas, V.; Larue, L. Spatiotemporal Gene Control by the Cre-ERT2 System in Melanocytes. genesis 2006, 44, 34-43, doi:10.1002/gene.20182.

11. Bosenberg, M.; Muthusamy, V.; Curley, D.P.; Wang, Z.; Hobbs, C.; Nelson, B.; Nogueira, C.; Horner II, J.W.; DePinho, R.; Chin, L. Characterization of Melanocyte-Specific Inducible Cre Recombinase Transgenic Mice. genesis 2006, 44, 262-267, doi:10.1002/dvg.20205.

12. Baynash, A.G.; Hosoda, K.; Giaid, A.; Richardson, J.A.; Emoto, N.; Hammer, R.E.; Yanagisawa, M. Interaction of Endothelin-3 with Endothelin-B Receptor Is Essential for Development of Epidermal Melanocytes and Enteric Neurons. Cell 1994, 79, 1277-1285, doi:10.1016/0092-8674(94)90018-3.

13. Hosoda, K.; Hammer, R.E.; Richardson, J.A.; Baynash, A.G.; Cheung, J.C.; Giaid, A.; Yanagisawa, M. Targeted and Natural (Piebald-Lethal) Mutations of Endothelin-B Receptor Gene Produce Megacolon Associated with Spotted Coat Color in Mice. Cell 1994, 79, 1267-1276, doi:10.1016/0092-8674(94)90017-5.

14. Garcia, R.J.; Ittah, A.; Mirabal, S.; Figueroa, J.; Lopez, L.; Glick, A.B.; Kos, L. Endothelin 3 Induces Skin Pigmentation in a Keratin-Driven Inducible Mouse Model. J Invest Dermatol 2008, 128, 131-142, doi:10.1038/sj.jid.5700948.

15. Benaduce, A.P.; Batista, D.; Grilo, G.; Jorge, K.; Cardero, D.; Milikowski, C.; Kos, L. Novel UV-Induced Melanoma Mouse Model Dependent on Endothelin3 Signaling. Pigment Cell Melanoma Res 2014, 27, 839-842, doi:10.1111/pcmr.12281.

16. Jain, F.; Longakit, A.; Huang, J.L.-Y.; Raamsdonk, C.D.V. Endothelin Signaling Promotes Melanoma Tumorigenesis Driven by Constitutively Active GNAQ. Pigment Cell \& Melanoma Research 2020, 33, 834-849, doi:10.1111/pcmr.12900.

17. Kumasaka, M.Y.; Yajima, I.; Hossain, K.; Iida, M.; Tsuzuki, T.; Ohno, T.; Takahashi, M.; Yanagisawa, M.; Kato, M. A Novel Mouse Model for De Novo Melanoma. Cancer Res 2010, 70, 24-29, doi:10.1158/0008-5472.CAN-09-2838.

18. Demunter, A.; De Wolf-Peeters, C.; Degreef, H.; Stas, M.; van den Oord, J.J. Expression of the Endothelin-B Receptor in Pigment Cell Lesions of the Skin. Evidence for Its Role as Tumor Progression Marker in Malignant Melanoma. Virchows Arch 2001, 438, 485-491, doi:10.1007/s004280000362.

19. Asundi, J.; Reed, C.; Arca, J.; McCutcheon, K.; Ferrando, R.; Clark, S.; Luis, E.; Tien, 
J.; Firestein, R.; Polakis, P. An Antibody-Drug Conjugate Targeting the Endothelin B Receptor for the Treatment of Melanoma. Clin Cancer Res 2011, 17, 965-975, doi:10.1158/1078-0432.CCR-10-2340.

20. Lahav, R.; Heffner, G.; Patterson, P.H. An Endothelin Receptor B Antagonist Inhibits Growth and Induces Cell Death in Human Melanoma Cells in Vitro and in Vivo. Proc Natl Acad Sci U S A 1999, 96, 11496-11500, doi:10.1073/pnas.96.20.11496.

21. Lahav, R.; Suvà, M.-L.; Rimoldi, D.; Patterson, P.H.; Stamenkovic, I. Endothelin Receptor B Inhibition Triggers Apoptosis and Enhances Angiogenesis in Melanomas. Cancer Res 2004, 64, 8945-8953, doi:10.1158/0008-5472.CAN-04-1510.

22. Swope, V.B.; Starner, R.J.; Rauck, C.; Abdel-Malek, Z.A. Endothelin-1 and $\alpha-$ Melanocortin Have Redundant Effects on Global Genome Repair in UV-Irradiated Human Melanocytes despite Distinct Signaling Pathways. Pigment Cell \& Melanoma Research 2020, 33, 293-304, doi:10.1111/pcmr.12823.

23. von Koschembahr, A.M.; Swope, V.B.; Starner, R.J.; Abdel-Malek, Z.A. Endothelin-1 Protects Human Melanocytes from UV-Induced DNA Damage by Activating JNK and P38 Signalling Pathways. Exp Dermatol 2015, 24, 269-274, doi:10.1111/exd.12638.

24. Freitas, J.T.; Lopez, J.; Llorian, C.; Boroni, M.; Kos, L. The Immunosuppressive Role of Edn3 Overexpression in the Melanoma Microenvironment. Pigment Cell Melanoma Res 2021, doi:10.1111/pcmr.13002.

25. Bagnato, A.; Natali, P.G. Endothelin Receptors as Novel Targets in Tumor Therapy. J Transl Med 2004, 2, 16, doi:10.1186/1479-5876-2-16.

26. Kefford, R.; Beith, J.M.; Van Hazel, G.A.; Millward, M.; Trotter, J.M.; Wyld, D.K.; Kusic, R.; Shreeniwas, R.; Morganti, A.; Ballmer, A.; et al. A Phase II Study of Bosentan, a Dual Endothelin Receptor Antagonist, as Monotherapy in Patients with Stage IV Metastatic Melanoma. Invest New Drugs 2007, 25, 247-252, doi:10.1007/s10637-0069014-7.

27. Kefford, R.F.; Clingan, P.R.; Brady, B.; Ballmer, A.; Morganti, A.; Hersey, P. A Randomized, Double-Blind, Placebo-Controlled Study of High-Dose Bosentan in Patients with Stage IV Metastatic Melanoma Receiving First-Line Dacarbazine Chemotherapy. Molecular Cancer 2010, 9, 69, doi:10.1186/1476-4598-9-69.

28. Sandhu, S.; McNeil, C.M.; LoRusso, P.; Patel, M.R.; Kabbarah, O.; Li, C.; Sanabria, S.; Flanagan, W.M.; Yeh, R.-F.; Brunstein, F.; et al. Phase I Study of the Anti-Endothelin B Receptor Antibody-Drug Conjugate DEDN6526A in Patients with Metastatic or Unresectable Cutaneous, Mucosal, or Uveal Melanoma. Invest New Drugs 2020, 38, 844854, doi:10.1007/s10637-019-00832-1.

29. García-Borrón, J.C.; Abdel-Malek, Z.; Jiménez-Cervantes, C. MC1R, the CAMP Pathway and the Response to Solar UV: Extending the Horizon beyond Pigmentation. Pigment Cell Melanoma Res 2014, 27, 699-720, doi:10.1111/pcmr.12257.

30. Baik, J.H.; Picetti, R.; Saiardi, A.; Thiriet, G.; Dierich, A.; Depaulis, A.; Le Meur, M.; Borrelli, E. Parkinsonian-like Locomotor Impairment in Mice Lacking Dopamine D2 Receptors. Nature 1995, 377, 424-428, doi:10.1038/377424a0.

31. Bertolotto, C.; Abbe, P.; Hemesath, T.J.; Bille, K.; Fisher, D.E.; Ortonne, J.P.; Ballotti, R. Microphthalmia Gene Product as a Signal Transducer in CAMP-Induced Differentiation of Melanocytes. $J$ Cell Biol 1998, 142, 827-835, doi:10.1083/jcb.142.3.827.

32. Goding, C.R.; Arnheiter, H. MITF-the First 25 Years. Genes Dev 2019, 33, 9831007, doi:10.1101/gad.324657.119.

33. Deraredj Nadim, W.; Hassanaly, S.; Bénédetti, H.; Kieda, C.; Grillon, C.; MorissetLopez, S. The GTPase-Activating Protein-Related Domain of Neurofibromin Interacts 
with MC1R and Regulates Pigmentation-Mediated Signaling in Human Melanocytes. Biochemical and Biophysical Research Communications 2021, 534, 758-764, doi:10.1016/j.bbrc.2020.11.003.

34. Tamate, H.B.; Takeuchi, T. Action of the e Locus of Mice in the Response of Phaeomelanic Hair Follicles to $\alpha$-Melanocyte-Stimulating Hormone in Vitro. Science 1984, 224, 1241-1242, doi:10.1126/science.6328651.

35. Robbins, L.S.; Nadeau, J.H.; Johnson, K.R.; Kelly, M.A.; Roselli-Rehfuss, L.; Baack, E.; Mountjoy, K.G.; Cone, R.D. Pigmentation Phenotypes of Variant Extension Locus Alleles Result from Point Mutations That Alter MSH Receptor Function. Cell 1993, 72, 827-834, doi:10.1016/0092-8674(93)90572-8.

36. Smith, R.; Healy, E.; Siddiqui, S.; Flanagan, N.; Steijlen, P.M.; Rosdahl, I.; Jacques, J.P.; Rogers, S.; Turner, R.; Jackson, I.J.; et al. Melanocortin 1 Receptor Variants in an Irish Population. J Invest Dermatol 1998, 111, 119-122, doi:10.1046/j.15231747.1998.00252.x.

37. Harding, R.M.; Healy, E.; Ray, A.J.; Ellis, N.S.; Flanagan, N.; Todd, C.; Dixon, C.; Sajantila, A.; Jackson, I.J.; Birch-Machin, M.A.; et al. Evidence for Variable Selective Pressures at MC1R. Am J Hum Genet 2000, 66, 1351-1361, doi:10.1086/302863.

38. Scott, M.C.; Wakamatsu, K.; Ito, S.; Kadekaro, A.L.; Kobayashi, N.; Groden, J.; Kavanagh, R.; Takakuwa, T.; Virador, V.; Hearing, V.J.; et al. Human Melanocortin 1 Receptor Variants, Receptor Function and Melanocyte Response to UV Radiation. J Cell Sci 2002, 115, 2349-2355.

39. Mitra, D.; Luo, X.; Morgan, A.; Wang, J.; Hoang, M.P.; Lo, J.; Guerrero, C.R.; Lennerz, J.K.; Mihm, M.C.; Wargo, J.A.; et al. An Ultraviolet-Radiation-Independent Pathway to Melanoma Carcinogenesis in the Red Hair/Fair Skin Background. Nature 2012, 491, 449-453, doi:10.1038/nature11624.

40. Herraiz, C.; Martínez-Vicente, I.; Maresca, V. The $\alpha$-Melanocyte-Stimulating Hormone/Melanocortin-1 Receptor Interaction: A Driver of Pleiotropic Effects beyond Pigmentation. Pigment Cell Melanoma Res 2021, 34, 748-761, doi:10.1111/pcmr.12980.

41. Swope, V.B.; Abdel-Malek, Z.A. Significance of the Melanocortin 1 and Endothelin B Receptors in Melanocyte Homeostasis and Prevention of Sun-Induced Genotoxicity. Front Genet 2016, 7, 146, doi:10.3389/fgene.2016.00146.

42. Castejón-Griñán, M.; Herraiz, C.; Olivares, C.; Jiménez-Cervantes, C.; GarcíaBorrón, J.C. CAMP-Independent Non-Pigmentary Actions of Variant Melanocortin 1 Receptor: AKT-Mediated Activation of Protective Responses to Oxidative DNA Damage. Oncogene 2018, 37, 3631-3646, doi:10.1038/s41388-018-0216-1.

43. Guida, S.; Guida, G.; Goding, C.R. MC1R Functions, Expression, and Implications for Targeted Therapy. Journal of Investigative Dermatology 2021, doi:10.1016/j.jid.2021.06.018.

44. Bautista, R.-M.F.; Carter, K.M.; Jarrett, S.G.; Napier, D.; Wakamatsu, K.; Ito, S.; D’Orazio, J.A. Cutaneous Pharmacologic CAMP Induction Induces Melanization of the Skin and Improves Recovery from Ultraviolet Injury in Melanocortin 1 Receptor-Intact or Heterozygous Skin. Pigment Cell Melanoma Res 2020, 33, 30-40, doi:10.1111/pcmr.12817.

45. D’Orazio, J.A.; Nobuhisa, T.; Cui, R.; Arya, M.; Spry, M.; Wakamatsu, K.; Igras, V.; Kunisada, T.; Granter, S.R.; Nishimura, E.K.; et al. Topical Drug Rescue Strategy and Skin Protection Based on the Role of Mc1r in UV-Induced Tanning. Nature 2006, 443, 340344, doi:10.1038/nature05098.

46. Koikov, L.; Starner, R.J.; Swope, V.B.; Upadhyay, P.; Hashimoto, Y.; Freeman, K.T.; Knittel, J.J.; Haskell-Luevano, C.; Abdel-Malek, Z.A. Development of HMC1R Selective 
Small Agonists for Sunless Tanning and Prevention of Genotoxicity of UV in Melanocytes. J Invest Dermatol 2021, 141, 1819-1829, doi:10.1016/j.jid.2020.11.034.

47. Dorsky, R.I.; Moon, R.T.; Raible, D.W. Control of Neural Crest Cell Fate by the Wnt Signalling Pathway. Nature 1998, 396, 370-373, doi:10.1038/24620.

48. Dunn, K.J.; Williams, B.O.; Li, Y.; Pavan, W.J. Neural Crest-Directed Gene Transfer Demonstrates Wnt1 Role in Melanocyte Expansion and Differentiation during Mouse Development. Proc Natl Acad Sci U S A 2000, 97, 10050-10055.

49. Ikeya, M.; Lee, S.M.K.; Johnson, J.E.; McMahon, A.P.; Takada, S. Wnt Signalling Required for Expansion of Neural Crest and CNS Progenitors. Nature 1997, 389, 966970, doi:10.1038/40146.

50. Dorsky, R.I.; Raible, D.W.; Moon, R.T. Direct Regulation of Nacre, a Zebrafish MITF Homolog Required for Pigment Cell Formation, by the Wnt Pathway. Genes Dev. 2000, 14, 158-162, doi:10.1101/gad.14.2.158.

51. Hari, L.; Brault, V.; Kléber, M.; Lee, H.-Y.; Ille, F.; Leimeroth, R.; Paratore, C.; Suter, U.; Kemler, R.; Sommer, L. Lineage-Specific Requirements of $\beta$-Catenin in Neural Crest Development. J Cell Biol 2002, 159, 867-880, doi:10.1083/jcb.200209039.

52. Luciani, F.; Champeval, D.; Herbette, A.; Denat, L.; Aylaj, B.; Martinozzi, S.; Ballotti, R.; Kemler, R.; Goding, C.R.; De Vuyst, F.; et al. Biological and Mathematical Modeling of Melanocyte Development. Development 2011, 138, 3943-3954, doi:10.1242/dev.067447.

53. Gallagher, S.J.; Rambow, F.; Kumasaka, M.; Champeval, D.; Bellacosa, A.; Delmas, V.; Larue, L. Beta-Catenin Inhibits Melanocyte Migration but Induces Melanoma Metastasis. Oncogene 2013, 32, 2230-2238, doi:10.1038/onc.2012.229.

54. Wang, Y.; Huso, D.; Cahill, H.; Ryugo, D.; Nathans, J. Progressive Cerebellar, Auditory, and Esophageal Dysfunction Caused by Targeted Disruption of The frizzled-4 Gene. J Neurosci 2001, 21, 4761-4771, doi:10.1523/JNEUROSCI.21-13-04761.2001.

55. Rodriguez-Hernandez, I.; Maiques, O.; Kohlhammer, L.; Cantelli, G.; Perdrix-Rosell, A.; Monger, J.; Fanshawe, B.; Bridgeman, V.L.; Karagiannis, S.N.; Penin, R.M.; et al. WNT11-FZD7-DAAM1 Signalling Supports Tumour Initiating Abilities and Melanoma Amoeboid Invasion. Nature Communications 2020, 11, doi:10.1038/s41467-020-189512.

56. Tiwary, S.; Xu, L. FRIZZLED7 Is Required for Tumor Initiation and Metastatic Growth of Melanoma Cells. PLoS One 2016, 11, e0147638, doi:10.1371/journal.pone.0147638.

57. Zhang, Y.; Wang, X. Targeting the Wnt/ $\beta$-Catenin Signaling Pathway in Cancer. $J$ Hematol Oncol 2020, 13, 165, doi:10.1186/s13045-020-00990-3.

58. Delmas, V.; Beermann, F.; Martinozzi, S.; Carreira, S.; Ackermann, J.; Kumasaka, M.; Denat, L.; Goodall, J.; Luciani, F.; Viros, A.; et al. Beta-Catenin Induces Immortalization of Melanocytes by Suppressing P16INK4a Expression and Cooperates with N-Ras in Melanoma Development. Genes Dev 2007, 21, 2923-2935, doi:10.1101/gad.450107.

59. Damsky, W.E.; Curley, D.P.; Santhanakrishnan, M.; Rosenbaum, L.E.; Platt, J.T.; Gould Rothberg, B.E.; Taketo, M.M.; Dankort, D.; Rimm, D.L.; McMahon, M.; et al. $\beta$ Catenin Signaling Controls Metastasis in Braf-Activated Pten-Deficient Melanomas. Cancer Cell 2011, 20, 741-754, doi:10.1016/j.ccr.2011.10.030.

60. Nsengimana, J.; Laye, J.; Filia, A.; O’Shea, S.; Muralidhar, S.; Poźniak, J.; Droop, A.; Chan, M.; Walker, C.; Parkinson, L.; et al. $\beta$-Catenin-Mediated Immune Evasion Pathway Frequently Operates in Primary Cutaneous Melanomas. J Clin Invest 2018, 128, 20482063, doi:10.1172/JCI95351.

61. Shah, K.V.; Chien, A.J.; Yee, C.; Moon, R.T. CTLA-4 Is a Direct Target of Wnt/ $\beta$ - 
Catenin Signaling and Is Expressed in Human Melanoma Tumors. Journal of Investigative Dermatology 2008, 128, 2870-2879, doi:10.1038/jid.2008.170.

62. Spranger, S.; Bao, R.; Gajewski, T.F. Melanoma-Intrinsic $\beta$-Catenin Signalling Prevents Anti-Tumour Immunity. Nature 2015, 523, 231-235, doi:10.1038/nature14404.

63. Eddy, K.; Chen, S. Glutamatergic Signaling a Therapeutic Vulnerability in Melanoma. Cancers (Basel) 2021, 13, 3874, doi:10.3390/cancers13153874.

64. Chen, S.; Zhu, H.; Wetzel, W.J.; Philbert, M.A. Spontaneous Melanocytosis in Transgenic Mice. J Invest Dermatol 1996, 106, 1145-1151, doi:10.1111/15231747.ep12340194.

65. Pollock, P.M.; Cohen-Solal, K.; Sood, R.; Namkoong, J.; Martino, J.J.; Koganti, A.; Zhu, H.; Robbins, C.; Makalowska, I.; Shin, S.-S.; et al. Melanoma Mouse Model Implicates Metabotropic Glutamate Signaling in Melanocytic Neoplasia. Nat Genet 2003, 34, 108112, doi:10.1038/ng1148.

66. Schiffner, S.; Chen, S.; Becker, J.C.; Bosserhoff, A.-K. Highly Pigmented Tg(Grm1) Mouse Melanoma Develops Non-Pigmented Melanoma Cells in Distant Metastases. Exp Dermatol 2012, 21, 786-788, doi:10.1111/j.1600-0625.2012.01560.x.

67. Shin, S.-S.; Namkoong, J.; Wall, B.A.; Gleason, R.; Lee, H.J.; Chen, S. Oncogenic Activities of Metabotropic Glutamate Receptor 1 (Grm1) in Melanocyte Transformation. Pigment Cell Melanoma Res 2008, 21, 368-378, doi:10.1111/j.1755-148X.2008.00452.x. 68. Ohtani, Y.; Harada, T.; Funasaka, Y.; Nakao, K.; Takahara, C.; Abdel-Daim, M.; Sakai, N.; Saito, N.; Nishigori, C.; Aiba, A. Metabotropic Glutamate Receptor Subtype-1 Is Essential for in Vivo Growth of Melanoma. Oncogene 2008, 27, 7162-7170, doi:10.1038/onc.2008.329.

69. Marín, Y.E.; Namkoong, J.; Cohen-Solal, K.; Shin, S.-S.; Martino, J.J.; Oka, M.; Chen, S. Stimulation of Oncogenic Metabotropic Glutamate Receptor 1 in Melanoma Cells Activates ERK1/2 via PKCepsilon. Cell Signal 2006, 18, 1279-1286, doi:10.1016/j.cellsig.2005.10.012.

70. Shin, S.-S.; Wall, B.A.; Goydos, J.S.; Chen, S. AKT2 Is a Downstream Target of Metabotropic Glutamate Receptor 1 (Grm1). Pigment Cell Melanoma Res 2010, 23, 103111, doi:10.1111/j.1755-148X.2009.00648.x.

71. Namkoong, J.; Shin, S.-S.; Lee, H.J.; Marín, Y.E.; Wall, B.A.; Goydos, J.S.; Chen, S. Metabotropic Glutamate Receptor 1 and Glutamate Signaling in Human Melanoma. Cancer Res 2007, 67, 2298-2305, doi:10.1158/0008-5472.CAN-06-3665.

72. Mehnert, J.M.; Silk, A.W.; Lee, J.H.; Dudek, L.; Jeong, B.-S.; Li, J.; Schenkel, J.M.; Sadimin, E.; Kane, M.; Lin, H.; et al. A Phase II Trial of Riluzole, an Antagonist of Metabotropic Glutamate Receptor 1 (GRM1) Signaling, in Patients with Advanced Melanoma. Pigment Cell Melanoma Res 2018, 31, 534-540, doi:10.1111/pcmr.12694.

73. Shah, R.; Singh, S.J.; Eddy, K.; Filipp, F.V.; Chen, S. Concurrent Targeting of Glutaminolysis and Metabotropic Glutamate Receptor 1 (GRM1) Reduces Glutamate Bioavailability in GRM1+ Melanoma. Cancer Res 2019, 79, 1799-1809, doi:10.1158/0008-5472.CAN-18-1500.

74. Choi, K.Y.; Chang, K.; Pickel, J.M.; Badger, J.D.; Roche, K.W. Expression of the Metabotropic Glutamate Receptor 5 (MGluR5) Induces Melanoma in Transgenic Mice. Proc Natl Acad Sci U S A 2011, 108, 15219-15224, doi:10.1073/pnas.1107304108.

75. Prickett, T.D.; Wei, X.; Cardenas-Navia, I.; Teer, J.K.; Lin, J.C.; Walia, V.; Gartner, J.; Jiang, J.; Cherukuri, P.F.; Molinolo, A.; et al. Exon Capture Analysis of G Protein-Coupled Receptors Identifies Activating Mutations in GRM3 in Melanoma. Nat Genet 2011, 43, 1119-1126, doi:10.1038/ng.950. 
76. Neto, A.; Ceol, C.J. Melanoma-Associated GRM3 Variants Dysregulate Melanosome Trafficking and CAMP Signaling. Pigment Cell \& Melanoma Research 2018, 31, 115-119, doi:10.1111/pcmr.12610.

77. Fan, Y.-N.; Li, C.; Huang, L.; Chen, L.; Tang, Z.; Han, G.; Liu, Y. Characterization of Group I Metabotropic Glutamate Receptors in Rat and Human Adrenal Glands. Front Physiol 2020, 11, 401, doi:10.3389/fphys.2020.00401.

78. Tucker, B.; Richards, R.I.; Lardelli, M. Contribution of MGluR and Fmr1 Functional Pathways to Neurite Morphogenesis, Craniofacial Development and Fragile X Syndrome. Human Molecular Genetics 2006, 15, 3446-3458, doi:10.1093/hmg/ddl422.

79. Villares, G.J.; Zigler, M.; Wang, H.; Melnikova, V.O.; Wu, H.; Friedman, R.; Leslie, M.C.; Vivas-Mejia, P.E.; Lopez-Berestein, G.; Sood, A.K.; et al. Targeting Melanoma Growth and Metastasis with Systemic Delivery of Liposome-Incorporated Protease-Activated Receptor-1 Small Interfering RNA. Cancer Res 2008, 68, 9078-9086, doi:10.1158/00085472.CAN-08-2397.

80. Zigler, M.; Kamiya, T.; Brantley, E.C.; Villares, G.J.; Bar-Eli, M. PAR-1 and Thrombin: The Ties That Bind the Microenvironment to Melanoma Metastasis. Cancer Res 2011, 71, 6561-6566, doi:10.1158/0008-5472.CAN-11-1432.

81. Jacquelot, N.; Duong, C.P.M.; Belz, G.T.; Zitvogel, L. Targeting Chemokines and Chemokine Receptors in Melanoma and Other Cancers. Front Immunol 2018, 9, 2480, doi:10.3389/fimmu.2018.02480.

82. Murakami, T.; Maki, W.; Cardones, A.R.; Fang, H.; Tun Kyi, A.; Nestle, F.O.; Hwang, S.T. Expression of CXC Chemokine Receptor-4 Enhances the Pulmonary Metastatic Potential of Murine B16 Melanoma Cells. Cancer Res 2002, 62, 7328-7334.

83. Ieranò, C.; D’Alterio, C.; Giarra, S.; Napolitano, M.; Rea, G.; Portella, L.; Santagata, A.; Trotta, A.M.; Barbieri, A.; Campani, V.; et al. CXCL12 Loaded-Dermal Filler Captures CXCR4 Expressing Melanoma Circulating Tumor Cells. Cell Death Dis 2019, 10, 562, doi:10.1038/s41419-019-1796-6.

84. Murakami, T.; Cardones, A.R.; Finkelstein, S.E.; Restifo, N.P.; Klaunberg, B.A.; Nestle, F.O.; Castillo, S.S.; Dennis, P.A.; Hwang, S.T. Immune Evasion by Murine Melanoma Mediated through CC Chemokine Receptor-10. The Journal of Experimental Medicine 2003, 198, 1337, doi:10.1084/jem.20030593.

85. Wiley, H.E.; Gonzalez, E.B.; Maki, W.; Wu, M.T.; Hwang, S.T. Expression of CC Chemokine Receptor-7 and Regional Lymph Node Metastasis of B16 Murine Melanoma. J Natl Cancer Inst 2001, 93, 1638-1643, doi:10.1093/jnci/93.21.1638.

86. Revankar, C.M.; Cimino, D.F.; Sklar, L.A.; Arterburn, J.B.; Prossnitz, E.R. A Transmembrane Intracellular Estrogen Receptor Mediates Rapid Cell Signaling. Science 2005, 307, 1625-1630, doi:10.1126/science.1106943.

87. Natale, C.A.; Li, J.; Zhang, J.; Dahal, A.; Dentchev, T.; Stanger, B.Z.; Ridky, T.W. Activation of G Protein-Coupled Estrogen Receptor Signaling Inhibits Melanoma and Improves Response to Immune Checkpoint Blockade. Elife 2018, 7, e31770, doi:10.7554/eLife.31770.

88. Luo, J.; Liu, D. Does GPER Really Function as a G Protein-Coupled Estrogen Receptor in Vivo? Front Endocrinol (Lausanne) 2020, 11, 148, doi:10.3389/fendo.2020.00148.

89. Incerti, B.; Cortese, K.; Pizzigoni, A.; Surace, E.M.; Varani, S.; Coppola, M.; Jeffery, G.; Seeliger, M.; Jaissle, G.; Bennett, D.C.; et al. Oa1 Knock-out: New Insights on the Pathogenesis of Ocular Albinism Type 1. Hum Mol Genet 2000, 9, 2781-2788, doi:10.1093/hmg/9.19.2781.

90. Matteson, P.G.; Desai, J.; Korstanje, R.; Lazar, G.; Borsuk, T.E.; Rollins, J.; Kadambi, 
S.; Joseph, J.; Rahman, T.; Wink, J.; et al. The Orphan G Protein-Coupled Receptor, Gpr161, Encodes the Vacuolated Lens Locus and Controls Neurulation and Lens Development. Proc Natl Acad Sci U S A 2008, 105, 2088-2093, doi:10.1073/pnas.0705657105.

91. Twigg, S.R.F.; Hufnagel, R.B.; Miller, K.A.; Zhou, Y.; McGowan, S.J.; Taylor, J.; Craft, J.; Taylor, J.C.; Santoro, S.L.; Huang, T.; et al. A Recurrent Mosaic Mutation in SMO, Encoding the Hedgehog Signal Transducer Smoothened, Is the Major Cause of CurryJones Syndrome. Am J Hum Genet 2016, 98, 1256-1265, doi:10.1016/j.ajhg.2016.04.007. 92. Hamm, H.E. The Many Faces of G Protein Signaling *. Journal of Biological Chemistry 1998, 273, 669-672, doi:10.1074/jbc.273.2.669.

93. Martin, E.L.; Rens-Domiano, S.; Schatz, P.J.; Hamm, H.E. Potent Peptide Analogues of a G Protein Receptor-Binding Region Obtained with a Combinatorial Library. J Biol Chem 1996, 271, 361-366, doi:10.1074/jbc.271.1.361.

94. Wettschureck, N.; Offermanns, S. Mammalian G Proteins and Their Cell Type Specific Functions. Physiol Rev 2005, 85, 1159-1204, doi:10.1152/physrev.00003.2005.

95. Inoue, A.; Raimondi, F.; Kadji, F.M.N.; Singh, G.; Kishi, T.; Uwamizu, A.; Ono, Y.; Shinjo, Y.; Ishida, S.; Arang, N.; et al. Illuminating G-Protein-Coupling Selectivity of GPCRs. Cell 2019, 177, 1933-1947.e25, doi:10.1016/j.cell.2019.04.044.

96. Sassone-Corsi, P. The Cyclic AMP Pathway. Cold Spring Harb Perspect Biol 2012, 4, a011148, doi:10.1101/cshperspect.a011148.

97. Sutherland, E.W.; Rall, T.W. Fractionation and Characterization of a Cyclic Adenine Ribonucleotide Formed by Tissue Particles. J Biol Chem 1958, 232, 1077-1091.

98. Zaccolo, M.; Zerio, A.; Lobo, M.J. Subcellular Organization of the CAMP Signaling Pathway. Pharmacol Rev 2021, 73, 278-309, doi:10.1124/pharmrev.120.000086.

99. Hanoune, J.; Defer, N. Regulation and Role of Adenylyl Cyclase Isoforms. Annu Rev Pharmacol Toxicol 2001, 41, 145-174, doi:10.1146/annurev.pharmtox.41.1.145.

100. Dessauer, C.W.; Scully, T.T.; Gilman, A.G. Interactions of Forskolin and ATP with the Cytosolic Domains of Mammalian Adenylyl Cyclase *. Journal of Biological Chemistry 1997, 272, 22272-22277, doi:10.1074/jbc.272.35.22272.

101. Plagge, A.; Kelsey, G.; Germain-Lee, E.L. Physiological Functions of the Imprinted

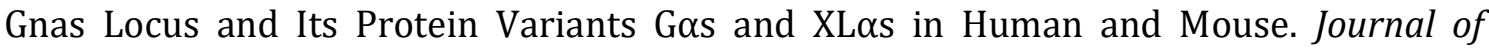
Endocrinology 2008, 196, 193-214, doi:10.1677/JOE-07-0544.

102. Sánchez-Más, J.; Guillo, L.A.; Zanna, P.; Jiménez-Cervantes, C.; García-Borrón, J.C. Role of G Protein-Coupled Receptor Kinases in the Homologous Desensitization of the Human and Mouse Melanocortin 1 Receptors. Mol Endocrinol 2005, 19, 1035-1048, doi:10.1210/me.2004-0227.

103. Innamorati, G.; Wilkie, T.M.; Kantheti, H.S.; Valenti, M.T.; Dalle Carbonare, L.; Giacomello, L.; Parenti, M.; Melisi, D.; Bassi, C. The Curious Case of G $\alpha$ s Gain-of-Function in Neoplasia. BMC Cancer 2018, 18, 293, doi:10.1186/s12885-018-4133-z.

104. The Cancer Genome Atlas Network Genomic Classification of Cutaneous Melanoma. Cell 2015, 161, 1681-1696, doi:10.1016/j.cell.2015.05.044.

105. Frey, U.; Fritz, A.; Rotterdam, S.; Schmid, K.; Potthoff, A.; Altmeyer, P.; Siffert, W.; Brockmeyer, N. GNAS1 T393C Polymorphism and Disease Progression in Patients with Malignant Melanoma. Eur J Med Res 2010, 15, 422-427, doi:10.1186/2047-783X-15-10422.

106. Frey, U.H.; Alakus, H.; Wohlschlaeger, J.; Schmitz, K.J.; Winde, G.; van Calker, H.G.; Jöckel, K.-H.; Siffert, W.; Schmid, K.W. GNAS1 T393C Polymorphism and Survival in Patients with Sporadic Colorectal Cancer. Clin Cancer Res 2005, 11, 5071-5077, doi:10.1158/1078-0432.CCR-05-0472.

107. Frey, U.H.; Eisenhardt, A.; Lümmen, G.; Rübben, H.; Jöckel, K.-H.; Schmid, K.W.; 
Siffert, W. The T393C Polymorphism of the G Alpha s Gene (GNAS1) Is a Novel Prognostic Marker in Bladder Cancer. Cancer Epidemiol Biomarkers Prev 2005, 14, 871 877, doi:10.1158/1055-9965.EPI-04-0720.

108. Thul, P.J.; Åkesson, L.; Wiking, M.; Mahdessian, D.; Geladaki, A.; Ait Blal, H.; Alm, T.; Asplund, A.; Björk, L.; Breckels, L.M.; et al. A Subcellular Map of the Human Proteome. Science 2017, 356, eaal3321, doi:10.1126/science.aal3321.

109. Uhlen, M.; Zhang, C.; Lee, S.; Sjöstedt, E.; Fagerberg, L.; Bidkhori, G.; Benfeitas, R.; Arif, M.; Liu, Z.; Edfors, F.; et al. A Pathology Atlas of the Human Cancer Transcriptome. Science 2017, 357, eaan2507, doi:10.1126/science.aan2507.

110. Nishina, H.; Nimota, K.; Kukimoto, I.; Maehama, T.; Takahashi, K.; Hoshino, S.; Kanaho, Y.; Katada, T. Significance of Thr182 in the Nucleotide-Exchange and GTPHydrolysis Reactions of the Alpha Subunit of GTP-Binding Protein Gi2. J Biochem 1995, 118, 1083-1089, doi:10.1093/jb/118.5.1083.

111. Pace, A.M.; Wong, Y.H.; Bourne, H.R. A Mutant Alpha Subunit of Gi2 Induces Neoplastic Transformation of Rat-1 Cells. Proc Natl Acad Sci U S A 1991, 88, 7031-7035, doi:10.1073/pnas.88.16.7031.

112. Cooper, D.M.F. Regulation and Organization of Adenylyl Cyclases and CAMP. Biochem J 2003, 375, 517-529, doi:10.1042/BJ20031061.

113. Halls, M.L.; Cooper, D.M.F. Adenylyl Cyclase Signalling Complexes Pharmacological Challenges and Opportunities. Pharmacology \& Therapeutics 2017, 172, 171-180, doi:10.1016/j.pharmthera.2017.01.001.

114. Kleinboelting, S.; Diaz, A.; Moniot, S.; van den Heuvel, J.; Weyand, M.; Levin, L.R.; Buck, J.; Steegborn, C. Crystal Structures of Human Soluble Adenylyl Cyclase Reveal Mechanisms of Catalysis and of Its Activation through Bicarbonate. Proc Natl Acad Sci U $S$ A 2014, 111, 3727-3732, doi:10.1073/pnas.1322778111.

115. Magro, C.M.; Neil Crowson, A.; Desman, G.; Zippin, J.H. Soluble Adenylyl Cyclase Antibody Profile as a Diagnostic Adjunct in the Assessment of Pigmented Lesions. Arch Dermatol 2012, 148, 335-344, doi:10.1001/archdermatol.2011.338.

116. Chen, J.; Wu, F.; Shi, Y.; Yang, D.; Xu, M.; Lai, Y.; Liu, Y. Identification of Key Candidate Genes Involved in Melanoma Metastasis. Mol Med Rep 2019, 20, 903-914, doi:10.3892/mmr.2019.10314.

117. Ma, M.; Dai, J.; Tang, H.; Xu, T.; Yu, S.; Si, L.; Cui, C.; Sheng, X.; Chi, Z.; Mao, L.; et al. MicroRNA-23a-3p Inhibits Mucosal Melanoma Growth and Progression through Targeting Adenylate Cyclase 1 and Attenuating CAMP and MAPK Pathways. Theranostics 2019, 9, 945-960, doi:10.7150/thno.30516.

118. Rodríguez, C.I.; Castro-Pérez, E.; Prabhakar, K.; Block, L.; Longley, B.J.; Wisinski, J.A.; Kimple, M.E.; Setaluri, V. EPAC-RAP1 Axis-Mediated Switch in the Response of Primary and Metastatic Melanoma to Cyclic AMP. Mol Cancer Res 2017, 15, 1792-1802, doi:10.1158/1541-7786.MCR-17-0067.

119. Rodríguez, C.I.; Castro-Pérez, E.; Longley, B.J.; Setaluri, V. Elevated Cyclic AMP Levels Promote BRAFCA/Pten-/- Mouse Melanoma Growth but PCREB Is Negatively Correlated with Human Melanoma Progression. Cancer Lett 2018, 414, 268-277, doi:10.1016/j.canlet.2017.11.027.

120. Johannessen, C.M.; Johnson, L.A.; Piccioni, F.; Townes, A.; Frederick, D.T.; Donahue, M.K.; Narayan, R.; Flaherty, K.T.; Wargo, J.A.; Root, D.E.; et al. A Melanocyte Lineage Program Confers Resistance to MAP Kinase Pathway Inhibition. Nature 2013, 504, 138-142, doi:10.1038/nature12688.

121. Omori, K.; Kotera, J. Overview of PDEs and Their Regulation. Circulation Research 2007, doi:10.1161/01.RES.0000256354.95791.f1. 
122. Bang, J.; Zippin, J.H. Cyclic Adenosine Monophosphate (CAMP) Signaling in Melanocyte Pigmentation and Melanomagenesis. Pigment Cell Melanoma Res 2021, 34, 28-43, doi:10.1111/pcmr.12920.

123. Khaled, M.; Levy, C.; Fisher, D.E. Control of Melanocyte Differentiation by a MITFPDE4D3 Homeostatic Circuit. Genes Dev 2010, 24, 2276-2281, doi:10.1101/gad.1937710.

124. Lin, D.-C.; Xu, L.; Ding, L.-W.; Sharma, A.; Liu, L.-Z.; Yang, H.; Tan, P.; Vadgama, J.; Karlan, B.Y.; Lester, J.; et al. Genomic and Functional Characterizations of Phosphodiesterase Subtype 4D in Human Cancers. Proc Natl Acad Sci U S A 2013, 110, 6109-6114, doi:10.1073/pnas.1218206110.

125. Marquette, A.; André, J.; Bagot, M.; Bensussan, A.; Dumaz, N. ERK and PDE4 Cooperate to Induce RAF Isoform Switching in Melanoma. Nat Struct Mol Biol 2011, 18, 584-591, doi:10.1038/nsmb.2022.

126. Dumaz, N.; Hayward, R.; Martin, J.; Ogilvie, L.; Hedley, D.; Curtin, J.A.; Bastian, B.C.; Springer, C.; Marais, R. In Melanoma, RAS Mutations Are Accompanied by Switching Signaling from BRAF to CRAF and Disrupted Cyclic AMP Signaling. Cancer Res 2006, 66, 9483-9491, doi:10.1158/0008-5472.CAN-05-4227.

127. Delyon, J.; Servy, A.; Laugier, F.; André, J.; Ortonne, N.; Battistella, M.; Mourah, S.; Bensussan, A.; Lebbé, C.; Dumaz, N. PDE4D Promotes FAK-Mediated Cell Invasion in BRAF-Mutated Melanoma. Oncogene 2017, 36, 3252-3262, doi:10.1038/onc.2016.469.

128. Walsh, D.A.; Perkins, J.P.; Krebs, E.G. An Adenosine 3',5'-MonophosphateDependant Protein Kinase from Rabbit Skeletal Muscle. Journal of Biological Chemistry 1968, 243, 3763-3765, doi:10.1016/S0021-9258(19)34204-8.

129. Skalhegg, B.S.; Tasken, K. Specificity in the CAMP/PKA Signaling Pathway. Differential Expression,Regulation, and Subcellular Localization of Subunits of PKA. Front Biosci 2000, 5, D678-693, doi:10.2741/skalhegg.

130. Taskén, K.; Skålhegg, B.S.; Taskén, K.A.; Solberg, R.; Knutsen, H.K.; Levy, F.O.; Sandberg, M.; Orstavik, S.; Larsen, T.; Johansen, A.K.; et al. Structure, Function, and Regulation of Human CAMP-Dependent Protein Kinases. Adv Second Messenger Phosphoprotein Res 1997, 31, 191-204, doi:10.1016/s1040-7952(97)80019-5.

131. Liu, Q.; Tong, D.; Liu, G.; Yi, Y.; Zhang, D.; Zhang, J.; Zhang, Y.; Huang, Z.; Li, Y.; Chen, R.; et al. Carney Complex with PRKAR1A Gene Mutation. Medicine (Baltimore) 2017, 96, e8999, doi:10.1097/MD.0000000000008999.

132. Kirschner, L.S.; Carney, J.A.; Pack, S.D.; Taymans, S.E.; Giatzakis, C.; Cho, Y.S.; ChoChung, Y.S.; Stratakis, C.A. Mutations of the Gene Encoding the Protein Kinase A Type IAlpha Regulatory Subunit in Patients with the Carney Complex. Nat Genet 2000, 26, 8992, doi:10.1038/79238.

133. Cohen, J.N.; Yeh, I.; Mully, T.W.; LeBoit, P.E.; McCalmont, T.H. Genomic and Clinicopathologic Characteristics of PRKAR1A-Inactivated Melanomas: Toward Genetic Distinctions of Animal-Type Melanoma/Pigment Synthesizing Melanoma. Am J Surg Pathol 2020, 44, 805-816, doi:10.1097/PAS.0000000000001458.

134. Beebe, S.J.; Salomonsky, P.; Holroyd, C.; Becker, D. Differential Expression of Cyclic AMP-Dependent Protein Kinase Isozymes in Normal Human Melanocytes and Malignant Melanomas. Cell Growth \& Differentiation 1993, 4, 1005.

135. Hiramoto, K.; Murata, T.; Shimizu, K.; Morita, H.; Inui, M.; Manganiello, V.C.; Tagawa, T.; Arai, N. Role of Phosphodiesterase 2 in Growth and Invasion of Human Malignant Melanoma Cells. Cell Signal 2014, 26, 1807-1817, doi:10.1016/j.cellsig.2014.03.031.

136. Lyons, J.; Bastian, B.C.; McCormick, F. MC1R and CAMP Signaling Inhibit Cdc25B 
Activity and Delay Cell Cycle Progression in Melanoma Cells. Proc Natl Acad Sci U S A 2013, 110, 13845-13850, doi:10.1073/pnas.1201917110.

137. Takahashi, M.; Li, Y.; Dillon, T.J.; Stork, P.J.S. Phosphorylation of Rap1 by CAMPDependent Protein Kinase (PKA) Creates a Binding Site for KSR to Sustain ERK Activation by CAMP. Journal of Biological Chemistry 2017, 292, 1449-1461, doi:10.1074/jbc.M116.768986.

138. Ostojić, J.; Yoon, Y.-S.; Sonntag, T.; Nguyen, B.; Vaughan, J.M.; Shokhirev, M.; Montminy, M. Transcriptional Co-Activator Regulates Melanocyte Differentiation and Oncogenesis by Integrating CAMP and MAPK/ERK Pathways. Cell Reports 2021, 35, 109136, doi:10.1016/j.celrep.2021.109136.

139. Buscà, R.; Ballotti, R. Cyclic AMP a Key Messenger in the Regulation of Skin Pigmentation. Pigment Cell Research 2000, 13, 60-69, doi:10.1034/j.16000749.2000.130203.x.

140. Mobley, A.K.; Braeuer, R.R.; Kamiya, T.; Shoshan, E.; Bar-Eli, M. Driving Transcriptional Regulators in Melanoma Metastasis. Cancer Metastasis Rev 2012, 31, 621-632, doi:10.1007/s10555-012-9358-8.

141. Dobroff, A.S.; Wang, H.; Melnikova, V.O.; Villares, G.J.; Zigler, M.; Huang, L.; Bar-Eli, M. Silencing CAMP-Response Element-Binding Protein (CREB) Identifies CYR61 as a Tumor Suppressor Gene in Melanoma. Journal of Biological Chemistry 2009, 284, 2619426206, doi:10.1074/jbc.M109.019836.

142. Xie, S.; Price, J.E.; Luca, M.; Jean, D.; Ronai, Z.; Bar-Eli, M. Dominant-Negative CREB Inhibits Tumor Growth and Metastasis of Human Melanoma Cells. Oncogene 1997, 15, 2069-2075, doi:10.1038/sj.onc.1201358.

143. Braeuer, R.R.; Zigler, M.; Villares, G.J.; Dobroff, A.S.; Bar-Eli, M. Transcriptional Control of Melanoma Metastasis: The Importance of the Tumor Microenvironment. Seminars in Cancer Biology 2011, 21, 83-88, doi:10.1016/j.semcancer.2010.12.007.

144. Chen, J.; Zhou, X.; Yang, J.; Sun, Q.; Liu, Y.; Li, N.; Zhang, Z.; Xu, H. Circ-GLI1 Promotes Metastasis in Melanoma through Interacting with P70S6K2 to Activate Hedgehog/GLI1 and Wnt/ $\beta$-Catenin Pathways and Upregulate Cyr61. Cell Death Dis 2020, 11, 1-16, doi:10.1038/s41419-020-02799-x.

145. White, J.R.; Thompson, D.T.; Koch, K.E.; Kiriazov, B.S.; Beck, A.C.; van der Heide, D.M.; Grimm, B.G.; Kulak, M.V.; Weigel, R.J. AP-2 $\alpha$-Mediated Activation of E2F and EZH2 Drives Melanoma Metastasis. Cancer Res 2021, 81, 4455-4470, doi:10.1158/00085472.CAN-21-0772.

146. Nemlich, Y.; Baruch, E.N.; Besser, M.J.; Shoshan, E.; Bar-Eli, M.; Anafi, L.; Barshack, I.; Schachter, J.; Ortenberg, R.; Markel, G. ADAR1-Mediated Regulation of Melanoma Invasion. Nat Commun 2018, 9, 2154, doi:10.1038/s41467-018-04600-2.

147. Hu, W.; Jin, L.; Jiang, C.C.; Long, G.V.; Scolyer, R.A.; Wu, Q.; Zhang, X.D.; Mei, Y.; Wu, M. AEBP1 Upregulation Confers Acquired Resistance to BRAF (V600E) Inhibition in Melanoma. Cell Death Dis 2013, 4, e914-e914, doi:10.1038/cddis.2013.441.

148. Zhang, H.; Kong, Q.; Wang, J.; Jiang, Y.; Hua, H. Complex Roles of CAMP-PKA-CREB Signaling in Cancer. Experimental Hematology \& Oncology 2020, 9, 32, doi:10.1186/s40164-020-00191-1.

149. Narita, M.; Murata, T.; Shimizu, K.; Nakagawa, T.; Sugiyama, T.; Inui, M.; Hiramoto, K.; Tagawa, T. A Role for Cyclic Nucleotide Phosphodiesterase 4 in Regulation of the Growth of Human Malignant Melanoma Cells. Oncology Reports 2007, 17, 1133-1139, doi:10.3892/or.17.5.1133.

150. Rodriguez, C.I.; Setaluri, V. EPAC Mediates the Dual Role of CAMP Signaling in Melanoma. Oncoscience 2018, 6, 283-284, doi:10.18632/oncoscience.463. 
151. Fajardo, A.M.; Piazza, G.A.; Tinsley, H.N. The Role of Cyclic Nucleotide Signaling Pathways in Cancer: Targets for Prevention and Treatment. Cancers (Basel) 2014, 6, 436-458, doi:10.3390/cancers6010436.

152. Robertson, A.G.; Shih, J.; Yau, C.; Gibb, E.A.; Oba, J.; Mungall, K.L.; Hess, J.M.; Uzunangelov, V.; Walter, V.; Danilova, L.; et al. Integrative Analysis Identifies Four Molecular and Clinical Subsets in Uveal Melanoma. Cancer Cell 2017, 32, 204-220.e15, doi:10.1016/j.ccell.2017.07.003.

153. Van Raamsdonk, C.D.; Griewank, K.G.; Crosby, M.B.; Garrido, M.C.; Vemula, S.; Wiesner, T.; Obenauf, A.C.; Wackernagel, W.; Green, G.; Bouvier, N.; et al. Mutations in GNA11 in Uveal Melanoma. $N$ Engl $J$ Med 2010, 363, 2191-2199, doi:10.1056/NEJMoa1000584.

154. Urtatiz, O.; Van Raamsdonk, C.D. Gnaq and Gna11 in the Endothelin Signaling Pathway and Melanoma. Front Genet 2016, 7, 59, doi:10.3389/fgene.2016.00059.

155. O’Hayre, M.; Vázquez-Prado, J.; Kufareva, I.; Stawiski, E.W.; Handel, T.M.; Seshagiri, S.; Gutkind, J.S. The Emerging Mutational Landscape of G Proteins and GProtein-Coupled Receptors in Cancer. Nat Rev Cancer 2013, 13, 412-424, doi:10.1038/nrc3521.

156. Maziarz, M.; Leyme, A.; Marivin, A.; Luebbers, A.; Patel, P.P.; Chen, Z.; Sprang, S.R.; Garcia-Marcos, M. Atypical Activation of the G Protein Goq by the Oncogenic Mutation Q209P. J Biol Chem 2018, 293, 19586-19599, doi:10.1074/jbc.RA118.005291.

157. Möller, I.; Murali, R.; Müller, H.; Wiesner, T.; Jackett, L.A.; Scholz, S.L.; Cosgarea, I.; van de Nes, J.A.; Sucker, A.; Hillen, U.; et al. Activating Cysteinyl Leukotriene Receptor 2 (CYSLTR2) Mutations in Blue Nevi. Mod Pathol 2017, 30, 350-356, doi:10.1038/modpathol.2016.201.

158. Huang, J.L.-Y.; Urtatiz, O.; Van Raamsdonk, C.D. Oncogenic G Protein GNAQ Induces Uveal Melanoma and Intravasation in Mice. Cancer Res 2015, 75, 3384-3397, doi:10.1158/0008-5472.CAN-14-3229.

159. Urtatiz, O.; Cook, C.; Huang, J.L. -Y.; Yeh, I.; Van Raamsdonk, C.D. GNAQQ209L Expression Initiated in Multipotent Neural Crest Cells Drives Aggressive Melanoma of the Central Nervous System. Pigment Cell \& Melanoma Research 2020, 33, 96-111, doi:10.1111/pcmr.12843.

160. Moore, A.R.; Ran, L.; Guan, Y.; Sher, J.J.; Hitchman, T.D.; Zhang, J.Q.; Hwang, C.; Walzak, E.G.; Shoushtari, A.N.; Monette, S.; et al. GNA11 Q209L Mouse Model Reveals RasGRP3 as an Essential Signaling Node in Uveal Melanoma. Cell Rep 2018, 22, 24552468, doi:10.1016/j.celrep.2018.01.081.

161. Annala, S.; Feng, X.; Shridhar, N.; Eryilmaz, F.; Patt, J.; Yang, J.; Pfeil, E.M.;

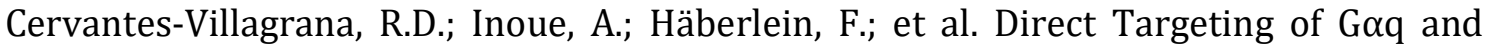
Go11 Oncoproteins in Cancer Cells. Sci Signal 2019, 12, eaau5948, doi:10.1126/scisignal.aau5948.

162. Kostenis, E.; Pfeil, E.M.; Annala, S. Heterotrimeric Gq Proteins as Therapeutic Targets? Journal of Biological Chemistry 2020, 295, 5206-5215, doi:10.1074/jbc.REV119.007061.

163. Ambrosini, G.; Pratilas, C.A.; Qin, L.-X.; Tadi, M.; Surriga, O.; Carvajal, R.D.; Schwartz, G.K. Identification of Unique MEK-Dependent Genes in GNAQ Mutant Uveal Melanoma Involved in Cell Growth, Tumor Cell Invasion and MEK-Resistance. Clin Cancer Res 2012, 18, 3552-3561, doi:10.1158/1078-0432.CCR-11-3086.

164. Asundi, J.; Lacap, J.A.; Clark, S.; Nannini, M.; Roth, L.; Polakis, P. MAPK Pathway Inhibition Enhances the Efficacy of an Anti-Endothelin B Receptor Drug Conjugate by Inducing Target Expression in Melanoma. Mol Cancer Ther 2014, 13, 1599-1610, 
doi:10.1158/1535-7163.MCT-13-0446.

165. Hitchman, T.D.; Bayshtok, G.; Ceraudo, E.; Moore, A.R.; Lee, C.; Jia, R.; Wang, N.; Pachai, M.R.; Shoushtari, A.N.; Francis, J.H.; et al. Combined Inhibition of Gaq and MEK Enhances Therapeutic Efficacy in Uveal Melanoma. Clin Cancer Res 2021, 27, 14761490, doi:10.1158/1078-0432.CCR-20-2860.

166. Smrcka, A.V.; Hepler, J.R.; Brown, K.O.; Sternweis, P.C. Regulation of Polyphosphoinositide-Specific Phospholipase C Activity by Purified Gq. Science 1991, 251, 804-807, doi:10.1126/science.1846707.

167. Taylor, S.J.; Chae, H.Z.; Rhee, S.G.; Exton, J.H. Activation of the Beta 1 Isozyme of Phospholipase C by Alpha Subunits of the Gq Class of G Proteins. Nature 1991, 350, 516518, doi:10.1038/350516a0.

168. Waldo, G.L.; Boyer, J.L.; Morris, A.J.; Harden, T.K. Purification of an AlF4- and GProtein Beta Gamma-Subunit-Regulated Phospholipase C-Activating Protein. J Biol Chem 1991, 266, 14217-14225.

169. Lyon, A.M.; Tesmer, J.J.G. Structural Insights into Phospholipase C- $\beta$ Function. Mol Pharmacol 2013, 84, 488-500, doi:10.1124/mol.113.087403.

170. Chua, V.; Lapadula, D.; Randolph, C.; Benovic, J.L.; Wedegaertner, P.B.; Aplin, A.E. Dysregulated GPCR Signaling and Therapeutic Options in Uveal Melanoma. Mol Cancer Res 2017, 15, 501-506, doi:10.1158/1541-7786.MCR-17-0007.

171. Johansson, P.; Aoude, L.G.; Wadt, K.; Glasson, W.J.; Warrier, S.K.; Hewitt, A.W.; Kiilgaard, J.F.; Heegaard, S.; Isaacs, T.; Franchina, M.; et al. Deep Sequencing of Uveal Melanoma Identifies a Recurrent Mutation in PLCB4. Oncotarget 2016, 7, 4624-4631, doi:10.18632/oncotarget.6614.

172. Li, J.; Zhao, X.; Wang, D.; He, W.; Zhang, S.; Cao, W.; Huang, Y.; Wang, L.; Zhou, S.; Luo, K. Up-Regulated Expression of Phospholipase C, B1 Is Associated with Tumor Cell Proliferation and Poor Prognosis in Hepatocellular Carcinoma. Onco Targets Ther 2016, 9, 1697-1706, doi:10.2147/OTT.S97189.

173. Sengelaub, C.A.; Navrazhina, K.; Ross, J.B.; Halberg, N.; Tavazoie, S.F. PTPRN2 and PLC $\beta 1$ Promote Metastatic Breast Cancer Cell Migration through PI(4,5)P2-dependent Actin Remodeling. EMBO J 2016, 35, 62-76, doi:10.15252/embj.201591973.

174. Arita, Y.; O'Driscoll, K.R.; Weinstein, I.B. Growth of Human Melanocyte Cultures Supported by 12-0-Tetradecanoylphorbol-13-Acetate Is Mediated through Protein Kinase C Activation. Cancer Res 1992, 52, 4514-4521.

175. Petit, V.; Raymond, J.; Alberti, C.; Pouteaux, M.; Gallagher, S.J.; Nguyen, M.Q.; Aplin, A.E.; Delmas, V.; Larue, L. C57BL/6 Congenic Mouse NRASQ61K Melanoma Cell Lines Are Highly Sensitive to the Combination of Mek and Akt Inhibitors in Vitro and in Vivo. Pigment Cell \& Melanoma Research 2019, 32, 829-841, doi:10.1111/pcmr.12807.

176. Tamura, A.; Halaban, R.; Moellmann, G.; Cowan, J.M.; Lerner, M.R.; Lerner, A.B. Normal Murine Melanocytes in Culture. In Vitro Cell Dev Biol 1987, 23, 519-522, doi:10.1007/BF02628423.

177. Iwasaki, T.; Yamauchi, M.; Liang, Z.; Itai, A.; Sakaguchi, M.; Nagano, T.; Kamada, S.; Oka, M. TPA Inhibits Melanoma Growth through Inactivation of STAT3 through Protein Tyrosine Phosphatases. Journal of Dermatological Science 2017, 86, e94, doi:10.1016/j.jdermsci.2017.02.275.

178. Jørgensen, K.; Skrede, M.; Cruciani, V.; Mikalsen, S.-O.; Slipicevic, A.; Flørenes, V.A. Phorbol Ester Phorbol-12-Myristate-13-Acetate Promotes Anchorage-Independent Growth and Survival of Melanomas through MEK-Independent Activation of ERK1/2. Biochem Biophys Res Commun 2005, 329, 266-274, doi:10.1016/j.bbrc.2005.01.143.

179. La Porta, C.A.; Porro, D.; Comolli, R. Opposite Effects of TPA on G1/S Transition 
and on Cell Size in the Low Metastatic B16F1 with Respect to High Metastatic BL6 Murine Melanoma Cells. Cancer Lett 1998, 132, 159-164, doi:10.1016/s03043835(98)00177-3.

180. Dissanayake, S.K.; Wade, M.; Johnson, C.E.; O’Connell, M.P.; Leotlela, P.D.; French, A.D.; Shah, K.V.; Hewitt, K.J.; Rosenthal, D.T.; Indig, F.E.; et al. The Wnt5A/Protein Kinase C Pathway Mediates Motility in Melanoma Cells via the Inhibition of Metastasis Suppressors and Initiation of an Epithelial to Mesenchymal Transition *. Journal of Biological Chemistry 2007, 282, 17259-17271, doi:10.1074/jbc.M700075200.

181. Zhao, X.; Geltinger, C.; Kishikawa, S.; Ohshima, K.; Murata, T.; Nomura, N.; Nakahara, T.; Yokoyama, K.K. Treatment of Mouse Melanoma Cells with Phorbol 12Myristate 13-Acetate Counteracts Mannosylerythritol Lipid-Induced Growth Arrest and Apoptosis. Cytotechnology 2000, 33, 123-130, doi:10.1023/A:1008129616127.

182. Foskett, J.K.; White, C.; Cheung, K.-H.; Mak, D.-O.D. Inositol Trisphosphate Receptor Ca2+ Release Channels. Physiol Rev 2007, 87, 593-658, doi:10.1152/physrev.00035.2006.

183. Cox, J.L.; Lancaster, T.; Carlson, C.G. Changes in the Motility of B16F10 Melanoma Cells Induced by Alterations in Resting Calcium Influx. Melanoma Research 2002, 12, 211-219.

184. Sun, J.; Lu, F.; He, H.; Shen, J.; Messina, J.; Mathew, R.; Wang, D.; Sarnaik, A.A.; Chang, W.-C.; Kim, M.; et al. STIM1- and Orai1-Mediated Ca2+ Oscillation Orchestrates Invadopodium Formation and Melanoma Invasion. J Cell Biol 2014, 207, 535-548, doi:10.1083/jcb.201407082.

185. Umemura, M.; Baljinnyam, E.; Feske, S.; De Lorenzo, M.S.; Xie, L.-H.; Feng, X.; Oda, K.; Makino, A.; Fujita, T.; Yokoyama, U.; et al. Store-Operated Ca2+ Entry (SOCE) Regulates Melanoma Proliferation and Cell Migration. PLoS One 2014, 9, e89292, doi:10.1371/journal.pone.0089292.

186. Denning, M.F. Specifying Protein Kinase C Functions in Melanoma. Pigment Cell \& Melanoma Research 2012, 25, 466-476, doi:10.1111/j.1755-148X.2012.01015.x.

187. Hoshi, N.; Langeberg, L.K.; Gould, C.M.; Newton, A.C.; Scott, J.D. Interaction with AKAP79 Modifies the Cellular Pharmacology of PKC. Mol Cell 2010, 37, 541-550, doi:10.1016/j.molcel.2010.01.014.

188. Park, H.-Y.; Wu, H.; Killoran, C.E.; Gilchrest, B.A. The Receptor for Activated CKinase-I (RACK-I) Anchors Activated PKC-Beta on Melanosomes. J Cell Sci 2004, 117, 3659-3668, doi:10.1242/jcs.01219.

189. Schechtman, D.; Mochly-Rosen, D. Adaptor Proteins in Protein Kinase C-Mediated Signal Transduction. Oncogene 2001, 20, 6339-6347, doi:10.1038/sj.onc.1204778.

190. Voris, J.P.; Sitailo, L.A.; Rahn, H.R.; Defnet, A.; Gerds, A.T.; Sprague, R.; Yadav, V.; Caroline Le Poole, I.; Denning, M.F. Functional Alterations in Protein Kinase C Beta II Expression in Melanoma. Pigment Cell Melanoma Res 2010, 23, 216-224, doi:10.1111/j.1755-148X.2009.00664.x.

191. Matsuoka, H.; Tsubaki, M.; Yamazoe, Y.; Ogaki, M.; Satou, T.; Itoh, T.; Kusunoki, T.; Nishida, S. Tamoxifen Inhibits Tumor Cell Invasion and Metastasis in Mouse Melanoma through Suppression of PKC/MEK/ERK and PKC/PI3K/Akt Pathways. Experimental Cell Research 2009, 315, 2022-2032, doi:10.1016/j.yexcr.2009.04.009.

192. Oka, M.; Kikkawa, U.; Nishigori, C. Protein Kinase C-BetaII Represses Hepatocyte Growth Factor-Induced Invasion by Preventing the Association of Adapter Protein Gab1 and Phosphatidylinositol 3-Kinase in Melanoma Cells. J Invest Dermatol 2008, 128, 188195, doi:10.1038/sj.jid.5700961.

193. Park, H.Y.; Russakovsky, V.; Ohno, S.; Gilchrest, B.A. The Beta Isoform of Protein 
Kinase C Stimulates Human Melanogenesis by Activating Tyrosinase in Pigment Cells. J Biol Chem 1993, 268, 11742-11749.

194. Chen, X.; Wu, Q.; Depeille, P.; Chen, P.; Thornton, S.; Kalirai, H.; Coupland, S.E.; Roose, J.P.; Bastian, B.C. RasGRP3 Mediates MAPK Pathway Activation in GNAQ Mutant Uveal Melanoma. Cancer Cell 2017, 31, 685-696.e6, doi:10.1016/j.ccell.2017.04.002.

195. Lau, E.; Kluger, H.; Varsano, T.; Lee, K.; Scheffler, I.; Rimm, D.L.; Ideker, T.; Ronai, Z.A. PKC $\varepsilon$ Promotes Oncogenic Functions of ATF2 in the Nucleus While Blocking Its Apoptotic Function at Mitochondria. Cell 2012, 148, 543-555, doi:10.1016/j.cell.2012.01.016.

196. Mhaidat, N.M.; Thorne, R.F.; Zhang, X.D.; Hersey, P. Regulation of DocetaxelInduced Apoptosis of Human Melanoma Cells by Different Isoforms of Protein Kinase C. Mol Cancer Res 2007, 5, 1073-1081, doi:10.1158/1541-7786.MCR-07-0059.

197. Aiba, Y.; Oh-hora, M.; Kiyonaka, S.; Kimura, Y.; Hijikata, A.; Mori, Y.; Kurosaki, T. Activation of RasGRP3 by Phosphorylation of Thr-133 Is Required for B Cell ReceptorMediated Ras Activation. Proc Natl Acad Sci U S A 2004, 101, 16612-16617, doi:10.1073/pnas.0407468101.

198. Johnson, J.E.; Goulding, R.E.; Ding, Z.; Partovi, A.; Anthony, K.V.; Beaulieu, N.; Tazmini, G.; Cornell, R.B.; Kay, R.J. Differential Membrane Binding and Diacylglycerol Recognition by C1 Domains of RasGRPs. Biochem J 2007, 406, 223-236, doi:10.1042/BJ20070294.

199. Teixeira, C.; Stang, S.L.; Zheng, Y.; Beswick, N.S.; Stone, J.C. Integration of DAG Signaling Systems Mediated by PKC-Dependent Phosphorylation of RasGRP3. Blood 2003, 102, 1414-1420, doi:10.1182/blood-2002-11-3621.

200. Cozzi, S.-J.; Parsons, P.G.; Ogbourne, S.M.; Pedley, J.; Boyle, G.M. Induction of Senescence in Diterpene Ester-Treated Melanoma Cells via Protein Kinase C-Dependent Hyperactivation of the Mitogen-Activated Protein Kinase Pathway. Cancer Res 2006, 66, 10083-10091, doi:10.1158/0008-5472.CAN-06-0348.

201. Schönwasser, D.C.; Marais, R.M.; Marshall, C.J.; Parker, P.J. Activation of the Mitogen-Activated Protein Kinase/Extracellular Signal-Regulated Kinase Pathway by Conventional, Novel, and Atypical Protein Kinase C Isotypes. Mol Cell Biol 1998, 18, 790798, doi:10.1128/MCB.18.2.790.

202. Tsubaki, M.; Matsuoka, H.; Yamamoto, C.; Kato, C.; Ogaki, M.; Satou, T.; Itoh, T.; Kusunoki, T.; Tanimori, Y.; Nishida, S. The Protein Kinase C Inhibitor, H7, Inhibits Tumor Cell Invasion and Metastasis in Mouse Melanoma via Suppression of ERK1/2. Clin Exp Metastasis 2007, 24, 431-438, doi:10.1007/s10585-007-9080-z.

203. Johannessen, C.M.; Boehm, J.S.; Kim, S.Y.; Thomas, S.R.; Wardwell, L.; Johnson, L.A.; Emery, C.M.; Stransky, N.; Cogdill, A.P.; Barretina, J.; et al. COT Drives Resistance to RAF Inhibition through MAP Kinase Pathway Reactivation. Nature 2010, 468, 968-972, doi:10.1038/nature09627.

204. Fu, Y.; Rathod, D.; Patel, K. Protein Kinase C Inhibitor Anchored BRD4 PROTAC PEGylated Nanoliposomes for the Treatment of Vemurafenib-Resistant Melanoma. Experimental Cell Research 2020, 396, 112275, doi:10.1016/j.yexcr.2020.112275.

205. Kwon, H.; Kim, J.; Jho, E.-H. Role of the Hippo Pathway and Mechanisms for Controlling Cellular Localization of YAP/TAZ. FEBS J 2021, doi:10.1111/febs.16091.

206. Yu, F.-X.; Zhao, B.; Panupinthu, N.; Jewell, J.L.; Lian, I.; Wang, L.H.; Zhao, J.; Yuan, H.; Tumaneng, K.; Li, H.; et al. Regulation of the Hippo-YAP Pathway by G-Protein Coupled Receptor Signaling. Cell 2012, 150, 780-791, doi:10.1016/j.cell.2012.06.037.

207. Feng, X.; Degese, M.S.; Iglesias-Bartolome, R.; Vaque, J.P.; Molinolo, A.A.; Rodrigues, M.; Zaidi, M.R.; Ksander, B.R.; Merlino, G.; Sodhi, A.; et al. Hippo-Independent 
Activation of YAP by the GNAQ Uveal Melanoma Oncogene through a Trio-Regulated Rho GTPase Signaling Circuitry. Cancer Cell 2014, 25, 831-845, doi:10.1016/j.ccr.2014.04.016.

208. Yu, F.-X.; Luo, J.; Mo, J.-S.; Liu, G.; Kim, Y.C.; Meng, Z.; Zhao, L.; Peyman, G.; Ouyang, H.; Jiang, W.; et al. Mutant Gq/11 Promote Uveal Melanoma Tumorigenesis by Activating YAP. Cancer Cell 2014, 25, 822-830, doi:10.1016/j.ccr.2014.04.017.

209. Vaqué, J.P.; Dorsam, R.T.; Feng, X.; Iglesias-Bartolome, R.; Forsthoefel, D.J.; Chen, Q.; Debant, A.; Seeger, M.A.; Ksander, B.R.; Teramoto, H.; et al. A Genome-Wide RNAi Screen Reveals a Trio-Regulated Rho GTPase Circuitry Transducing Mitogenic Signals Initiated by G Protein-Coupled Receptors. Mol Cell 2013, 49, 94-108, doi:10.1016/j.molcel.2012.10.018.

210. Paradis, J.S.; Acosta, M.; Saddawi-Konefka, R.; Kishore, A.; Lubrano, S.; Gomes, F.; Arang, N.; Tiago, M.; Coma, S.; Wu, X.; et al. Synthetic Lethal Screens Reveal Cotargeting FAK and MEK as a Multimodal Precision Therapy for GNAQ-Driven Uveal Melanoma. Clin Cancer Res 2021, 27, 3190-3200, doi:10.1158/1078-0432.CCR-20-3363.

211. Shaulian, E.; Karin, M. AP-1 in Cell Proliferation and Survival. Oncogene 2001, 20, 2390-2400, doi:10.1038/sj.onc.1204383.

212. Du, L.; Anderson, A.; Nguyen, K.; Ojeda, S.S.; Ortiz-Rivera, I.; Nguyen, T.N.; Zhang, T.; Kaoud, T.S.; Gray, N.S.; Dalby, K.N.; et al. JNK2 Is Required for the Tumorigenic Properties of Melanoma Cells. ACS Chem Biol 2019, 14, 1426-1435, doi:10.1021/acschembio.9b00083.

213. Estrada, Y.; Dong, J.; Ossowski, L. Positive Crosstalk between ERK and P38 in Melanoma Stimulates Migration and in Vivo Proliferation. Pigment Cell Melanoma Res 2009, 22, 66-76, doi:10.1111/j.1755-148X.2008.00520.x.

214. Pathria, G.; Garg, B.; Garg, K.; Wagner, C.; Wagner, S.N. Dual C-Jun N-Terminal Kinase-Cyclin D1 and Extracellular Signal-Related Kinase-c-Jun Disjunction in Human Melanoma. Br J Dermatol 2016, 175, 1221-1231, doi:10.1111/bjd.14713.

215. Ma, Y.; Wang, L.; He, F.; Yang, J.; Ding, Y.; Ge, S.; Fan, X.; Zhou, Y.; Xu, X.; Jia, R. LACTB Suppresses Melanoma Progression by Attenuating PP1A and YAP Interaction. Cancer Lett 2021, 506, 67-82, doi:10.1016/j.canlet.2021.02.022.

216. Nallet-Staub, F.; Marsaud, V.; Li, L.; Gilbert, C.; Dodier, S.; Bataille, V.; Sudol, M.; Herlyn, M.; Mauviel, A. Pro-Invasive Activity of the Hippo Pathway Effectors YAP and TAZ in Cutaneous Melanoma. J Invest Dermatol 2014, 134, 123-132, doi:10.1038/jid.2013.319.

217. Zhang, X.; Yang, L.; Szeto, P.; Abali, G.K.; Zhang, Y.; Kulkarni, A.; Amarasinghe, K.; Li, J.; Vergara, I.A.; Molania, R.; et al. The Hippo Pathway Oncoprotein YAP Promotes Melanoma Cell Invasion and Spontaneous Metastasis. Oncogene 2020, 39, 5267-5281, doi:10.1038/s41388-020-1362-9.

218. Zhao, B.; Xie, J.; Zhou, X.; Zhang, L.; Cheng, X.; Liang, C. YAP Activation in Melanoma Contributes to Anoikis Resistance and Metastasis. Exp Biol Med (Maywood) 2021, 246, 888-896, doi:10.1177/1535370220977101.

219. Lui, J.W.; Moore, S.P.G.; Huang, L.; Ogomori, K.; Li, Y.; Lang, D. YAP Facilitates Melanoma Migration through Regulation of Actin-Related Protein 2/3 Complex Subunit 5 (ARPC5). Pigment Cell Melanoma Res 2021, doi:10.1111/pcmr.13013.

220. Tan, S.; Zhao, Z.; Qiao, Y.; Zhang, B.; Zhang, T.; Zhang, M.; Qi, J.; Wang, X.; Meng, M.; Zhou, Q. Activation of the Tumor Suppressive Hippo Pathway by Triptonide as a New Strategy to Potently Inhibit Aggressive Melanoma Cell Metastasis. Biochemical Pharmacology 2021, 185, 114423, doi:10.1016/j.bcp.2021.114423.

221. Flem-Karlsen, K.; McFadden, E.; Omar, N.; Haugen, M.H.; Øy, G.F.; Ryder, T.; 
Gullestad, H.P.; Hermann, R.; Mælandsmo, G.M.; Flørenes, V.A. Targeting AXL and the DNA Damage Response Pathway as a Novel Therapeutic Strategy in Melanoma. Mol Cancer Ther 2020, 19, 895-905, doi:10.1158/1535-7163.MCT-19-0290.

222. Müller, J.; Krijgsman, O.; Tsoi, J.; Robert, L.; Hugo, W.; Song, C.; Kong, X.; Possik, P.A.; Cornelissen-Steijger, P.D.M.; Geukes Foppen, M.H.; et al. Low MITF/AXL Ratio Predicts Early Resistance to Multiple Targeted Drugs in Melanoma. Nat Commun 2014, 5, 5712, doi:10.1038/ncomms6712.

223. Tizpa, E.; Young, H.J.; Bonjoc, K.-J.C.; Chang, C.-W.; Liu, Y.; Foulks, J.M.; Chaudhry, A. Role of AXL in Metastatic Melanoma and Impact of TP-0903 as a Novel Therapeutic Option for Melanoma Brain Metastasis. JCO 2020, 38, e22021-e22021, doi:10.1200/JC0.2020.38.15_suppl.e22021.

224. Kunz, M.; Moeller, S.; Koczan, D.; Lorenz, P.; Wenger, R.H.; Glocker, M.O.; Thiesen, H.-J.; Gross, G.; Ibrahim, S.M. Mechanisms of Hypoxic Gene Regulation of Angiogenesis Factor Cyr61 in Melanoma Cells *. Journal of Biological Chemistry 2003, 278, 4565145660, doi:10.1074/jbc.M301373200.

225. Borsotti, P.; Ghilardi, C.; Ostano, P.; Silini, A.; Dossi, R.; Pinessi, D.; Foglieni, C.; Scatolini, M.; Lacal, P.M.; Ferrari, R.; et al. Thrombospondin-1 Is Part of a SlugIndependent Motility and Metastatic Program in Cutaneous Melanoma, in Association with VEGFR-1 and FGF-2. Pigment Cell \& Melanoma Research 2015, 28, 73-81, doi:10.1111/pcmr.12319.

226. Jayachandran, A.; Anaka, M.; Prithviraj, P.; Hudson, C.; McKeown, S.J.; Lo, P.-H.; Vella, L.J.; Goding, C.R.; Cebon, J.; Behren, A. Thrombospondin 1 Promotes an Aggressive Phenotype through Epithelial-to-Mesenchymal Transition in Human Melanoma. Oncotarget 2014, 5, 5782-5797.

227. Verfaillie, A.; Imrichova, H.; Atak, Z.K.; Dewaele, M.; Rambow, F.; Hulselmans, G.; Christiaens, V.; Svetlichnyy, D.; Luciani, F.; Van den Mooter, L.; et al. Decoding the Regulatory Landscape of Melanoma Reveals TEADS as Regulators of the Invasive Cell State. Nat Commun 2015, 6, 6683, doi:10.1038/ncomms7683.

228. Hart, M.J.; Jiang, X.; Kozasa, T.; Roscoe, W.; Singer, W.D.; Gilman, A.G.; Sternweis, P.C.; Bollag, G. Direct Stimulation of the Guanine Nucleotide Exchange Activity of P115 RhoGEF by Galpha13. Science 1998, 280, 2112-2114, doi:10.1126/science.280.5372.2112.

229. Suzuki, N.; Nakamura, S.; Mano, H.; Kozasa, T. Galpha 12 Activates Rho GTPase through Tyrosine-Phosphorylated Leukemia-Associated RhoGEF. Proc Natl Acad Sci U S A 2003, 100, 733-738, doi:10.1073/pnas.0234057100.

230. Chen, Z.; Singer, W.D.; Sternweis, P.C.; Sprang, S.R. Structure of the P115RhoGEF RgRGS Domain-Galpha13/I1 Chimera Complex Suggests Convergent Evolution of a GTPase Activator. Nat Struct Mol Biol 2005, 12, 191-197, doi:10.1038/nsmb888.

231. Fukuhara, S.; Murga, C.; Zohar, M.; Igishi, T.; Gutkind, J.S. A Novel PDZ Domain Containing Guanine Nucleotide Exchange Factor Links Heterotrimeric G Proteins to Rho. J Biol Chem 1999, 274, 5868-5879, doi:10.1074/jbc.274.9.5868.

232. Suzuki, I.; Cone, R.D.; Im, S.; Nordlund, J.; Abdel-Malek, Z.A. Binding of Melanotropic Hormones to the Melanocortin Receptor MC1R on Human Melanocytes Stimulates Proliferation and Melanogenesis. Endocrinology 1996, 137, 1627-1633, doi:10.1210/endo.137.5.8612494.

233. Vogt, S.; Grosse, R.; Schultz, G.; Offermanns, S. Receptor-Dependent RhoA Activation in G12/G13-Deficient Cells: Genetic Evidence for an Involvement of Gq/G11.J Biol Chem 2003, 278, 28743-28749, doi:10.1074/jbc.M304570200.

234. Wells, C.D.; Liu, M.-Y.; Jackson, M.; Gutowski, S.; Sternweis, P.M.; Rothstein, J.D.; 
Kozasa, T.; Sternweis, P.C. Mechanisms for Reversible Regulation between G13 and Rho Exchange Factors. J Biol Chem 2002, 277, 1174-1181, doi:10.1074/jbc.M105274200.

235. Elste, A.P.; Petersen, I. Expression of Proteinase-Activated Receptor 1-4 (PAR 1-4) in Human Cancer. J Mol Histol 2010, 41, 89-99, doi:10.1007/s10735-010-9274-6.

236. Mo, J.-S.; Yu, F.-X.; Gong, R.; Brown, J.H.; Guan, K.-L. Regulation of the Hippo-YAP Pathway by Protease-Activated Receptors (PARs). Genes Dev. 2012, 26, 2138-2143, doi:10.1101/gad.197582.112.

237. Kelly, P.; Stemmle, L.N.; Madden, J.F.; Fields, T.A.; Daaka, Y.; Casey, P.J. A Role for the G12 Family of Heterotrimeric G Proteins in Prostate Cancer Invasion. J Biol Chem 2006, 281, 26483-26490, doi:10.1074/jbc.M604376200.

238. Kelly, P.; Moeller, B.J.; Juneja, J.; Booden, M.A.; Der, C.J.; Daaka, Y.; Dewhirst, M.W.; Fields, T.A.; Casey, P.J. The G12 Family of Heterotrimeric G Proteins Promotes Breast Cancer Invasion and Metastasis. Proc Natl Acad Sci U S A 2006, 103, 8173-8178, doi:10.1073/pnas.0510254103.

239. Minami, K.; Ueda, N.; Ishimoto, K.; Tsujiuchi, T. Lysophosphatidic Acid Receptor-2 (LPA2)-Mediated Signaling Enhances Chemoresistance in Melanoma Cells Treated with Anticancer Drugs. Mol Cell Biochem 2020, 469, 89-95, doi:10.1007/s11010-020-03730w.

240. Larue, L.; Delmas, V. The WNT/Beta-Catenin Pathway in Melanoma. Front Biosci 2006, 11, 733-742, doi:10.2741/1831.

241. Zhan, T.; Rindtorff, N.; Boutros, M. Wnt Signaling in Cancer. Oncogene 2017, 36, 1461-1473, doi:10.1038/onc.2016.304.

242. Takada, R.; Satomi, Y.; Kurata, T.; Ueno, N.; Norioka, S.; Kondoh, H.; Takao, T.; Takada, S. Monounsaturated Fatty Acid Modification of Wnt Protein: Its Role in Wnt Secretion. Developmental Cell 2006, 11, 791-801, doi:10.1016/j.devcel.2006.10.003.

243. Willert, K.; Brown, J.D.; Danenberg, E.; Duncan, A.W.; Weissman, I.L.; Reya, T.; Yates, J.R.; Nusse, R. Wnt Proteins Are Lipid-Modified and Can Act as Stem Cell Growth Factors. Nature 2003, 423, 448-452, doi:10.1038/nature01611.

244. Lee, E.; Salic, A.; Krüger, R.; Heinrich, R.; Kirschner, M.W. The Roles of APC and Axin Derived from Experimental and Theoretical Analysis of the Wnt Pathway. PLOS Biology 2003, 1, e10, doi:10.1371/journal.pbio.0000010.

245. Salic, A.; Lee, E.; Mayer, L.; Kirschner, M.W. Control of Beta-Catenin Stability: Reconstitution of the Cytoplasmic Steps of the Wnt Pathway in Xenopus Egg Extracts. Mol Cell 2000, 5, 523-532, doi:10.1016/s1097-2765(00)80446-3.

246. Valenta, T.; Hausmann, G.; Basler, K. The Many Faces and Functions of $\beta$-Catenin. EMBO J 2012, 31, 2714-2736, doi:10.1038/emboj.2012.150.

247. Aktary, Z.; Bertrand, J.U.; Larue, L. The WNT-Less Wonder: WNT-Independent $\beta$ Catenin Signaling. Pigment Cell \& Melanoma Research 2016, 29, 524-540, doi:10.1111/pcmr.12501.

248. Schepsky, A.; Bruser, K.; Gunnarsson, G.J.; Goodall, J.; Hallsson, J.H.; Goding, C.R.; Steingrimsson, E.; Hecht, A. The Microphthalmia-Associated Transcription Factor Mitf Interacts with Beta-Catenin to Determine Target Gene Expression. Mol. Cell. Biol. 2006, 26, 8914-8927, doi:10.1128/MCB.02299-05.

249. Saito, H.; Yasumoto, K.-I.; Takeda, K.; Takahashi, K.; Fukuzaki, A.; Orikasa, S.; Shibahara, S. Melanocyte-Specific Microphthalmia-Associated Transcription Factor Isoform Activates Its Own Gene Promoter through Physical Interaction with LymphoidEnhancing Factor 1. J Biol Chem 2002, 277, 28787-28794, doi:10.1074/jbc.M203719200.

250. Kawakami, A.; Fisher, D.E. The Master Role of Microphthalmia-Associated 
Transcription Factor in Melanocyte and Melanoma Biology. Lab Invest 2017, 97, 649656, doi:10.1038/labinvest.2017.9.

251. Ballotti, R.; Cheli, Y.; Bertolotto, C. The Complex Relationship between MITF and the Immune System: A Melanoma ImmunoTherapy (Response) Factor? Mol Cancer 2020, 19, 170, doi:10.1186/s12943-020-01290-7.

252. Baljinnyam, E.; Umemura, M.; De Lorenzo, M.S.; Xie, L.-H.; Nowycky, M.; Iwatsubo,

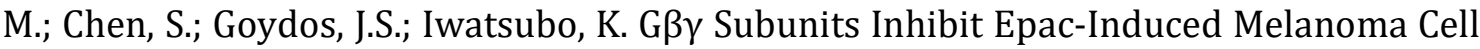
Migration. BMC Cancer 2011, 11, 256, doi:10.1186/1471-2407-11-256.

253. Bonacci, T.M.; Ghosh, M.; Malik, S.; Smrcka, A.V. Regulatory Interactions between the Amino Terminus of G-Protein Betagamma Subunits and the Catalytic Domain of Phospholipase Cbeta2. J Biol Chem 2005, 280, 10174-10181, doi:10.1074/jbc.M412514200.

254. Leopoldt, D.; Hanck, T.; Exner, T.; Maier, U.; Wetzker, R.; Nürnberg, B. G $\beta \gamma$ Stimulates Phosphoinositide 3-Kinase- $\gamma$ by Direct Interaction with Two Domains of the Catalytic P110 Subunit *. Journal of Biological Chemistry 1998, 273, 7024-7029, doi:10.1074/jbc.273.12.7024.

255. Pfeil, E.M.; Brands, J.; Merten, N.; Vögtle, T.; Vescovo, M.; Rick, U.; Albrecht, I.-M.; Heycke, N.; Kawakami, K.; Ono, Y.; et al. Heterotrimeric G Protein Subunit Gaq Is a Master Switch for G $\beta \gamma$-Mediated Calcium Mobilization by Gi-Coupled GPCRs. Mol Cell 2020, 80, 940-954.e6, doi:10.1016/j.molcel.2020.10.027.

256. Sellers, L.A.; Alderton, F.; Carruthers, A.M.; Schindler, M.; Humphrey, P.P. Receptor Isoforms Mediate Opposing Proliferative Effects through Gbetagamma-Activated P38 or Akt Pathways. Mol Cell Biol 2000, 20, 5974-5985, doi:10.1128/MCB.20.16.59745985.2000.

257. Luttrell, L.M.; Ferguson, S.S.; Daaka, Y.; Miller, W.E.; Maudsley, S.; Della Rocca, G.J.; Lin, F.; Kawakatsu, H.; Owada, K.; Luttrell, D.K.; et al. Beta-Arrestin-Dependent Formation of Beta2 Adrenergic Receptor-Src Protein Kinase Complexes. Science 1999, 283, 655-661, doi:10.1126/science.283.5402.655.

258. Miller, W.E.; Maudsley, S.; Ahn, S.; Khan, K.D.; Luttrell, L.M.; Lefkowitz, R.J. BetaArrestin1 Interacts with the Catalytic Domain of the Tyrosine Kinase c-SRC. Role of BetaArrestin1-Dependent Targeting of c-SRC in Receptor Endocytosis. J Biol Chem 2000, 275, 11312-11319, doi:10.1074/jbc.275.15.11312.

259. Krupnick, J.G.; Goodman, O.B.; Keen, J.H.; Benovic, J.L. Arrestin/Clathrin Interaction. Localization of the Clathrin Binding Domain of Nonvisual Arrestins to the Carboxy Terminus. J Biol Chem 1997, 272, 15011-15016, doi:10.1074/jbc.272.23.15011. 260. Gurevich, V.V.; Gurevich, E.V. Arrestins: Critical Players in Trafficking of Many GPCRs. Prog Mol Biol Transl Sci 2015, 132, 1-14, doi:10.1016/bs.pmbts.2015.02.010.

261. Shenoy, S.K.; Lefkowitz, R.J. Multifaceted Roles of Beta-Arrestins in the Regulation of Seven-Membrane-Spanning Receptor Trafficking and Signalling. Biochem J 2003, 375, 503-515, doi:10.1042/BJ20031076.

262. Oakley, R.H.; Laporte, S.A.; Holt, J.A.; Caron, M.G.; Barak, L.S. Differential Affinities of Visual Arrestin, BArrestin1, and BArrestin2 for G Protein-Coupled Receptors Delineate Two Major Classes of Receptors*. Journal of Biological Chemistry 2000, 275, 17201-17210, doi:10.1074/jbc.M910348199.

263. Miller, W.E.; Lefkowitz, R.J. Expanding Roles for Beta-Arrestins as Scaffolds and Adapters in GPCR Signaling and Trafficking. Curr Opin Cell Biol 2001, 13, 139-145, doi:10.1016/s0955-0674(00)00190-3.

264. Shenoy, S.K.; Lefkowitz, R.J. Seven-Transmembrane Receptor Signaling through Beta-Arrestin. Sci STKE 2005, 2005, cm10, doi:10.1126/stke.2005/308/cm10. 
265. Zhai, P.; Yamamoto, M.; Galeotti, J.; Liu, J.; Masurekar, M.; Thaisz, J.; Irie, K.; Holle, E.; Yu, X.; Kupershmidt, S.; et al. Cardiac-Specific Overexpression of AT1 Receptor Mutant Lacking G Aq/Gai Causes Hypertrophy and Bradycardia in Transgenic Mice. The Journal of clinical investigation 2005, 115, 3045-3056, doi:10.1172/JCI25330.

266. Beaulieu, J.-M.; Sotnikova, T.D.; Marion, S.; Lefkowitz, R.J.; Gainetdinov, R.R.; Caron, M.G. An Akt/Beta-Arrestin 2/PP2A Signaling Complex Mediates Dopaminergic Neurotransmission and Behavior. Cell 2005, 122, 261-273, doi:10.1016/j.cell.2005.05.012.

267. McDonald, P.H.; Chow, C.-W.; Miller, W.E.; Laporte, S.A.; Field, M.E.; Lin, F.-T.; Davis, R.J.; Lefkowitz, R.J. $\beta$-Arrestin 2: A Receptor-Regulated MAPK Scaffold for the Activation of JNK3. Science 2000, 290, 1574-1577, doi:10.1126/science.290.5496.1574. 268. Luttrell, L.M.; Roudabush, F.L.; Choy, E.W.; Miller, W.E.; Field, M.E.; Pierce, K.L.; Lefkowitz, R.J. Activation and Targeting of Extracellular Signal-Regulated Kinases by $\beta$ Arrestin Scaffolds. PNAS 2001, 98, 2449-2454, doi:10.1073/pnas.041604898.

269. Perry, S.J.; Baillie, G.S.; Kohout, T.A.; McPhee, I.; Magiera, M.M.; Ang, K.L.; Miller, W.E.; McLean, A.J.; Conti, M.; Houslay, M.D.; et al. Targeting of Cyclic AMP Degradation to B2-Adrenergic Receptors by $\beta$-Arrestins. Science 2002, 298, 834-836, doi:10.1126/science.1074683.

270. Abrisqueta, M.; Herraiz, C.; Pérez Oliva, A.B.; Sanchez-Laorden, B.L.; Olivares, C.; Jiménez-Cervantes, C.; García-Borrón, J.C. Differential and Competitive Regulation of Human Melanocortin 1 Receptor Signaling by $\beta$-Arrestin Isoforms. J Cell Sci 2013, 126, 3724-3737, doi:10.1242/jcs.128322.

271. Martínez-Vicente, I.; Abrisqueta, M.; Herraiz, C.; Jiménez-Cervantes, C.; GarcíaBorrón, J.C.; Olivares, C. Functional Characterization of a C-Terminal Splice Variant of the Human Melanocortin 1 Receptor. Exp Dermatol 2020, 29, 610-615, doi:10.1111/exd.14118.

272. Abreu, N.; Acosta-Ruiz, A.; Xiang, G.; Levitz, J. Mechanisms of Differential Desensitization of Metabotropic Glutamate Receptors. Cell Reports 2021, 35, 109050, doi:10.1016/j.celrep.2021.109050.

273. Ceraudo, E.; Horioka, M.; Mattheisen, J.M.; Hitchman, T.D.; Moore, A.R.; Kazmi, M.A.; Chi, P.; Chen, Y.; Sakmar, T.P.; Huber, T. Direct Evidence That the GPCR CysLTR2 Mutant Causative of Uveal Melanoma Is Constitutively Active with Highly Biased Signaling. J Biol Chem 2021, 296, 100163, doi:10.1074/jbc.RA120.015352.

274. Bhullar, K.S.; Lagarón, N.O.; McGowan, E.M.; Parmar, I.; Jha, A.; Hubbard, B.P.; Rupasinghe, H.P.V. Kinase-Targeted Cancer Therapies: Progress, Challenges and Future Directions. Molecular Cancer 2018, 17, 48, doi:10.1186/s12943-018-0804-2.

275. Menichetti, R.; Kanekal, K.H.; Bereau, T. Drug-Membrane Permeability across Chemical Space. ACS Cent. Sci. 2019, 5, 290-298, doi:10.1021/acscentsci.8b00718.

276. Sharma, A.; Vaghasiya, K.; Ray, E.; Verma, R.K. Lysosomal Targeting Strategies for Design and Delivery of Bioactive for Therapeutic Interventions. J Drug Target 2018, 26, 208-221, doi:10.1080/1061186X.2017.1374390.

277. Liu, D.; Schilling, B.; Liu, D.; Sucker, A.; Livingstone, E.; Jerby-Arnon, L.; Zimmer, L.; Gutzmer, R.; Satzger, I.; Loquai, C.; et al. Integrative Molecular and Clinical Modeling of Clinical Outcomes to PD1 Blockade in Patients with Metastatic Melanoma. Nat Med 2019, 25, 1916-1927, doi:10.1038/s41591-019-0654-5.

278. Campbell, A.P.; Smrcka, A.V. Targeting G Protein-Coupled Receptor Signalling by Blocking G Proteins. Nat Rev Drug Discov 2018, 17, 789-803, doi:10.1038/nrd.2018.135. 279. Chidiac, P.; Hebert, T.E.; Valiquette, M.; Dennis, M.; Bouvier, M. Inverse Agonist Activity of Beta-Adrenergic Antagonists. Mol Pharmacol 1994, 45, 490-499. 
280. de Ligt, R.A.F.; Kourounakis, A.P.; IJzerman, A.P. Inverse Agonism at G ProteinCoupled Receptors: (Patho)Physiological Relevance and Implications for Drug Discovery. Br J Pharmacol 2000, 130, 1-12, doi:10.1038/sj.bjp.0703311.

281. Pozvek, G.; Hilton, J.M.; Quiza, M.; Houssami, S.; Sexton, P.M. Structure/Function Relationships of Calcitonin Analogues as Agonists, Antagonists, or Inverse Agonists in a Constitutively Activated Receptor Cell System. Mol Pharmacol 1997, 51, 658-665, doi:10.1124/mol.51.4.658.

282. Wu, V.; Yeerna, H.; Nohata, N.; Chiou, J.; Harismendy, O.; Raimondi, F.; Inoue, A.; Russell, R.B.; Tamayo, P.; Gutkind, J.S. Illuminating the Onco-GPCRome: Novel G ProteinCoupled Receptor-Driven Oncocrine Networks and Targets for Cancer Immunotherapy. $J$ Biol Chem 2019, 294, 11062-11086, doi:10.1074/jbc.REV119.005601.

283. Smith, M.P.; Rowling, E.J.; Miskolczi, Z.; Ferguson, J.; Spoerri, L.; Haass, N.K.; Sloss, 0.; McEntegart, S.; Arozarena, I.; von Kriegsheim, A.; et al. Targeting Endothelin Receptor Signalling Overcomes Heterogeneity Driven Therapy Failure. EMBO Mol Med 2017, 9, 1011-1029, doi:10.15252/emmm.201607156.

284. Ben-Baruch, A. Site-Specific Metastasis Formation. Cell Adh Migr 2009, 3, 328333.

285. Chen, W.; Hoffmann, A.D.; Liu, H.; Liu, X. Organotropism: New Insights into Molecular Mechanisms of Breast Cancer Metastasis. npj Precision Onc 2018, 2, 1-12, doi:10.1038/s41698-018-0047-0.

286. Fagerberg, L.; Hallström, B.M.; Oksvold, P.; Kampf, C.; Djureinovic, D.; Odeberg, J.; Habuka, M.; Tahmasebpoor, S.; Danielsson, A.; Edlund, K.; et al. Analysis of the Human Tissue-Specific Expression by Genome-Wide Integration of Transcriptomics and Antibody-Based Proteomics *. Molecular \& Cellular Proteomics 2014, 13, 397-406, doi:10.1074/mcp.M113.035600.

287. Forrest, A.R.R.; Kawaji, H.; Rehli, M.; Kenneth Baillie, J.; de Hoon, M.J.L.; Haberle, V.; Lassmann, T.; Kulakovskiy, I.V.; Lizio, M.; Itoh, M.; et al. A Promoter-Level Mammalian Expression Atlas. Nature 2014, 507, 462-470, doi:10.1038/nature13182.

288. Melé, M.; Ferreira, P.G.; Reverter, F.; DeLuca, D.S.; Monlong, J.; Sammeth, M.; Young, T.R.; Goldmann, J.M.; Pervouchine, D.D.; Sullivan, T.J.; et al. Human Genomics. The Human Transcriptome across Tissues and Individuals. Science 2015, 348, 660-665, doi:10.1126/science.aaa0355.

289. Pierson, E.; Consortium, the Gte.; Koller, D.; Battle, A.; Mostafavi, S. Sharing and Specificity of Co-Expression Networks across 35 Human Tissues. PLOS Computational Biology 2015, 11, e1004220, doi:10.1371/journal.pcbi.1004220.

290. Jo, M.; Jung, S.T. Engineering Therapeutic Antibodies Targeting G-ProteinCoupled Receptors. Exp Mol Med 2016, 48, e207-e207, doi:10.1038/emm.2015.105.

291. Latorraca, N.R.; Venkatakrishnan, A.J.; Dror, R.O. GPCR Dynamics: Structures in Motion. Chem Rev 2017, 117, 139-155, doi:10.1021/acs.chemrev.6b00177.

292. Pauwels, J.; Fijałkowska, D.; Eyckerman, S.; Gevaert, K. Mass Spectrometry and the Cellular Surfaceome. Mass Spectrometry Reviews 2021, n/a, doi:10.1002/mas.21690.

293. Alhosaini, K.; Azhar, A.; Alonazi, A.; Al-Zoghaibi, F. GPCRs: The Most Promiscuous Druggable Receptor of the Mankind. Saudi Pharm J 2021, 29, 539-551, doi:10.1016/j.jsps.2021.04.015.

294. Kuhlmann, L.; Cummins, E.; Samudio, I.; Kislinger, T. Cell-Surface Proteomics for the Identification of Novel Therapeutic Targets in Cancer. Expert Rev Proteomics 2018, 15, 259-275, doi:10.1080/14789450.2018.1429924.

295. Sun, F.; Suttapitugsakul, S.; Wu, R. Unraveling the Surface Glycoprotein Interaction Network by Integrating Chemical Crosslinking with MS-Based Proteomics. 
Chem Sci 2021, 12, 2146-2155, doi:10.1039/d0sc06327d.

296. Qin, S.; Meng, M.; Yang, D.; Bai, W.; Lu, Y.; Peng, Y.; Song, G.; Wu, Y.; Zhou, Q.; Zhao, S.; et al. High-Throughput Identification of G Protein-Coupled Receptor Modulators through Affinity Mass Spectrometry Screening. Chem. Sci. 2018, 9, 3192-3199, doi:10.1039/C7SC04698G.

297. Crotty, S.; Pipkin, M.E. In Vivo RNAi Screens: Concepts and Applications. Trends Immunol 2015, 36, 315-322, doi:10.1016/j.it.2015.03.007.

298. Driever, W.; Solnica-Krezel, L.; Schier, A.F.; Neuhauss, S.C.; Malicki, J.; Stemple, D.L.; Stainier, D.Y.; Zwartkruis, F.; Abdelilah, S.; Rangini, Z.; et al. A Genetic Screen for Mutations Affecting Embryogenesis in Zebrafish. Development 1996, 123, 37-46.

299. Haffter, P.; Granato, M.; Brand, M.; Mullins, M.C.; Hammerschmidt, M.; Kane, D.A.; Odenthal, J.; van Eeden, F.J.; Jiang, Y.J.; Heisenberg, C.P.; et al. The Identification of Genes with Unique and Essential Functions in the Development of the Zebrafish, Danio Rerio. Development 1996, 123, 1-36.

300. Keatinge, M.; Tsarouchas, T.M.; Munir, T.; Porter, N.J.; Larraz, J.; Gianni, D.; Tsai, H.-H.; Becker, C.G.; Lyons, D.A.; Becker, T. CRISPR GRNA Phenotypic Screening in Zebrafish Reveals Pro-Regenerative Genes in Spinal Cord Injury. PLOS Genetics 2021, 17, e1009515, doi:10.1371/journal.pgen.1009515.

301. Trubiroha, A.; Gillotay, P.; Giusti, N.; Gacquer, D.; Libert, F.; Lefort, A.; Haerlingen, B.; De Deken, X.; Opitz, R.; Costagliola, S. A Rapid CRISPR/Cas-Based Mutagenesis Assay in Zebrafish for Identification of Genes Involved in Thyroid Morphogenesis and Function. Sci Rep 2018, 8, 5647, doi:10.1038/s41598-018-24036-4.

302. Howe, K.; Clark, M.D.; Torroja, C.F.; Torrance, J.; Berthelot, C.; Muffato, M.; Collins, J.E.; Humphray, S.; McLaren, K.; Matthews, L.; et al. The Zebrafish Reference Genome Sequence and Its Relationship to the Human Genome. Nature 2013, 496, 498-503, doi:10.1038/nature12111.

303. Langenhan, T.; Barr, M.M.; Bruchas, M.R.; Ewer, J.; Griffith, L.C.; Maiellaro, I.; Taghert, P.H.; White, B.H.; Monk, K.R. Model Organisms in G Protein-Coupled Receptor Research. Mol Pharmacol 2015, 88, 596-603, doi:10.1124/mol.115.098764.

304. Frantz, W.T.; Ceol, C.J. From Tank to Treatment: Modeling Melanoma in Zebrafish. Cells 2020, 9, 1289, doi:10.3390/cells9051289.

305. Patton, E.E.; Mueller, K.L.; Adams, D.J.; Anandasabapathy, N.; Aplin, A.E.; Bertolotto, C.; Bosenberg, M.; Ceol, C.J.; Burd, C.E.; Chi, P.; et al. Melanoma Models for the next Generation of Therapies. Cancer Cell 2021, 39, 610-631, doi:10.1016/j.ccell.2021.01.011.

306. Manzotti, C.; Audisio, R.A.; Pratesi, G. Importance of Orthotopic Implantation for Human Tumors as Model Systems: Relevance to Metastasis and Invasion. Clin Exp Metastasis 1993, 11, 5-14, doi:10.1007/BF00880061.

307. Lee, Y.; Basith, S.; Choi, S. Recent Advances in Structure-Based Drug Design Targeting Class A G Protein-Coupled Receptors Utilizing Crystal Structures and Computational Simulations. J Med Chem 2018, 61, 1-46, doi:10.1021/acs.jmedchem.6b01453.

308. García-Nafría, J.; Tate, C.G. Cryo-Electron Microscopy: Moving Beyond X-Ray Crystal Structures for Drug Receptors and Drug Development. Annu Rev Pharmacol Toxicol 2020, 60, 51-71, doi:10.1146/annurev-pharmtox-010919-023545.

309. Okada, T.; Le Trong, I.; Fox, B.A.; Behnke, C.A.; Stenkamp, R.E.; Palczewski, K. XRay Diffraction Analysis of Three-Dimensional Crystals of Bovine Rhodopsin Obtained from Mixed Micelles. Journal of Structural Biology 2000, 130, 73-80, doi:10.1006/jsbi.1999.4209. 
310. Tate, C.G.; Schertler, G.F.X. Engineering G Protein-Coupled Receptors to Facilitate Their Structure Determination. Curr Opin Struct Biol 2009, 19, 386-395, doi:10.1016/j.sbi.2009.07.004.

311. Lebon, G.; Bennett, K.; Jazayeri, A.; Tate, C.G. Thermostabilisation of an AgonistBound Conformation of the Human Adenosine A(2A) Receptor. J Mol Biol 2011, 409, 298-310, doi:10.1016/j.jmb.2011.03.075.

312. Rosenbaum, D.M.; Cherezov, V.; Hanson, M.A.; Rasmussen, S.G.F.; Thian, F.S.; Kobilka, T.S.; Choi, H.-J.; Yao, X.-J.; Weis, W.I.; Stevens, R.C.; et al. GPCR Engineering Yields High-Resolution Structural Insights into Beta2-Adrenergic Receptor Function. Science 2007, 318, 1266-1273, doi:10.1126/science.1150609.

313. Tate, C.G. Practical Considerations of Membrane Protein Instability during Purification and Crystallisation. Methods Mol Biol 2010, 601, 187-203, doi:10.1007/9781-60761-344-2_12.

314. Ishchenko, A.; Stauch, B.; Han, G.W.; Batyuk, A.; Shiriaeva, A.; Li, C.; Zatsepin, N.; Weierstall, U.; Liu, W.; Nango, E.; et al. Toward G Protein-Coupled Receptor StructureBased Drug Design Using X-Ray Lasers. IUCrJ 2019, 6, 1106-1119, doi:10.1107/S2052252519013137.

315. Liu, H.; Lee, W. The XFEL Protein Crystallography: Developments and Perspectives. Int J Mol Sci 2019, 20, 3421, doi:10.3390/ijms20143421.

316. McMullan, G.; Faruqi, A.R.; Henderson, R. Direct Electron Detectors. Methods Enzymol 2016, 579, 1-17, doi:10.1016/bs.mie.2016.05.056.

317. Vinothkumar, K.R.; Henderson, R. Single Particle Electron Cryomicroscopy: Trends, Issues and Future Perspective. $Q$ Rev Biophys 2016, 49, e13, doi:10.1017/S0033583516000068.

318. Zivanov, J.; Nakane, T.; Forsberg, B.O.; Kimanius, D.; Hagen, W.J.; Lindahl, E.; Scheres, S.H. New Tools for Automated High-Resolution Cryo-EM Structure Determination in RELION-3. Elife 2018, 7, e42166, doi:10.7554/eLife.42166.

319. Congreve, M.; Graaf, C. de; Swain, N.A.; Tate, C.G. Impact of GPCR Structures on Drug Discovery. Cell 2020, 181, 81-91, doi:10.1016/j.cell.2020.03.003.

320. Danev, R.; Belousoff, M.; Liang, Y.-L.; Zhang, X.; Eisenstein, F.; Wootten, D.; Sexton, P.M. Routine Sub-2.5 Å Cryo-EM Structure Determination of GPCRs. Nat Commun 2021, 12, 4333, doi:10.1038/s41467-021-24650-3.

321. Zhang, M.; Gui, M.; Wang, Z.-F.; Gorgulla, C.; Yu, J.J.; Wu, H.; Sun, Z.J.; Klenk, C.; Merklinger, L.; Morstein, L.; et al. Cryo-EM Structure of an Activated GPCR-G Protein Complex in Lipid Nanodiscs. Nat Struct Mol Biol 2021, 28, 258-267, doi:10.1038/s41594-020-00554-6.

322. Shimada, I.; Ueda, T.; Kofuku, Y.; Eddy, M.T.; Wüthrich, K. GPCR Drug Discovery: Integrating Solution NMR Data with Crystal and Cryo-EM Structures. Nat Rev Drug Discov 2019, 18, 59-82, doi:10.1038/nrd.2018.180.

323. Baek, M.; DiMaio, F.; Anishchenko, I.; Dauparas, J.; Ovchinnikov, S.; Lee, G.R.; Wang, J.; Cong, Q.; Kinch, L.N.; Schaeffer, R.D.; et al. Accurate Prediction of Protein Structures and Interactions Using a Three-Track Neural Network. Science 2021, 373, 871-876, doi:10.1126/science.abj8754.

324. Jumper, J.; Evans, R.; Pritzel, A.; Green, T.; Figurnov, M.; Ronneberger, 0.; Tunyasuvunakool, K.; Bates, R.; Žídek, A.; Potapenko, A.; et al. Highly Accurate Protein Structure Prediction with AlphaFold. Nature 2021, 596, 583-589, doi:10.1038/s41586021-03819-2.

325. Tunyasuvunakool, K.; Adler, J.; Wu, Z.; Green, T.; Zielinski, M.; Žídek, A.; Bridgland, A.; Cowie, A.; Meyer, C.; Laydon, A.; et al. Highly Accurate Protein Structure Prediction 
for the Human Proteome. Nature 2021, 596, 590-596, doi:10.1038/s41586-021-038281.

326. Bender, B.J.; Marlow, B.; Meiler, J. Improving Homology Modeling from LowSequence Identity Templates in Rosetta: A Case Study in GPCRs. PLoS Comput Biol 2020, 16, e1007597, doi:10.1371/journal.pcbi.1007597.

327. Esguerra, M.; Siretskiy, A.; Bello, X.; Sallander, J.; Gutiérrez-de-Terán, H. GPCRModSim: A Comprehensive Web Based Solution for Modeling G-Protein Coupled Receptors. Nucleic Acids Res 2016, 44, W455-462, doi:10.1093/nar/gkw403.

328. Worth, C.L.; Kreuchwig, F.; Tiemann, J.K.S.; Kreuchwig, A.; Ritschel, M.; Kleinau, G.; Hildebrand, P.W.; Krause, G. GPCR-SSFE 2.0-a Fragment-Based Molecular Modeling Web Tool for Class A G-Protein Coupled Receptors. Nucleic Acids Res 2017, 45, W408-W415, doi:10.1093/nar/gkx399.

329. Zhang, J.; Yang, J.; Jang, R.; Zhang, Y. GPCR-I-TASSER: A Hybrid Approach to G Protein-Coupled Receptor Structure Modeling and the Application to the Human Genome. Structure 2015, 23, 1538-1549, doi:10.1016/j.str.2015.06.007.

330. Mullard, A. What Does AlphaFold Mean for Drug Discovery? Nat Rev Drug Discov 2021, 20, 725-727, doi:10.1038/d41573-021-00161-0.

331. Potterton, A.; Heifetz, A.; Townsend-Nicholson, A. Synergistic Use of GPCR Modeling and SDM Experiments to Understand Ligand Binding. In Computational Methods for GPCR Drug Discovery; Heifetz, A., Ed.; Methods in Molecular Biology; Springer: New York, NY, 2018; pp. 335-343 ISBN 978-1-4939-7465-8.

332. Zhou, Q.; Yang, D.; Wu, M.; Guo, Y.; Guo, W.; Zhong, L.; Cai, X.; Dai, A.; Jang, W.; Shakhnovich, E.I.; et al. Common Activation Mechanism of Class A GPCRs. eLife 2019, 8, e50279, doi:10.7554/eLife.50279.

333. Di Roberto, R.B.; Chang, B.; Peisajovich, S.G. The Directed Evolution of Ligand Specificity in a GPCR and the Unequal Contributions of Efficacy and Affinity. Sci Rep 2017, 7, 16012, doi:10.1038/s41598-017-16332-2.

334. Hughes, J.; Rees, S.; Kalindjian, S.; Philpott, K. Principles of Early Drug Discovery. Br J Pharmacol 2011, 162, 1239-1249, doi:10.1111/j.1476-5381.2010.01127.x.

335. von Ahsen, 0.; Bömer, U. High-Throughput Screening for Kinase Inhibitors. ChemBioChem 2005, 6, 481-490, doi:10.1002/cbic.200400211.

336. Jones, A.J.Y.; Gabriel, F.; Tandale, A.; Nietlispach, D. Structure and Dynamics of GPCRs in Lipid Membranes: Physical Principles and Experimental Approaches. Molecules 2020, 25, 4729, doi:10.3390/molecules25204729.

337. Kitaeva, K.V.; Rutland, C.S.; Rizvanov, A.A.; Solovyeva, V.V. Cell Culture Based in Vitro Test Systems for Anticancer Drug Screening. Frontiers in Bioengineering and Biotechnology 2020, 8, 322, doi:10.3389/fbioe.2020.00322.

338. González, N.; Mantey, S.A.; Pradhan, T.K.; Sancho, V.; Moody, T.W.; Coy, D.H.; Jensen, R.T. Characterization of Putative GRP- and NMB-Receptor Antagonist's Interaction with Human Receptors. Peptides 2009, 30, 1473-1486, doi:10.1016/j.peptides.2009.05.007.

339. Uehara, H.; González, N.; Sancho, V.; Mantey, S.A.; Nuche-Berenguer, B.; Pradhan, T.; Coy, D.H.; Jensen, R.T. Pharmacology and Selectivity of Various Natural and Synthetic Bombesin Related Peptide Agonists for Human and Rat Bombesin Receptors Differs. Peptides 2011, 32, 1685-1699, doi:10.1016/j.peptides.2011.06.017.

340. Zhang, R.; Xie, X. Tools for GPCR Drug Discovery. Acta Pharmacol Sin 2012, 33, 372-384, doi:10.1038/aps.2011.173.

341. Maurel, D.; Comps-Agrar, L.; Brock, C.; Rives, M.-L.; Bourrier, E.; Ayoub, M.A.; Bazin, H.; Tinel, N.; Durroux, T.; Prézeau, L.; et al. Cell-Surface Protein-Protein 
Interaction Analysis with Time-Resolved FRET and Snap-Tag Technologies: Application to GPCR Oligomerization. Nat Methods 2008, 5, 561-567, doi:10.1038/nmeth.1213.

342. Valencia, C.; Dujet, C.; Margathe, J.-F.; Iturrioz, X.; Roux, T.; Trinquet, E.; Villa, P.; Hibert, M.; Dupuis, E.; Llorens-Cortes, C.; et al. A Time-Resolved FRET Cell-Based Binding Assay for the Apelin Receptor. ChemMedChem 2017, 12, 925-931, doi:10.1002/cmdc.201700106.

343. Titus, S.; Neumann, S.; Zheng, W.; Southall, N.; Michael, S.; Klumpp, C.; Yasgar, A.; Shinn, P.; Thomas, C.J.; Inglese, J.; et al. Quantitative High-Throughput Screening Using a Live-Cell CAMP Assay Identifies Small-Molecule Agonists of the TSH Receptor. J Biomol Screen 2008, 13, 120-127, doi:10.1177/1087057107313786.

344. Trinquet, E.; Bouhelal, R.; Dietz, M. Monitoring Gq-Coupled Receptor Response through Inositol Phosphate Quantification with the IP-One Assay. Expert Opinion on Drug Discovery 2011, 6, 981-994, doi:10.1517/17460441.2011.608658.

345. Katsuya, K.; Hori, Y.; Oikawa, D.; Yamamoto, T.; Umetani, K.; Urashima, T.; Kinoshita, T.; Ayukawa, K.; Tokunaga, F.; Tamaru, M. High-Throughput Screening for Linear Ubiquitin Chain Assembly Complex (LUBAC) Selective Inhibitors Using Homogenous Time-Resolved Fluorescence (HTRF)-Based Assay System. SLAS DISCOVERY: Advancing the Science of Drug Discovery 2018, 23, 1018-1029, doi:10.1177/2472555218793066.

346. Lotta, L.A.; Mokrosiński, J.; Mendes de Oliveira, E.; Li, C.; Sharp, S.J.; Luan, J.; Brouwers, B.; Ayinampudi, V.; Bowker, N.; Kerrison, N.; et al. Human Gain-of-Function MC4R Variants Show Signaling Bias and Protect against Obesity. Cell 2019, 177, 597 607.e9, doi:10.1016/j.cell.2019.03.044.

347. Zindel, D.; Vol, C.; Lecha, O.; Bequignon, I.; Bilgic, M.; Vereecke, M.; CharrierSavournin, F.; Romier, M.; Trinquet, E.; Pin, J.-P.; et al. HTRF® Total and Phospho-YAP (Ser127) Cellular Assays. In The Hippo Pathway: Methods and Protocols; Hergovich, A., Ed.; Methods in Molecular Biology; Springer: New York, NY, 2019; pp. 153-166 ISBN 978-1-4939-8910-2.

348. Liu, L.; Jockers, R. Structure-Based Virtual Screening Accelerates GPCR Drug Discovery. Trends in Pharmacological Sciences 2020, 41, 382-384, doi:10.1016/j.tips.2020.04.001.

349. Shoichet, B.K.; Kobilka, B.K. Structure-Based Drug Screening for G ProteinCoupled Receptors. Trends Pharmacol Sci 2012, 33, 268-272, doi:10.1016/j.tips.2012.03.007.

350. Stein, R.M.; Kang, H.J.; McCorvy, J.D.; Glatfelter, G.C.; Jones, A.J.; Che, T.; Slocum, S.; Huang, X.-P.; Savych, O.; Moroz, Y.S.; et al. Virtual Discovery of Melatonin Receptor Ligands to Modulate Circadian Rhythms. Nature 2020, 579, 609-614, doi:10.1038/s41586-020-2027-0.

351. Ebalunode, J.O.; Zheng, W.; Tropsha, A. Application of QSAR and Shape Pharmacophore Modeling Approaches for Targeted Chemical Library Design. In Chemical Library Design; Zhou, J.Z., Ed.; Methods in Molecular Biology; Humana Press: Totowa, NJ, 2011; pp. 111-133 ISBN 978-1-60761-931-4.

352. Green, H.; Koes, D.R.; Durrant, J.D. DeepFrag: A Deep Convolutional Neural Network for Fragment-Based Lead Optimization. Chem. Sci. 2021, 12, 8036-8047, doi:10.1039/D1SC00163A.

353. Neves, B.J.; Braga, R.C.; Melo-Filho, C.C.; Moreira-Filho, J.T.; Muratov, E.N.; Andrade, C.H. QSAR-Based Virtual Screening: Advances and Applications in Drug Discovery. Front Pharmacol 2018, 9, 1275, doi:10.3389/fphar.2018.01275.

354. Chung, T.D.Y.; Terry, D.B.; Smith, L.H. In Vitro and In Vivo Assessment of ADME 
and PK Properties During Lead Selection and Lead Optimization - Guidelines, Benchmarks and Rules of Thumb. In Assay Guidance Manual; Markossian, S., Grossman, A., Brimacombe, K., Arkin, M., Auld, D., Austin, C.P., Baell, J., Chung, T.D.Y., Coussens, N.P., Dahlin, J.L., Devanarayan, V., Foley, T.L., Glicksman, M., Hall, M.D., Haas, J.V., Hoare, S.R.J., Inglese, J., Iversen, P.W., Kales, S.C., Lal-Nag, M., Li, Z., McGee, J., McManus, O., Riss, T., Saradjian, P., Sittampalam, G.S., Tarselli, M., Trask, O.J., Wang, Y., Weidner, J.R., Wildey, M.J., Wilson, K., Xia, M., Xu, X., Eds.; Eli Lilly \& Company and the National Center for Advancing Translational Sciences: Bethesda (MD), 2004.

355. Guan, L.; Yang, H.; Cai, Y.; Sun, L.; Di, P.; Li, W.; Liu, G.; Tang, Y. ADMET-Score - a Comprehensive Scoring Function for Evaluation of Chemical Drug-Likeness †Electronic Supplementary Information (ESI) Available. See DOI: 10.1039/C8md00472b. Medchemcomm 2018, 10, 148-157, doi:10.1039/c8md00472b.

356. Akil, H.; Quintana, M.; Raymond, J.H.; Billoux, T.; Benboubker, V.; Besse, S.; Auzeloux, P.; Delmas, V.; Petit, V.; Larue, L.; et al. Efficacy of Targeted Radionuclide Therapy Using [131I]ICF01012 in 3D Pigmented BRAF- and NRAS-Mutant Melanoma Models and In Vivo NRAS-Mutant Melanoma. Cancers 2021, 13, 1421, doi:10.3390/cancers13061421.

357. Norain, A.; Dadachova, E. Targeted Radionuclide Therapy of Melanoma. Seminars in Nuclear Medicine 2016, 46, 250-259, doi:10.1053/j.semnuclmed.2015.12.005.

\section{Figure legends}

\section{Figure 1}

GPCR signaling pathways. Note that the $\mathrm{G}_{\mathrm{q} / 11}$ et $\mathrm{G}_{12 / 13} \mathrm{G}$-protein share a common downstream signaling pathways - YAP1. All the receptors are susceptible to induce the $G \beta / \gamma$ \& the $\beta$-arrestin biased signaling pathways. 